\title{
The water and land footprint of meat and milk production and consumption in Kenya: \\ Implications for sustainability and food security.
}
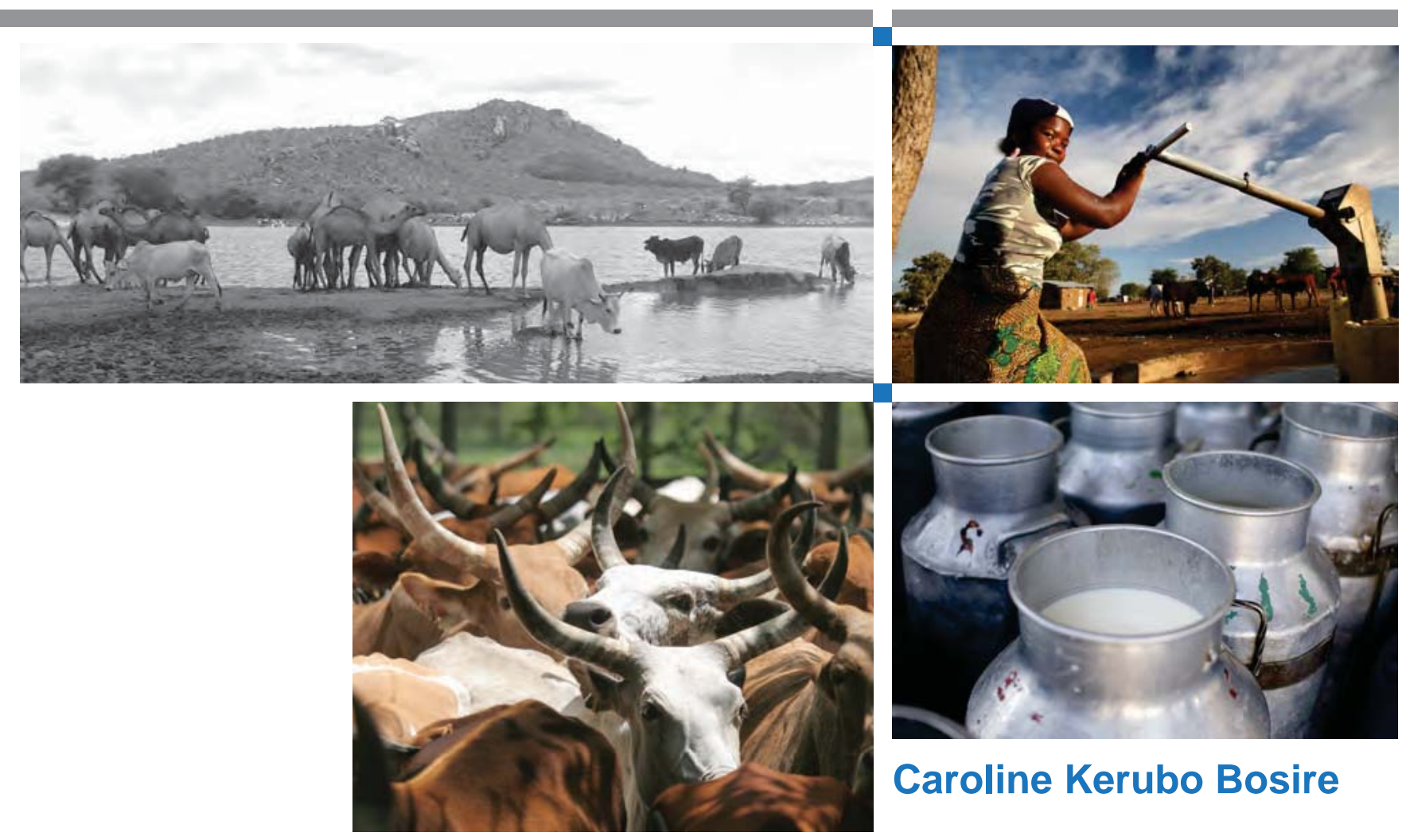

Caroline Kerubo Bosire 
THE WATER AND LAND FOOTPRINTS OF MEAT AND MILK PRODUCTION AND CONSUMPTION IN KENYA: IMPLICATIONS FOR SUSTAINABILITY AND FOOD SECURITY. 
Graduation committee:

Prof.dr. G.P.M.R. Dewulf

Prof.dr.ir. A.Y. Hoekstra

Dr. M.S. Krol

Prof.dr. J.C.J. Kwadijk

Prof.dr. S.M.M. Kuks

Prof.dr.ir. I.J.M. de Boer

Prof. dr. P. Martens
University of Twente, chairman and secretary University of Twente, promoter

University of Twente, co-promoter

University of Twente

University of Twente

Wageningen UR

Maastricht University

Cover: Design by Muthoni Njiru and Images by ILRI

Copyrights (c) by Caroline Kerubo Bosire, Enschede, The Netherlands

ISBN: 978-90-365-4246-3

DOI: $10.3990 / 1.9789036542463$ 


\title{
THE WATER AND LAND FOOTPRINTS OF MEAT AND MILK PRODUCTION AND CONSUMPTION IN KENYA: IMPLICATIONS FOR SUSTAINABILITY AND FOOD SECURITY.
}

\section{DISSERTATION}

\author{
to obtain \\ the degree of doctor at the University of Twente, \\ on the authority of the rector magnificus, \\ Prof.dr. T.T.M Palstra, \\ on account of the decision of the graduation committee, \\ To be publicly defended \\ on Thursday 8 December 2016 at 11:00
}

by

Caroline Kerubo Bosire

born on 5 June 1978

at Nairobi, Kenya 
This dissertation has been approved by:

Prof. dr. ir. A. Y. Hoekstra promoter

Dr. M.S. Krol

co-promoter 
Contents

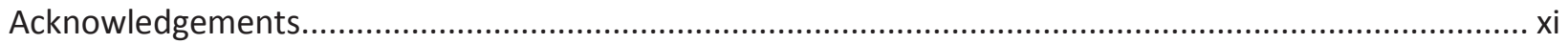

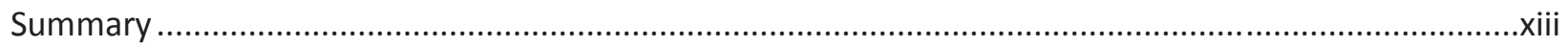

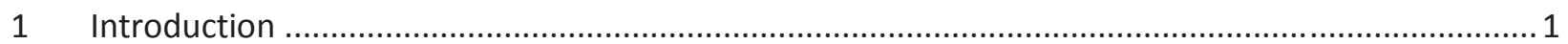

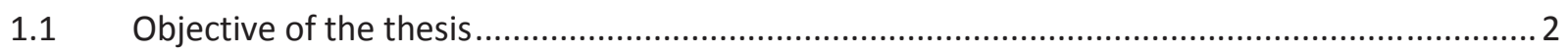

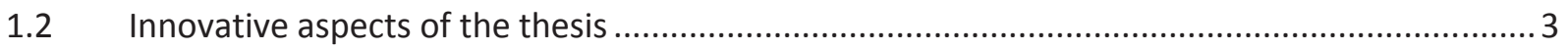

1.2.1 Meeting increased consumptive demand through changes in agricultural productivity....... 3

1.2.2 Composite indicators for assessing water and land use ................................................ 3

1.2.3 Spatially disaggregated analysis of water and land use ................................................... 4

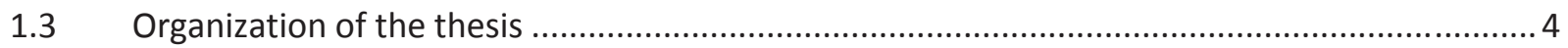

2 Trends and spatial variation in water and land footprints of meat and milk production systems in

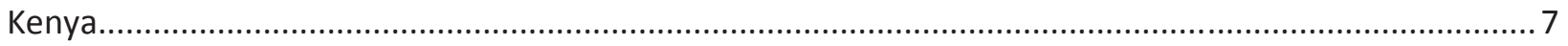

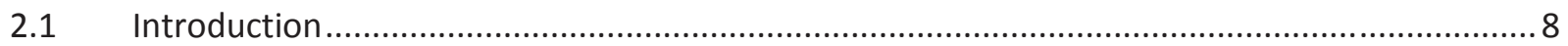

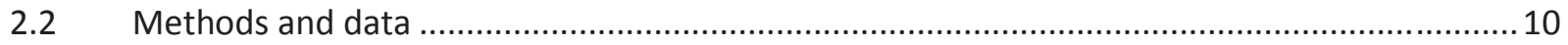

2.2.1 Characterizing the production systems ….................................................................. 11

2.2.2 Livestock numbers in each production system ......................................................... 11

2.2.3 Estimating the total annual production of animal products ............................................ 14

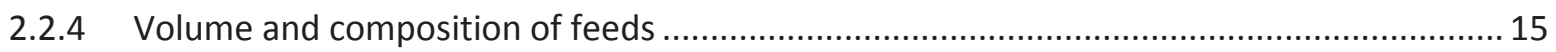

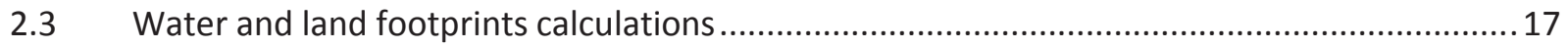


2.3.1 Water footprints of livestock products

2.3.2 Estimating the water footprint of feed $\left(W F_{\text {feed }}\right)$ .18

2.3.3 The water footprint of feed ingredients 19

2.3.4 Land footprint of livestock products 20

$2.4 \quad$ Results 21

2.4.1 Changes in the numbers and distributions of cattle and shoats in the arid, semi-arid and humid production systems.

2.4.2 The water and land footprints of milk and meat production

2.5 Discussion 28

2.5.1 General limitations of data and scope of conclusions 28

2.5.2 Combining water and land footprints to enhance assessment of resource demands for milk and meat production. .29

2.5.3 Decline in cattle numbers and increased importance of shoats and camels for subsistence. 29

2.5.4 Dominance of cattle in freshwater and land use towards milk and meat production 30

2.5.5 Effect of productivity changes on water and land footprints 30

2.6 Conclusion and recommendations 32

3 Meat and milk production scenarios and the associated land footprint in Kenya. .34

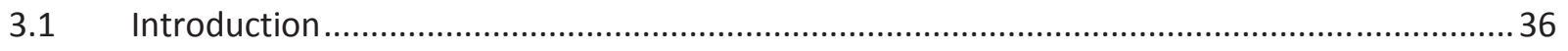

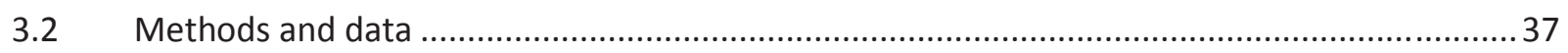


3.2.1 Identification of land available for livestock production

3.2.2 Land suitability estimation

3.2.3 Intensification: quantifying the maximum production potential with current livestock numbers

3.2.4 Maximum production potential with current total land use

3.2.5 Estimating land use for livestock production.

3.2.6 General limitation of data and methods.

3.3 Results

3.3.1 Total agricultural land and suitability for crop production 49

3.3.2 Land available for agriculture in Kenya...... 51

3.3.3 Production potential of meat and milk under increasing intensification under current land use $\quad 52$

3.3.4 Increase in production potential and growth in per capita supply of milk and meat. 54

3.3.5 Potential for resource savings under increasing intensification..... 54

3.4 Discussion 57

3.4.1 Increased livestock production potential or output .57

3.4.2 Implications for food security . .59

3.4.3 Decline in quantity of land used through intensification of production....... 60

3.5 Conclusion 62 
$4 \quad$ Urban consumption of meat and milk and its green and blue water footprints - patterns in the 1980s and 2000s for Nairobi, Kenya. 64

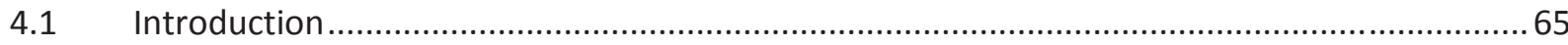

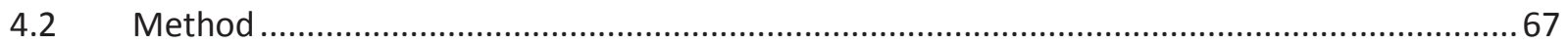

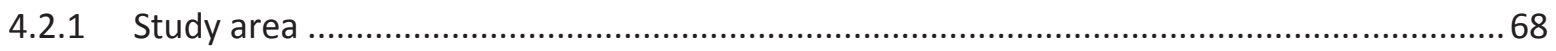

4.2.2 Population and meat and milk consumption data (Steps1-5) .........................................69

4.2.3 Assessing the water footprint of milk and meat consumption (Steps 6-12) ......................71

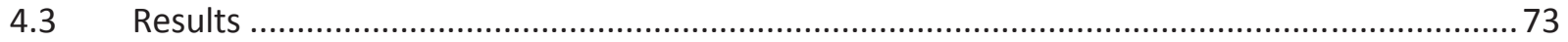

4.3.1 Population changes in Kenya and Nairobi between the 1980 s and 2000s ........................73

4.3.2 Consumption of meat and milk in Kenya and Nairobi between the 1980s and 2000s.........73

4.3.3 Water footprint of milk and meat consumption per income group ................................... 75

4.3.4 Domestic and foreign water dependence of meat and milk consumption in Nairobi..........78

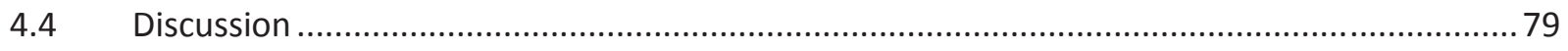

4.4.1 Consumption of meat and milk in Kenya and Nairobi ................................................... 79

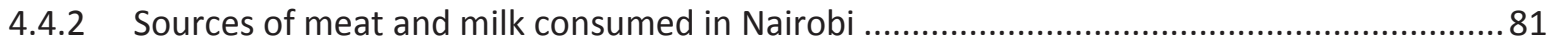

4.4.3 Influence of income on water footprint of milk and meat consumption in Nairobi ............82

4.4.4 The domestic and foreign water footprints of milk and meat consumption in Nairobi .......83

4.4.5 Urban growth, the resultant water footprint increase and the implications for blue water scarcity 84

4.5 Limitations and assumptions of the study 85 
4.6 Conclusion

5 The effect of changing meat and milk consumption on future water and land footprints in Kenya. 88

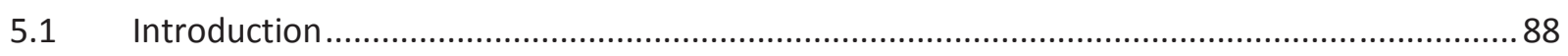

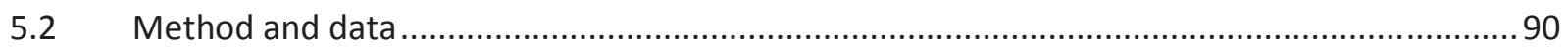

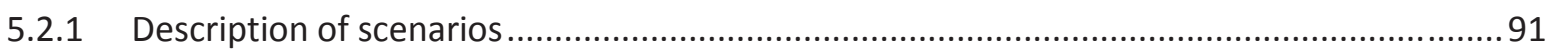

5.2.2 Assessment of water and land footprints of livestock production and consumption ..........96

5.2.3 Assessment of economic water and land productivity of meat and milk production ..........97

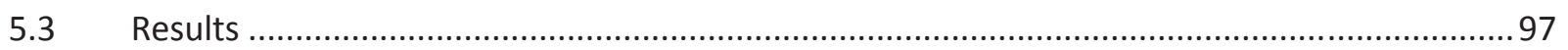

5.3.1 Water and land footprints of meat and milk production in Kenya by 2030 ......................97

5.3.2 Water and land footprints of meat and milk consumption in Kenya by $2030 \ldots \ldots \ldots \ldots \ldots \ldots . . . . . .98$

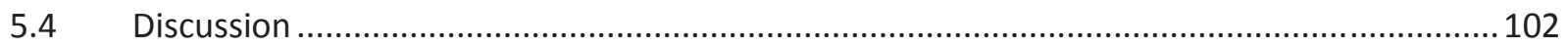

5.4.1 Population growth under the BAU and S2030 scenarios ............................................. 102

5.4.2 Consumption changes under the two scenarios.......................................................... 102

5.4.3 Production changes under the two scenarios........................................................... 102

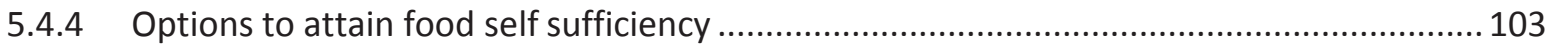

5.4.5 Water and land footprint associated with the two scenarios........................................ 104

5.4.6 Economic water and land footprint associated with the two scenarios............................ 105

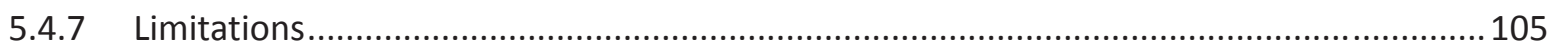

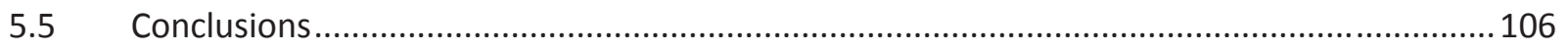




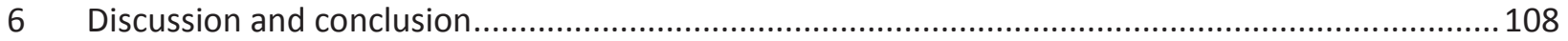

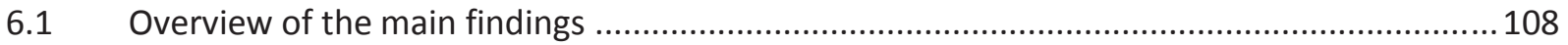

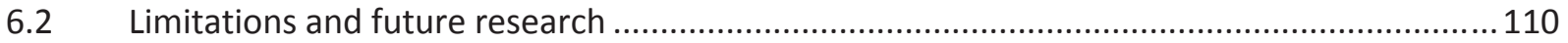

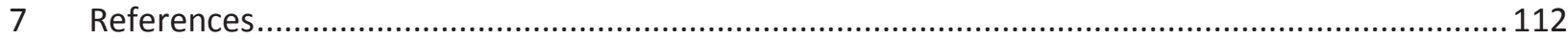

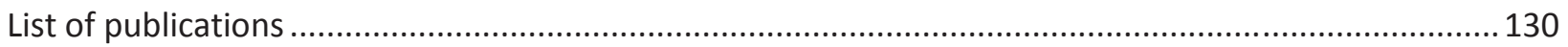

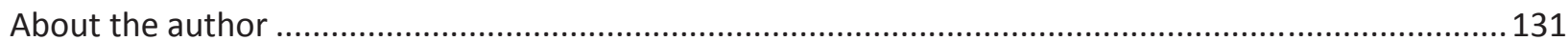




\section{Acknowledgements}

I would like to express my gratitude to my promoter, Professor Arjen Hoekstra, whose expertise and guidance added considerably to my graduate experience. I appreciate his vast knowledge and skill in many areas. I would also like to thank the co-promoters Dr. Maarten Krol and Dr. Jan De Leeuw for the assistance they provided at all levels of the graduate research. I would like to thank the Director General Dr, Jimmy Smith at the International Livestock Research Institute (ILRI) for providing me with the opportunity to have a graduate programme under the "sandwich" format with the University of Twente under the Netherlands Fellowship Programme (NFP). Finally, I would like to thank Dr. Mohammed Said, Professor Derek Baker, Dr. Polly Ericksen, Dr, Mats Lannerstad and Dr. Nadhem Mtimet for the supervision during the extensive time in the graduate studies spent at ILRI.

I would like to thank Dr John Githaiga and Dr. Robert Chira whose motivation and encouragement placed me on the journey to a PhD right after my undergraduate studies. It was through their persistence, understanding and kindness that I was encouraged to apply for graduate training. I doubt that I will ever be able to convey my appreciation fully. I will for ever be grateful to Dr. Joseph Ogutu who introduced me to Dr Jan De Leeuw who helped in shaping my study towards water use in agriculture in an innovative way.

I must also acknowledge Joke Meyer who made my life at the university very easy. Thank you Joke for always responding to my distress calls and making sure that I travel safe and get settled back into the studies both in Kenya and in the Netherlands. I would also like to thank Brigitte and Anke for their support in organising my time in the Netherlands.

I would like to make a special mention of Mesfin Mekonnen who helped me understand the technical components of the thesis as well orienting me to life in the Netherlands. Thanks also goes out to my fellow colleague Joep Schyns for the Dutch translation of the summary. I would also like to thank my fellow PhD candidates in WEM and ITC Zhuo La, Jane Ndung'u, Hatem Chouchane, Vincent Odongo, Dawit Woubishet, Francis Kamau, Abebe Chukalla, Ana Paula Schwantes and all the others with whom I shared an office space during the past five years for our philosophical debates, exchanges of knowledge, skills, and venting of frustration during my graduate program. All these interactions helped enrich the experience. 
I would also like to thank my friends for all the support through the journey to date. Susan who made sure I did not get lost on the first day in Netherlands though she could not be there to show me the exact train to take to Enschede. To all my other friends who supported me in various ways through the various stages and challenges in the studies, I would need a whole thesis to mention you all personally, but I do thank you for the support.

Finally, I would like to appreciate the support I have had from my family through my entire life and in particular, I must acknowledge daddy, Dr. Nyanusi, who once called Joke all the way from Nairobi in the morning to wish me a happy birthday and was already referring to me as Dr. Bosire in 2010. Thank you daddy, I miss you at this time. I dedicate this thesis to you. My mum, who always made sure she kept me focused on the $\mathrm{PhD}$ and prayed consistently for this final outcome. My brothers and sisters also made this journey bearable. Dear Munyao, the level of support you have given me cannot be fully described in this acknowledgment. Thank you for always believing in me and pushing me to deliver even in the moments of extreme frustration. I wouldn't have been able to achieve what I have without your love and encouragement. As always, you remind me that God always has a plan for us and everything will be well.

Caroline Bosire

Enschede, November 2016 


\section{Summary}

Food consumption and production are increasingly becoming delinked due to enhanced agricultural productivity that has generated production surpluses in production areas and the globalization of trade. The environmental impact of food consumption is thus increasingly indirect, i.e. not immediately in the same place as in which the consumption takes place. Another development is the increasing fraction of animal source foods in the diet of people, adding to the indirect environmental impacts of consumption because the environmental footprint of animal products is generally larger than the footprint of the crop products they replace. This is particularly relevant in developing countries where the consumption of meat and milk is growing more rapid than in developed countries. The objective of this thesis is to explore the historic, current and future consumption and production patterns of meat and milk in Kenya and link this to an assessment of the associated water and land footprints. The research has been set-up in four subsequent studies. The first study assesses the historical trend in the water and land footprints of meat and milk production in Kenya. The second study explores the potential to meet the projected increase in demand for livestock products within the environmental boundaries. In the third study we assess the historical trends in the water footprint of meat and milk consumption in Nairobi, a rapidly growing megacity. In the fourth study we assess the future water and land footprints within a food self-sufficiency perspective. Below is a summary of the main findings of the study.

Past and current water and land footprints of meat and milk production. Global consumption of livestock products is increasing steadily due to population growth, poverty reduction and dietary changes, raising the demand for already scarce freshwater and land resources. We analyse the changes associated with direct and indirect use of freshwater and land for meat and milk production in three production systems in Kenya between the 1980 s and 2000s. Two resource use indicators are used; the water footprint $\left(\mathrm{m}^{3} /\right.$ year) and land footprint (ha), to assess changes in freshwater and land use for cattle, goats, sheep and camels in arid, semi-arid and humid production systems. The amounts of freshwater and land resources used for production are determined mainly by production volumes and feed conversion efficiencies. Green water and grazing land footprints dominated in all production systems due to the predominance of indirect use of water to support forage production. The national average footprints per unit of beef and milk show a modest decrease due to a relative shift of production to the more resourceefficient humid production system. We show that given the potential increase in demand for livestock 
products and limited freshwater and land availability, feed conversion efficiencies should be the main targeted improvement in livestock production and this can be achieved by rehabilitating degraded rangelands, adopting improved breeds and application of appropriate feed composition.

Land footprint of meat and milk production under intensification. Increasing demands for meat and milk in developing countries and the associated growth in production are driving the expansion of agriculture at the expense of environmental conservation and other land uses. The second study of this thesis presents and analyses land availability and land footprints of livestock intensification for five scenarios representing various degrees of intensification of meat and milk production by cattle, sheep, goats and camels in arid, semi-arid and humid production systems in Kenya. For each scenario, we quantify the potential availability of grassland and cropland for meat and milk production by cattle, sheep, goats and camel in the arid, semi-arid and humid production systems. The land footprint (ha) is used to assess changes in land use associated with livestock production. Land availability and land footprints of livestock intensification for five scenarios representing various degrees of intensification of meat and milk production are analysed. The first three scenarios are defined by increasing levels of input and management, ranging from low (scenario S1), intermediate (S2) to high (S3) input feed crop cultivation and livestock production. Reference scenario S1 has production practices and output of meat and milk similar to current production practices. Two additional scenarios, S4 and S5, explore opportunities for lessening environmental pressure through reduction of the land footprint of meat and milk production. We estimate that the potential increase in production from the reference scenario due to intensification is $80 \%$ for milk and $113 \%$ for meat. The area of grazing land, as a percent of the total potentially available grazing land, decreases from $10 \%$ to $6 \%$ as productivity increases from scenario S1 to S5. Cropland usage increases from $4 \%$ in scenario S1 to $11 \%$ in S5. Reduced land demand indicates the possibility that intensification may help reduce the pressure on land and hence promote environmental conservation. Overall, the results suggest that it is possible to increase production to meet increasing demands for meat and milk while also gaining land for environmental conservation through intensification.

Urban consumption of meat and milk and its green and blue water footprints - patterns in the 1980s and 2000s for Nairobi, Kenya. Various studies show that the developing world experiences and will continue to experience a rise in consumption of animal proteins, particularly in cities, as a result of continued urbanization and income growth. Given the relatively large water footprint (WF) of animal 
products, this trend is likely to increase the pressure on already scarce water resources. We document the changes between the 1980s and 2000s in consumption of meat and milk for three income classes in Nairobi, the ratio of domestic production to imports, and the WF (the volume of freshwater consumed) to produce these commodities in Kenya and abroad. Nairobi's middle-income class grew much faster than the overall population. In addition, milk consumption per capita by the middle-income group grew faster than for the city's population as a whole. Contrary to expectation, meat consumption per capita in Nairobi declined by $11 \%$. Nevertheless, total meat consumption increased by a factor 2.2 as a result of population growth, whilst total milk consumption grew by a factor 5 . As a result, the total WF of meat consumption increased by a factor 2.3 and the total WF of milk consumption by a factor 4.2 . The increase in milk consumption was met by increased domestic production, whereas the growth in meat consumption was partly met through imports and an enlargement of the footprint in the countries neighbouring Kenya. A likely future rise in the consumption of meat and milk in Nairobi will further enlarge the city's WF. Given Kenya's looming blue water scarcity, it is anticipated that this WF will increasingly spill over the borders of the country. Accordingly, policies aimed at meeting the rise in demand for meat and milk should consider the associated environmental constraints and the economic implications both nationally and internationally.

The effect of increasing meat and milk consumption on the future growth of water and land footprints. Population growth and rising affluence increase the demand for agricultural commodities, while urbanization and globalization enlarge consumer-producer distances. The associated growth in trade in agricultural products results in increasing dependence on natural resources in the producing regions. This study assesses the impact of changing meat and milk consumption on natural resources use in Kenya, considering two socio-economic development scenarios, namely the Business As Usual (BAU) and Kenya Vision 2030 (S2030) scenarios. Two resource use indicators, water footprint and land footprint, are used to represent human appropriation of water and land resources for meat and milk production, trade and consumption in 2030. Overall meat and milk production and consumption are projected to be higher in the S2030 than in the BAU scenario. The fraction of imported meat in total meat consumption is expected to grow between 2009 and 2030 from 37\% to 45\% in both scenarios. The fraction of imported milk in total milk consumption will remain at $13 \%$ in the S2030 scenario but grow towards $20 \%$ in the BAU scenario. From 2009 to 2030, the water and land footprints of meat production will grow by $93 \%$ and $91 \%$ in BAU and by $45 \%$ and $23 \%$ in $\mathbf{5 2 0 3 0}$. The water and land footprints of milk production will both grow by $59 \%$ in 
BAU and by $18 \%$ and $14 \%$ in S2030. The use of water and land for producing meat and milk in Kenya will thus grow under both scenarios, but less in S2030 than in BAU, despite the stronger growth of meat and milk consumption per capita in S2030, which can be explained by the smaller population growth in the S2030 scenario and the greater improvements in water and land productivities. The Vision 2030 strategy for improving livestock production in Kenya is of great importance to reduce the speed with which the environmental footprint of the sector will increase, but it will be insufficient to stabilize or even reduce the sector's footprint. Besides, reducing the dependency on foreign land and water resources would require a yet more ambitious policy.

To conclude, there is a large potential to increase productivity in Kenya through sustainable intensification. However, it is important to note the non-uniformity in the potential to increase productivity. Across three systems, severe historic declines in productivity in the arid and semi-arid systems but a concurrent increase in productivity in the intensifying humid system have been demonstrated. Though there are generic proposals for further productivity improvements, they do not explicitly address the non-uniformity and expected results still fall short of sustainably meeting the projected increased demand for animal source foods. 


\section{Introduction}

Fresh water and bioproductive land are two natural resources necessary for sustaining human consumptive demand. Over the years, it has become apparent that the depletion of these resources to meet growing human demand, as evidenced by incidences of groundwater depletion, soil loss, drying up of fresh water bodies and land degradation, may become unsustainable if no interventions are put in place (Chertow 2000, Bac et al. 2011). These outcomes point to a breach of the planetary boundaries set by the limited availability of natural resources (Steffen et al. 2015). This has been brought about by socioeconomic factors such as population growth, urbanization, economic growth, changes in consumption patterns, and land use changes. These factors determine the rate and trajectory of human appropriation of natural capital, fresh water and bioproductive land (Rockström et al. 2010).

Urbanization and income growth have been associated with dietary changes that, in turn, increase the pressure on the environment, because wealth increases allow for purchase of more food per capita and dietary preferences shift towards commodities with greater per unit impact on the environment (van der Zijpp 1999, Delgado 2003, Mekonnen and Hoekstra 2012). The developing world is projected to consume about $63 \%$ of the total meat consumed globally by the year 2020 and about eight times more milk than in developed countries (Delgado 2003, Msangi and Rosegrant 2012). Despite the increased consumption of these foods, an increase that should improve the quality of diets, the level of malnutrition in the developing countries is still quite high (Neumann et al. 2002, Randolph et al. 2007, Gómez et al. 2013).

For many developing countries, the causes of food insecurity vary but are mainly due to a variety of factors and their interactions. These include human population growth, a colonial legacy of agricultural policies that pay more attention to large-scale export crops at the expense of self-sufficiency and supplying national demand by smallholder farmers, market distortions created by the successful subsidized agricultural sectors in the developed world, and globalization of trade (Hall 2000, Herrero et al. 2010b). Increasing demands are met through improvements in agricultural productivity and other technological advances that enhance human exploitation of natural capital (Boserup 1993, Thornton 2010). These changes in agricultural productivity can lead to either positive outcomes such as landscapes and basins with both economic and ecological value or result in land degradation and groundwater depletion or impoverished ecosystem, which, in turn, will determine the sustainability of human consumption (Foley 
et al. 2011). In many agricultural systems in developing countries, productivity is still very low (Bruinsma 2003), showing particularly in low efficiency of using land and water resources. The potential to increase the water and land productivities in these regions through improved crop and livestock yields is large (Falkenmark et al. 2009, Herrero et al. 2010b, Erb et al. 2012). The combination of unsustainable consumption and inefficient production points to the need for a second green revolution, especially for sub-Saharan Africa, so as to meet the requirements of sustainable agricultural production: food security and poverty alleviation in the developing regions that are currently still lagging behind (Dawson et al. 2016).

As demand increases and the available freshwater and land within regions and countries is no longer sufficient to meet increasing demand, trade becomes an important means to meet the gap associated with the supply deficit (Folke et al. 1997, Hoekstra and Chapagain 2008, Erb et al. 2009a, Hubacek et al. 2009). As trade increases in importance, consumers become delinked from the impact they have on the areas that supply the products they consume (Seto et al. 2012). Given the increased pressure on the environment due to human demand for resource intensive products such as meat and milk, there is a need to create better understanding and awareness of the link between consumption and production. In order to highlight and monitor human impacts, there is a need for development of assessment methods that illustrate the levels of appropriation and possible impacts attributable to activities geared towards meeting human demand (Rees and Wackernagel 1996, Hoekstra and Hung 2002). Water and land footprints are well developed indicators to highlight the use of freshwater and biologically productive land associated with production and consumption patterns (Hoekstra 2009, Wackernagel 2009). In addition, they are useful tools in communicating complex sustainability problems to a wide and diverse audience.

\subsection{Objective of the thesis}

The objective of this thesis is to estimate the historic, current and future water and land footprints of meat and milk consumption and production in Kenya. The focus in this thesis is on ruminant meat and milk production and consumption.

The objective is achieved through carrying out four studies. The first study analyses changes associated with production of meat and milk in Kenya between 1980 and 2012. This sets the backdrop on which the historical and current water and land footprints of meat and milk production in Kenya are assessed. In the 
second study, the potential for increased production in Kenya and the associated land footprint is assessed. This study aims to answer questions on the capacity of domestic livestock production to meet the projected increase in demand for meat and milk in Kenya and at the same time mitigate pressure on the environment. The third study aims to meet the objective of understanding meat and milk consumption in Kenya and the associated water footprint over a similar period as the first study. This objective is met through looking at a case study of the capital Nairobi. Nairobi is considered to be representative of the various population segments in Kenya and their associated dietary patterns and therefore appropriate in giving an overview of Kenya's water footprint historically. Additionally, the richness of data for Nairobi facilitates drawing conclusions on changes associated with population and urban growth. In the fourth study, possible future water and land footprints of Kenya are assessed. This fourth study assesses the impacts of absence or implementation of newly planned policies on production and consumption on future food security prospects for Kenya. This allows for an assessment of the implications of production and consumption outcomes on water and land use in the future.

\subsection{Innovative aspects of the thesis}

\subsubsection{Meeting increased consumptive demand through changes in agricultural productivity}

Advancing urbanization, growth in human population and sustained economic growth are the main contributing factors to rising food requirements and a change in dietary preferences towards more livestock intensive diets (van der Zijpp 1999, Ndambi et al. 2007, Msangi and Rosegrant 2012). Though many studies have focused on these factors and how diets are projected to change, few studies have assessed the link between these dietary changes and the demand they impose on natural resources (Hoekstra 2014). In this thesis, we assess the changes in consumption of meat and milk in Kenya and present estimates of the associated changes in the amounts of freshwater and land required to produce these commodities. The possibility to lower the water and land footprints associated with a particular consumption pattern through improvements in livestock productivity is demonstrated by differential patterns in these indicators under different scenarios.

\subsubsection{Composite indicators for assessing water and land use}

The use of indicators of resource appropriation, such as water, ecological and carbon footprints, in isolation has led some authors to question their usefulness (Fiala 2008, Vanham and Bidoglio 2013). 
Analyses that use multiple indicators may enhance their effectiveness in sharpening our understanding of resource use dynamics and possible trade-offs (Hoekstra and Wiedmann 2014). The water footprint is an indicator of water use in relation to the production of consumer goods and is expressed in terms of the water volume evaporated or polluted (Hoekstra et al. 2011). The water footprint is composed of three components: green, blue and grey (Chapagain and Hoekstra 2003). These components of the water footprint are used to indicate both spatial and temporal uses of water and compare these to freshwater availability (Falkenmark et al. 2009, Hoekstra et al. 2012). The consumption, production and trade in various products and their associated demand for freshwater resources are spatially and temporally articulated by their respective water footprints (Hoekstra and Chapagain 2008, van Oel et al. 2009, Hoekstra and Mekonnen 2012). The land footprint assesses the 'actual land used' for producing consumer goods and services and is an indicator of human appropriation of biologically productive land, differing slightly from the ecological footprint by estimating actual hectares (ha) instead of normalised 'global hectares' (gha) (van Vuuren and Smeets 2000, Erb 2004, Wackernagel et al. 2004). The importance of the disaggregation into a cropland footprint and the grazing land footprint is the usefulness in clearly interpreting outcomes of consumption, production and trade on land availability and interactions with competing claims (Erb et al. 2009a, Kastner et al. 2015). In this thesis, the two indicators are considered both to assess the added value of combining resource use indicators.

\subsubsection{Spatially disaggregated analysis of water and land use}

Consumption and production of livestock products and the associated water and land footprints are assessed at disaggregated levels. Consumption is assessed at a scale that allows an assessment of the implication of income on the water and land footprint. Production is assessed at a scale that allows for the analysis of the differences associated with policy and practice in livestock production to be assessed. Additionally, livestock production is also practiced along a wide gradient of agro-ecological zones and therefore, it is important to clearly distinguish production systems. This is done here to allow for a more in-depth assessment of spatially disaggregated water and land use for livestock production.

\subsection{Organization of the thesis}

The thesis starts with a historical analysis of the water and land footprints of meat and milk production in Kenya in chapter 2 . The water and land footprints are presented for three of the dominant ruminant 
species; cattle, sheep and goats and camels. National water and land footprint of meat and milk is further disaggregated into three production systems: based in the arid, semi-arid and humid environment respectively. The analysis for these species and in the production systems is carried out for two periods spanning 30 years. The value of using a composite indicator to assess resource use is also tested in this chapter.

The third chapter explores the potential to improve meat and milk production in Kenya. Five intensification scenarios are developed, using a set of assumptions relating to land availability for livestock production and the potential production of meat and milk by cattle, shoats and camels in three production systems. From chapter 2 eight factors that determine the production potential for meat and milk in the five scenarios are selected: 1) types of land used, 2) feed composition, 3) land productivity, 4) feed conversion efficiency, 5) livestock productivity, 6) ratios of the different livestock species, 7) livestock breeds, and 8) ratios of meat and milk produced. The land footprint associated with the alternative improvements of meat and milk production is also assessed. The potential land saving from improved productivity under three scenarios is outlined and linked to the increased production.

Chapter 4 quantifies the total amount of meat and milk consumed overall in Kenya and then focuses on the consumption associated with Nairobi residents. Environmental pressure linked to consumption is assessed based on whether the consumed livestock products are domestic or foreign in origin. This chapter also compares the consumption patterns for the 1980 s and 2000 s to establish temporal changes. The water footprints associated with the meat and milk consumption in the city are contextualized in terms of their domestic and foreign components. By this analysis, we show the dependence of Nairobi on foreign water resources and what this implies in terms of reliance on imports. A comparison between the blue water use for livestock production and the blue water scarcity in Kenya's three production systems is also assessed. This gives an indication of the sustainability of consumption of meat and milk in Kenya.

In the fifth chapter, two water footprint and land footprint scenarios are developed: a Business as Usual scenario and a scenario based on Kenya's development strategy to the year 2030. The three divers of change in the scenarios are: i) population changes, ii) production of meat and milk, and iii) consumption of meat and milk. By comparing consumption and production and assessing the future needed changes in the virtual water and land imports for meat and milk in Kenya, this chapter is able to make conclusions on 
the likely future food security outcomes for Kenya. The final chapter concludes the thesis and highlights the main findings and recommendations. 


\title{
2 Trends and spatial variation in water and land footprints of meat and milk production systems in Kenya ${ }^{1}$
}

\begin{abstract}
Global consumption of livestock products is increasing steadily due to human population growth, poverty reduction and dietary changes raising the demand for already scarce freshwater and land resources. Here, we analyse the changes associated with direct and indirect use of freshwater and land for meat and milk production in three production systems in Kenya between the 1980s and 2000s. We use two resource use indicators, the water footprint ( $\mathrm{m}^{3} /$ year) and land footprint (ha), to assess changes in freshwater and land use for cattle, goats, sheep and camels in arid, semi-arid and humid production systems. We estimate actual water and land use using Kenya-wide data for yields, feed composition and feed conversion efficiencies. Our results show that the amounts of freshwater and land resources used for production are determined mainly by production volumes and feed conversion efficiencies. Total water and land footprints of milk production increased for goats, sheep and camels but decreased by half for cattle in arid and semi-arid production systems, in correspondence with similar changes in the total numbers of each livestock species. Green water and grazing land footprints dominated in all production systems due to the predominance of indirect use of water to support forage production. The per unit meat footprint for cattle increased significantly between the 1980s and 2000s in all production systems, due to adverse trends in feed conversion efficiency, while changes in the water and land footprints of other animal products were small, due to modest changes in all influencing factors. In contrast, national average footprints per unit of beef and milk show a modest decrease due to a relative shift of production to the more resource-efficient humid production system. Given the potential increase in demand for livestock products and limited
\end{abstract}

\footnotetext{
${ }^{1}$ Published as Bosire et al. (2015)
} 
freshwater and land availability, feed conversion efficiencies should be improved by rehabilitating degraded rangelands, adopting improved breeds and using appropriate feed composition.

\subsection{Introduction}

Depletion of natural resources by humans, particularly for food production, is widely recognized as a significant threat to the sustainability of consumption (Chertow 2000, Bac et al. 2011). Growing resource use intensities have led to groundwater depletion, soil loss, drying up of fresh water reserves and land degradation globally (Meyer and Turner 1994, Campbell et al. 2005, Oago and Odada 2007). Despite the mounting physical evidence of environmental degradation, the relation between consumption in specific regions and its impact on the environment in the production areas is usually not well recognised and quantified. Attempts to bridge this knowledge gap has motivated the development of various resource use indicators, such as the water and ecological footprints (Rees and Wackernagel 1996, Hoekstra and Hung 2002).

The water footprint is an indicator of water use in relation to the production of consumer goods and is expressed in terms of the water volume evaporated or polluted (Hoekstra et al. 2011). A water footprint is composed of three components: the green, blue, and grey water footprints. The green water footprint refers to the consumptive use of rainwater from lands used for crop production or grazing, while the blue water footprint refers to the consumptive use of water from rivers, lakes, wetlands and aquifers. Consumptive water use refers to both the volume of water that evaporates and returns to the same catchment or to the sea and that which is incorporated into pasture and crops. The green water footprint is relevant in both rain-fed and irrigated agriculture, while the blue water footprint refers to water consumption in irrigated agriculture as well as in households and industries. The grey water footprint is an indicator of water pollution and refers to the volume of water that is required to assimilate pollutants such as fertilizers, in mainly industrial production systems, in order to meet water quality standards. The water footprint of a live animal consists of two components: the direct water footprint related to the drinking water and service water consumed and the indirect water footprint of the feed (Chapagain and Hoekstra 2003). The land footprint is defined here as the 'actual land used' for producing consumer goods and services (Erb 2004). We distinguished between two components: the cropland footprint and the 
grazing land footprint. The land footprint is similar to the more widely known ecological footprint and only differs in its representation of land use in terms of actual hectares (ha) instead of normalised 'global hectares' (gha) (van Vuuren and Smeets 2000, Wackernagel et al. 2004). Land appropriation is typically measured across five distinct land use types: cropland, grazing land, fishing ground, forest land, and builtup land.

The use of these indicators in isolation has led some authors to question their usefulness (Fiala 2008, Vanham and Bidoglio 2013). This criticism can be addressed by assessing both indicators rather than just one of them. Only few studies have so far combined the water and ecological or land footprints (Hubacek et al. 2009, Ewing et al. 2012). Yet, analyses employing such a combination may enhance their effectiveness in sharpening our understanding of resource use dynamics and possible trade-offs (Hoekstra and Wiedmann 2014).

The footprint indicators have been applied at various spatial and temporal scales to quantify the demand exerted by humans on natural resources (Wackernagel et al. 1999, Monfreda et al. 2004, Moran et al. 2008, Chapagain and Hoekstra 2011, McMichael and Butler 2011, Mekonnen and Hoekstra 2011b). These studies aim to uncover the indirect effect of consumers on the environment. Though thorough, these studies often only provide general overviews of human appropriation of freshwater and land, and only a few account for the local heterogeneity inherent in resource utilization (Ridoutt et al. 2011) and consider the changes over time in water and land footprints per unit of production (Zoumides et al. 2014).

In Kenya, meat and milk production shows spatial variation driven principally by climate related agricultural production potential and associated land use. Market-oriented milk production primarily occurs in high altitude areas, usually classified as the humid production system (Ngigi 2005). The latter production system constitutes the main dairy production areas in Kenya, where production is mainly by smallholder dairy farms and market oriented. The dairy herds comprise mainly exotic-local breed crosses and the feeding system is largely cut-and-carry and dominated by the use of Napier grass (Pennisetum purpureum) (Thorpe et al. 2000, FAO 2005). On the other hand are the arid and semi-arid lands production systems in which about $70 \%$ of livestock is reared and where the main feeding system is extensive grazing. The production in these systems is mainly for subsistence, with milk supply being the prime production objective. Even so, cattle offtake for beef marketing still accounts for a large proportion of total output in these systems (Grandin 1988, Aklilu et al. 2002, Onono et al. 2013). About 22\% of the cattle offtake within 
this system relates to imported cattle from neighbouring countries (Behnke and Muthami 2011). However, increasing water scarcity and changing land tenure arrangements in these systems progressively hinder optimal use of the expansive land resources available in these pastoral production systems. So far, there has not been any study focusing on the spatial variation in the use of freshwater and land across these production systems in Kenya.

The expected change over time is intensification in both meat and milk production, a common outcome of interventions aimed at integrating rural within national economies. In Kenya, cattle breeding programmes initially focused on improving beef cattle to meet rising demands for beef under the Kenya Beef Industry Development Project (Kosgey et al. 2011). This involved crossing the indigenous Zebu or Boran cattle with the exotic Simmental, the dual purpose Sahiwal and improved Boran breeds. After Independence in 1963, most of these programs broke down or were abandoned and emphasis shifted to smallholder dairy production in the humid areas. This involved cross-breeding the exotic Friesian, Ayrshire, Guernsey and Jersey breeds with the indigenous cattle breeds, thereby increasing - the milk yields of the latter breeds in the humid systems. The intensification of production necessitated by the improved breeds usually entails the use of elevated levels of input, putting greater strain on the available natural resources (Erb 2004). Given the prevailing scarcity of resources, the increasing demand for livestock products and the drive for intensification, especially in developing countries, there is undoubtedly a need for increased efficiency in resource use. An assessment of the changes in efficiency of production practices undertaken to meet the growing demands in these systems is thus an essential first step in designing strategies for improving their efficiencies.

In this paper we use the water and land footprint indicators to explore spatial and temporal changes in the use of freshwater and land resources for meat and milk production in Kenya. We also assess the factors constraining efficiency across the production systems between two periods, 1980s and 2000s. We then outline how production parameters govern the use of freshwater and land resources and, finally, make recommendations on ways to improve efficiency in water and land use.

\subsection{Methods and data}


Our analysis proceeds in four phases. As Kenyan production systems can be divided into distinct geographical zones in terms of agro-ecological characteristics, the main livestock product, the scale of production and husbandry technique, we first delineate the various production systems in Kenya. Secondly, we estimate the number of animals and the volumes of meat and milk production in each of the production systems. The third stage involves the assignment of feed estimates to the various livestock species within the various production systems. Finally, we determine the water and land footprints of meat and milk production per production system in the 1980s (1977-1990) and 2000s (2001-2012), and analyse the changes that have occurred over this period.

\subsubsection{Characterizing the production systems}

Robinson et al. (2011) give a literature overview of different classification schemes of livestock production systems. In this study, we distinguish three broad categories based on a combination of agro-ecological factors and production patterns (Pratt and Gwynne 1977, Grandin 1988, Rege 2001): humid, semi-arid and arid production systems.

Humid production systems are located in areas receiving an average rainfall exceeding $800 \mathrm{~mm}$, have soils of high fertility and hence high potential for biomass production and modest pest and disease problems. In Kenya, this category covers the areas in Central Kenya, the Central Rift Valley to Western Kenya and most of the Coastal strip (Ouma et al. 2000). The semi-arid production system has an average annual rainfall between 600 and $800 \mathrm{~mm}$, a medium potential for biomass production and livestock production is hindered by the prevalence of trypanosomiasis. The areas covered by this production system are located in parts of Southern and Eastern Kenya, areas neighbouring the humid production systems to the north and south and the coastal strip. The last system, the arid production system, has an average annual rainfall of less than $600 \mathrm{~mm}$, a low potential for biomass production and livestock production is hindered by the prevalence of various diseases (Grandin 1988, De Leeuw and Rey 1995, Ndambi et al. 2007). Biomass production varies greatly across the systems from $25 \mathrm{~kg} / \mathrm{ha}$ in the humid systems to as low as $8 \mathrm{~kg} / \mathrm{ha}$ in the arid system (Ouda 2001). Per production system, we identified the areas within Kenya where the system occurs and collected relevant data, such as livestock densities, production estimates and diets.

\subsubsection{Livestock numbers in each production system}


Livestock densities in the arid and semi-arid production systems were estimated from the aerial survey monitoring data collected by the Kenya Directorate of Resource Surveys and Remote Sensing (DRDRS) covering 1977 to 2012 as part of an ongoing Kenya-wide rangeland monitoring program, described previously by (Norton-Griffiths 1975, Ottichilo et al. 2000). Flight transects were oriented in an east-west or north-south direction depending on the terrain. The altitude of the survey flights averaged about 120 $\mathrm{m}$ above the ground. Two experienced and well trained rear seat observers count animals located between the rods attached to the wing struts of the airplane. Groups of more than 10 animals were photographed and later counted using an overhead projector.

DRSRS has conducted more than 272 aerial surveys in 22 administrative counties of Kenya that fall within the arid and semi-arid regions. The surveys cover some $437,000 \mathrm{~km}^{2}$. We obtain the net area of 437,000 $\mathrm{km}^{2}$ by deducting $75,000 \mathrm{~km}^{2}$ designated as protected areas in which livestock access is explicitly prohibited from the total area survey by DRSRS of 512,000 km² (Bertzky et al. 2012).

Population estimates were calculated using Jolly's Method 2 (Jolly 1969). Population size estimates and the density (number $/ \mathrm{km}^{2}$ ) of each livestock species were averaged per grid cell ( 5 by $5 \mathrm{~km}^{2}$ ) over the two time periods spanning 1977-1990 (1980s) and 2001-2012 (2000s) in order to minimize the stochastic variation in the individual survey counts.

For the humid production system, a dataset on dairy production in the Kenyan highlands collected in 2005 and considered representative of intensive smallholder dairy production was used (Waithaka et al. 2006). We derived the 1980s livestock estimates using proportional contribution to total livestock numbers by each production system from Behnke and Muthami (2011). To ensure consistency in reporting of outputs per unit area, the Geographic Information System (GIS) spatial layers of the production system and smallholder dairy were overlaid to extract data on the numbers of dairy cows in the production system in 2005. To estimate the number of dairy cows in the herd for both datasets, the dominant breeds of cattle and milk production for each of the three production systems, all the parameters defining herd composition and milk output per breed were extracted from the literature (De Leeuw and Wilson 1987, Staal et al. 2001, Bebe et al. 2003, Bouwman et al. 2005, Ngigi 2005). 


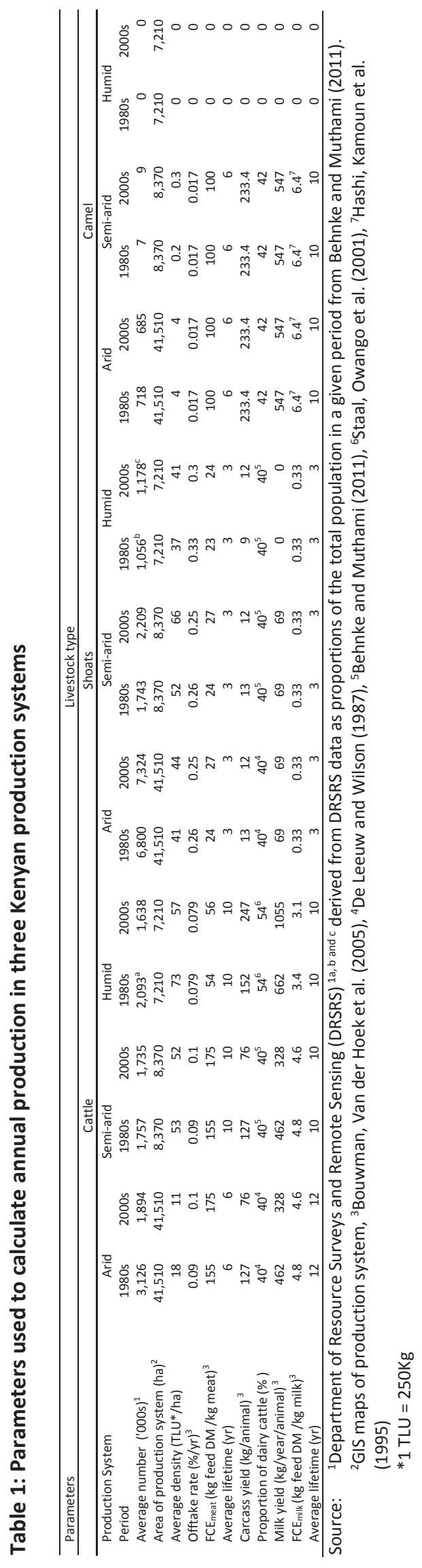

$\stackrel{m}{-}$ 


\subsubsection{Estimating the total annual production of animal products}

Various parameters from published studies and grey literature were used to estimate both meat and milk production in each of the three production systems (Table 1). The data were then used to quantify the products, the output of each product per animal and per unit of land area. We assume that there is no milk production by sheep and goats (lumped together during aerial surveys and referred to as 'shoats' throughout this paper) in the humid production systems.

The total annual production of meat in each production system was then calculated as follows. The meat production $\left(P_{\text {meat }[a, s]}\right.$, ton/yr) per animal in category a (beef cattle, camel, sheep and goat) in production system s (arid, semiarid, humid) is estimated by multiplying the carcass yield per slaughtered animal ( $C Y[a, s])$ by the annual number of animals slaughtered $(S A[a, s])$ :

$P_{\text {meat }[a, s]}=C Y[a, s] \times S A[a, s]$

The carcass yields for cattle and shoats were obtained from Bouwman et al. (2005).

The number of animals slaughtered in each production system was calculated by multiplying the total animal numbers $\operatorname{Pop}[a, s]$ by the net offtake rate $O R[a, s]$ :

$S A_{[a, s]}=\operatorname{Pop}[a, s] \times O R[a, s]$

Data on offtake rates was applied as a net offtake rate following Bouwman et al. (2005).

Total annual milk production (tonne) per animal for each production system was calculated as follows:

$P_{\text {milk }}[a, s]=M Y[a, s] \times D C[a, s]$

where $P_{\text {milk }}$ represents the production of milk per cow or shoat in production system $s, M Y[a, s](\mathrm{kg})$ is the milk yield per dairy cow in each production system and $D C[a, s]$ is the number of dairy cows in each production system, resulting from the total number of cows and the proportion of lactating cows from 
Table 1. The yield estimate is derived by assigning the yield attributed to the predominant breed i.e. Zebu, crossbreed or exotic, as the milk yield estimate within a specific production system (King 1983, Rege 2001, Staal et al. 2001, Ngigi 2005).

\subsubsection{Volume and composition of feeds}

The diet of livestock in Kenya varies widely and depending on the agro-ecology as well as the type and level of intensification of the production system (Owen et al. 2004). To estimate the spatial distribution of feed demand, a method that allows the prediction of daily feed intake by using information on diet composition and quality, feed conversion efficiency and milk and/or meat production was employed. The estimation of quantities of feed, feed composition, sources of feed and feed yields per unit area within each production system was made by combining parameters from the literature (Tables 1, 2), with the estimates of livestock numbers in (Table 1 ). 


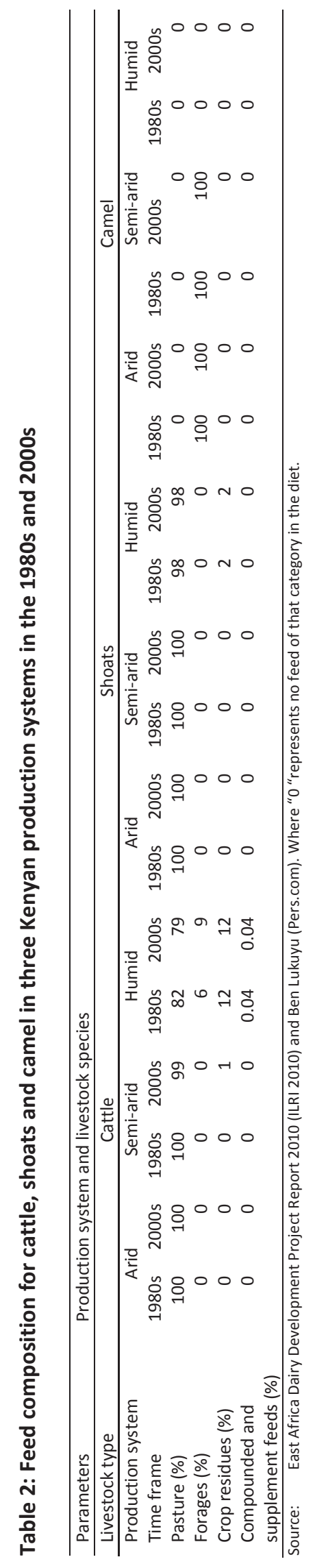


To estimate the feed volume in each system, a relationship linking the feed conversion factor of the production system to the product output was developed (Greer and Thorbecke 1986):

Feed $_{[a, s]}=$ FCE $_{[a, s]} \times P_{[a, s]}$

Feed $_{[a, s]}($ ton/yr) is the total amount of feed consumed by an animal in category $a$ in production system

s, $F C E_{[a, s]}$ is the feed conversion efficiency (kg dry mass of feed/ $\mathrm{kg}$ product) for animal $a$ in production system $S$ and $P_{[a, s]}(\mathrm{kg} / \mathrm{yr})$ is the amount of product (milk, meat) produced by animal $a$ in production system $S$. The feed conversion efficiencies for the 1980 s and 2000 s were taken from Bouwman et al. (2005) and represent aggregate values.

We distinguish the feeds into four classes: (i) pasture, which includes hay and silage; (ii) planted forage; (iii) crop residues; and (iv) compounded feed and supplements. The feed composition in the humid system for cattle, which focuses on dairy, was obtained from studies carried out at six sites within the East African Dairy Development project that estimated feed composition in this production system (ILRI 2010). For the pastoral systems - arid and semi-arid - we assumed that livestock diet is derived solely from natural grazing resources for the 1980s. In the semi-arid production system feed composition for the 2000s, we assume a proportion of crop residue in the diet. In-depth analysis of the dietary composition was not possible due to the large area covered in this study and the broad array of plant forage species, both of which complicate collection of reliable information on the species composition of the forage plants.

\subsection{Water and land footprints calculations}

\subsubsection{Water footprints of livestock products}

For beef cattle, the calculation of water footprint is most useful when an animal is considered at the end of its lifetime, because it is this total that will be allocated to the various resulting products (e.g. meat, leather). For dairy cattle, it is most straightforward to look at the water footprint of the animal per year, 
averaged over its lifetime, because one can easily relate this annual animal water footprint to its average annual milk production (Mekonnen and Hoekstra 2010b). Therefore, the water footprint of an animal can be expressed in terms of $\mathrm{m}^{3} / \mathrm{yr} /$ animal, or, when summed over the lifetime of the animal, in terms of $\mathrm{m}^{3}$ /animal. The water footprint of an animal can thus be expressed as:

$W F[a, s]=W F_{\text {feed }}[a, s]+W F_{\text {drink }}[a, s]+W F_{\text {serv }}[a, s]$

where $W F_{\text {feed }}[a, s], W F_{\text {drink }}[a, s]$ and $W F_{\text {serv }}[a, s]$ represent the water footprint of an animal in category $a$ in production system s, related to feed, drinking water and service water consumption, respectively; the feed water footprint generally dominates the other components by far. Service water refers to the water used for cleaning the area occupied by the animals, washing the animal and carrying out other services necessary to maintain the environment. The water footprint for drinking and servicing estimates were taken from Mekonnen and Hoekstra (2010b).

\subsubsection{Estimating the water footprint of feed $\left(W F_{\text {feed }}\right)$}

The water footprint of an animal related to the feed consumed consists of two parts: (i) the water footprint of the various feed ingredients; and (ii) the water that is used to mix the feed ingredients:

$W F_{\text {feed }}[a, s]=\sum_{p=1}^{n}\left(\right.$ Feed $\left.[a, s, p] \times W F_{\text {prod }}^{*}[p]\right)+W F_{\text {mixing }}[a, s]$

where Feed $[a, s, p]$ is the annual amount of feed ingredient $p$ consumed by an animal in category $a$ in production system $s$ (tonne/yr) and $W F_{\text {mixing }}[a, s]$ is the volume of water consumed by mixing the feed for 
an animal in category $a$ in production system $s\left(\mathrm{~m}^{3} / \mathrm{yr} /\right.$ animal). $W F_{\text {prod }}^{*}[p]$ is the average water footprint of the various crops, roughages and crop by-products $p\left(\mathrm{~m}^{3} /\right.$ ton) weighted over the production locations. All other categories of feed than supplemental and compounded feed are assumed to be produced and consumed within the production system. Supplemental and compounded feed was further characterised as consisting of maize as the main cereal. Given that maize in Kenya originates from both domestic and foreign (imported) sources, we use an average value that is weighted by the relative proportions of domestic production and imports (Mekonnen and Hoekstra 2011b).

$$
W F_{\text {prod }}^{*}[p]=\frac{P_{[p]} \cdot W F_{\text {prod }}[p]+\sum_{n_{e}} V W I[p]}{P_{[p]}+\sum_{n_{e}} P_{n_{e}}}
$$

where $W F_{\text {prod }}[p]\left(\mathrm{m}^{3} /\right.$ tonne $)$ is the water footprint of feed product $p$ produced in Kenya, VWI $[p]$ ( $\mathrm{m}^{3} /$ tonne) the virtual water import of product $p$ from the feed exporting nation $n_{e}, P_{[p]}$ the quantity of feed product $p$ in Kenya (tonne/yr) and $P_{n_{e}}$ the quantity of the imported feed product $p$ from the exporting country $n_{e}$ (tonne/yr).

\subsubsection{The water footprint of feed ingredients}

The water footprints of the various crops, roughages and crop by-products $\left(W F_{\text {prod }}^{*}[p], \mathrm{m}^{3} /\right.$ ton $)$ that are eaten by cattle and shoats have been calculated following the method of Hoekstra and Chapagain (2008). The water footprints of feed crops were estimated using a crop water use model that estimates crop water footprints at a $5 \times 5$ arc minute spatial resolution globally (Mekonnen and Hoekstra 2011b) and aggregated to the scale of the three previously described Kenyan production systems. Grey water footprints were estimated by considering only leaching and runoff of nitrogen fertilizers (Mekonnen and Hoekstra 2010a). 


\subsubsection{Land footprint of livestock products}

Our focus is mainly on production of livestock products, which includes direct use of pastures, but also the land associated with production of animal feed. Therefore, livestock production is associated with both grassland and cropland. Cropland, the most productive land use type, consists of the area required to grow all crop products. Grazing land has lower productivity than the croplands and consists of grasslands - cultivated and natural - used to provide feed to animals (Borucke et al. 2013). Standard calculations of ecological footprint apply equivalence factors to standardize land types, since not all land is equally productive (Wackernagel et al. 1999, Borucke et al. 2013). The equivalence factor ensures that the total land used at the global scale will be equal to the total available land used. Our categorization of the production systems based on the agro-ecological factors, accounts for low productivity of marginal grasslands that differ from grasslands in high potential lands. Differences in yield and environmental impact on the grasslands in low and high potential lands determine the use of this resource. As we intend to assess the actual amount of land used for livestock production in Kenya, we do not apply the equivalence factors in our calculations.

We attributed land area associated with the production of feed crops to each livestock product considering (i) the feed consumed per animal, (ii) country specific yields, (iii) domestic production and import of the different feed crops. Land use associated with grass production is based on grassland production and corresponding yield in the three production systems previously outlined for Kenya. By using local yields, we ensure that the calculated area is representative of the actual area used for production in Kenya (van Vuuren and Smeets 2000). The land use (ha) within a production system is estimated based on the land used for domestic production minus those related to exports plus those related to imports. For all categories of feed except compounded feed and supplements, we assume that there is no import or export of these feed components from the production system. For the category of supplement and compounded feeds, that only considers maize germ as the main cereal in the feed, we use import and export values in the calculation by extending equation (7) as follows: 
Land_use $_{p, s}=\frac{\operatorname{Prod}_{p, s}}{Y_{p, s}}+\sum_{n_{e}} \frac{I M P_{p, s}}{Y_{p, n_{e}}}-\frac{E X P_{p, s}}{Y_{p, s}^{*}}$

where Land_use $e_{p, s}$ (ha) is land area associated with the production of feed product $p$ in production system $S, I M P$ (tonne/yr) the imported quantity of feed product $p$ from exporting nation $n_{e}, E X P$ (tonne/yr) the quantity of feed product $p$ exported from Kenya. $Y_{p, s}$ (tonne/ha) the annual yield of product $p$ in Kenya, $Y_{p, n_{e}}$ (tonne/ha) the yield of product $p$ in the exporting country and $Y_{p, s}^{*}$ (tonne/ha) the weighted average of local production yield and import yield. For domestically produced feed we use local yield calculations for the specific production system. For the exported products we use a weighted average yield, while for imported products, the yields of the source countries are used.

\subsection{Results}

\subsubsection{Changes in the numbers and distributions of cattle and shoats in the arid, semi-arid and humid production systems}

Cattle, shoat and camel densities showed opposite trends between the 1980s and 2000s as shown in Fig.

1. Cattle numbers declined by $22 \%$ in the humid and $39 \%$ in the arid production systems between the 1980s and the 2000s. However, the decline was not uniform across the production systems as cattle densities increased in parts of the semi-arid production system bordering the coastal strip. Shoat densities increased across all the production systems, with the highest increase (27\%) recorded in the semi-arid production system between the 1980s and 2000s. The highest increase in camel density was observed for the semi-arid production system, where their numbers went up by $27 \%$.

Figure 1: Map of cattle, shoat and camel densities in Kenya in the three production systems in the (a) 1980s and (b) 2000s. 

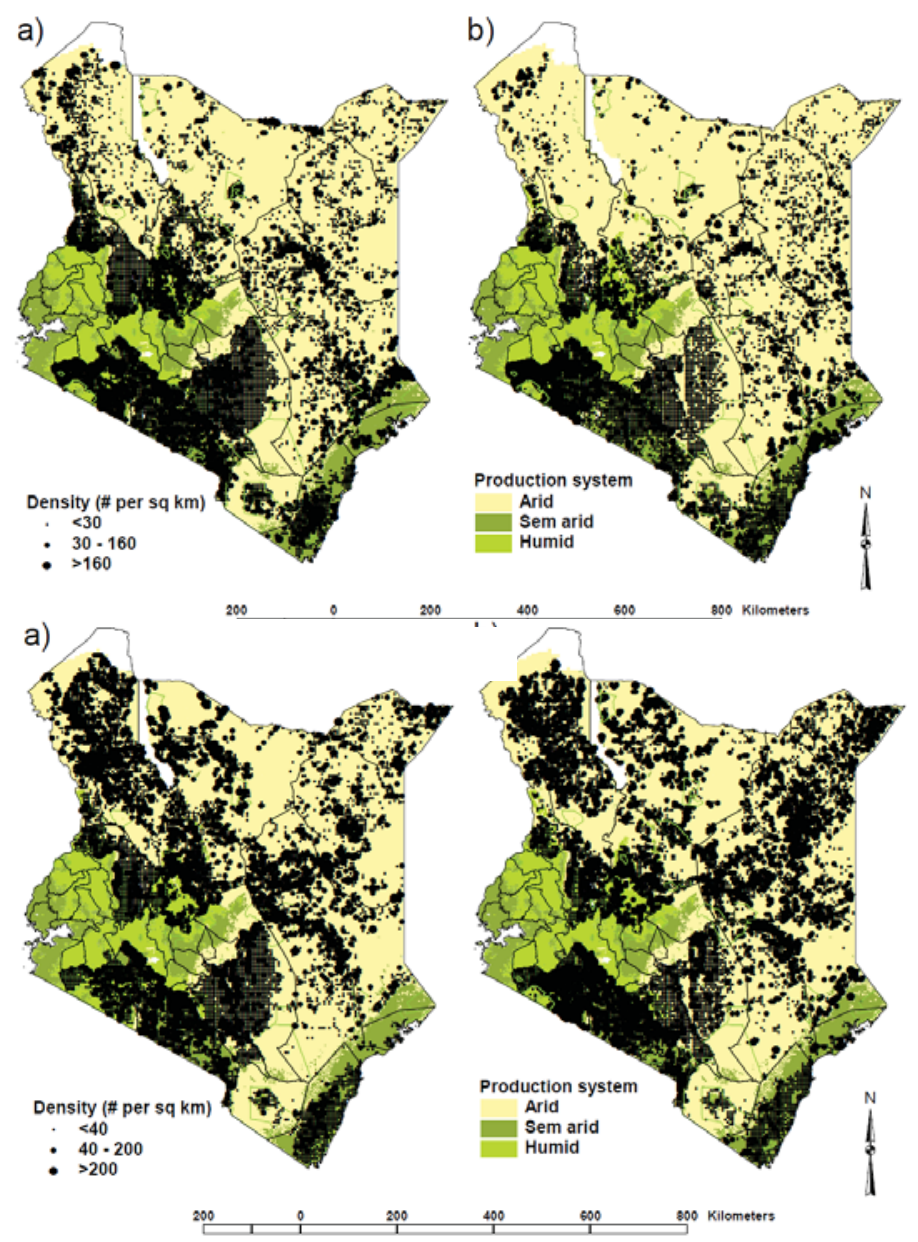

a)

b)

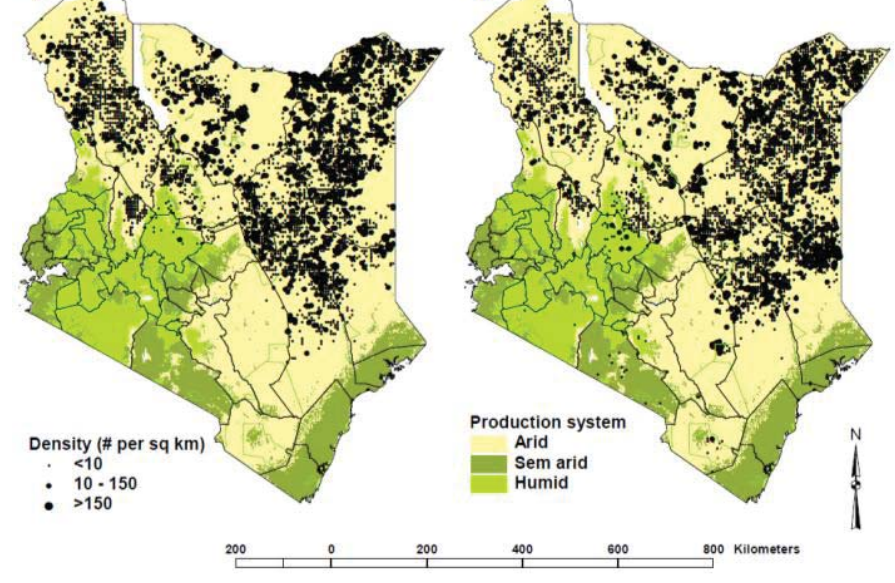




\subsubsection{The water and land footprints of milk and meat production}

\subsubsection{Total water and land footprints of meat and milk production}

In both the 1980s and the 2000s, shoats outnumbered all the other species (Figure 2). However, cattle dominated the production of meat and milk in both periods and across all the production systems. Shoat production of meat and milk in the arid production system in the 2000s was similar to that of cattle despite the fact that shoats were about four times as many. Figure 3, presents the total water and land footprint for milk and meat production. The total water footprint of meat production was 15 to 44 times larger than the corresponding water footprint of milk production for all the livestock species across the production systems. The total water footprint of milk and meat production was largest in the arid production system. For cattle, the water footprint dropped dramatically between the 1980s and 2000s, except in the humid production system. However, the water footprint for shoat production showed a persistently larger water footprint in the 2000s than the 1980s.

The cattle land footprint showed an overall trend similar to that for the water footprint, with a general decrease evident between the 1980s and the 2000s. Production of meat and milk had the largest land footprint in the arid production system. Land footprint of milk production by cattle was similar between the 1980s in the arid and the 1980s and 2000s in the humid production systems. Cattle land footprint of milk and meat production in the humid production system increased by $7 \%$ and $25 \%$, respectively, despite a $22 \%$ decline in cattle numbers between the 1980 s and 2000 s. 


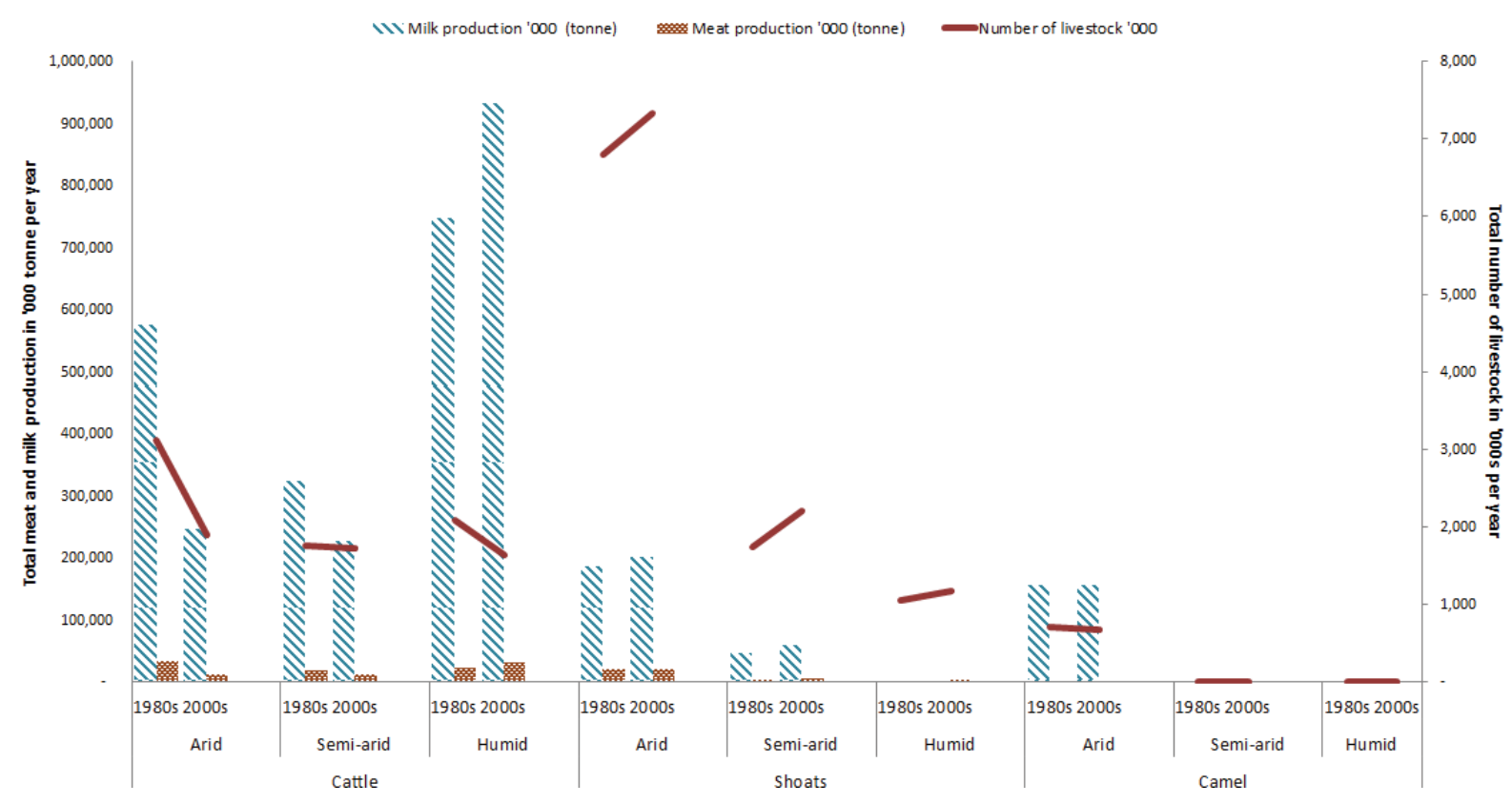

Figure 2: The total meat and milk production (left vertical axis) and total number (right vertical axis) of cattle, shoats and camel in Kenya in the three production systems in the 1980s and 2000s.

\subsubsection{Contribution of green and blue water footprints to product footprint}

Figure 4 shows the proportion of green and blue water footprints per tonne of milk and meat produced. There was considerable variation in the green and blue water footprint of milk and meat across the production systems. A grey footprint is present but represents only a very small proportion of the footprint per tonne of product. The grey footprint therefore does not show in the figures and we do not carry it forward in the analysis. Milk production had a higher proportion of blue to green water footprint than meat production did. The contribution of blue water footprint to the total water footprint per tonne of milk produced ranged from $2 \%$ to $19 \%$ across all production systems. Milk production by shoats showed a higher percentage (19\%) of blue water footprint in the arid and semi-arid production system than that exhibited by milk production from cattle $(2 \%)$ in the same systems. The blue water footprint of camel milk production of $7 \%$ falls between that of cattle and shoats. The green water footprint dominated the production of meat by cattle, shoats and camels across all the three production systems. The proportion 
of blue water footprint out of the product total, associated with meat production ranged from 1 to $7 \%$. The increase in the water and land footprints per tonne of meat production for both cattle and shoats between the 1980s and the 2000s is mostly due to worsened feed conversion efficiency for meat production; conversely, improved feed conversion efficiency for milk production leads to reducing footprints per tonne of milk for most animal species and production systems. In the 1980s, the water footprint of milk production in the humid system was closer to that in the arid and semi-arid systems than in the 2000s. This is indicative of a similarity in breeds and feeds in all the three production systems in the 1980s. For the 2000s, there is a huge gap between the milk yield in the arid and semi-arid production systems and the humid system due to the enhanced productivity associated with breed improvement and increase in milk yield per cow, which lowered the water footprint of production per tonne.

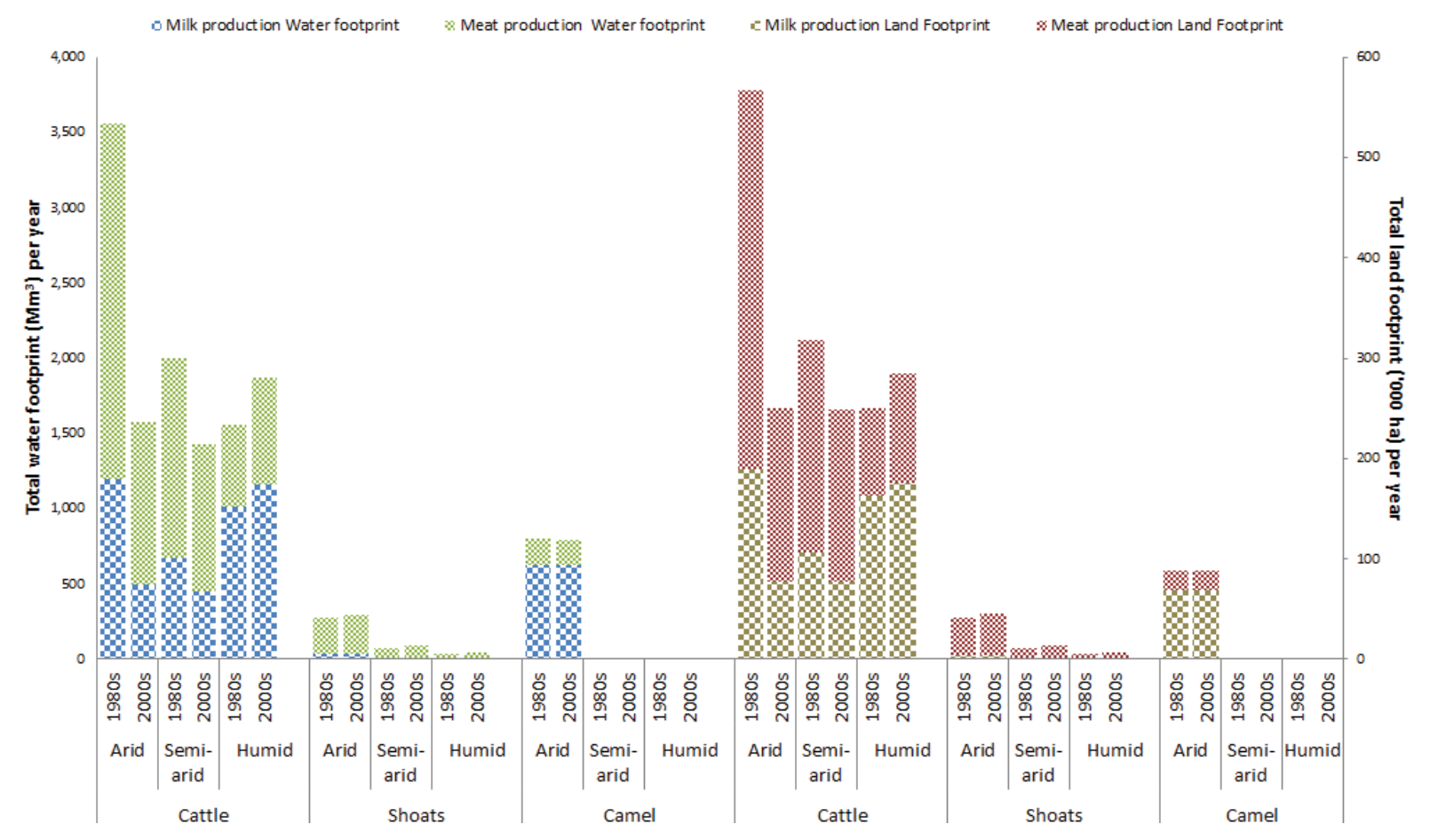

Figure 3: The total water (left vertical axis) and land (right vertical axis) footprint of meat and milk production in Kenya in the three production systems in the 1980s and 2000s.

\subsubsection{Grazing and cropland footprint per tonne of animal product}


The grazing land footprint dominated the production of milk and meat across all production systems between the 1980s and 2000s (Figure 4). In the arid and semi-arid production systems, the land footprint of cattle and shoat meat production increased between the 1980s and 2000s. In the humid production system, by contrast, there was a slight decrease in grazing and cropland footprints for beef production. There was a decrease in the land footprint per tonne of cow milk between the 1980s and 2000s. The grazing land footprint of beef production was about 30 times larger than that of the grazing land footprint of milk production.

The grazing land footprint of milk production by cattle was larger for the arid and semi-arid systems than for the humid production system. Similarly, cropland requirement for milk production by cattle was higher for the semi-arid than for the humid production system. Camel milk production had the largest grazing land footprint, though their feed composition was assumed to be $100 \%$ natural forage. Camel feed is defined as forage but because their range is confined to arid and semi-arid systems, we assigned their land footprint to the grazing component. In the arid and semi-arid production systems, the land footprint of a tonne of camel milk was 1.3 and 18 times larger than the land footprint of cattle and shoat milk, respectively. Shoats showed the smallest land footprint in the humid production system. 
(a)

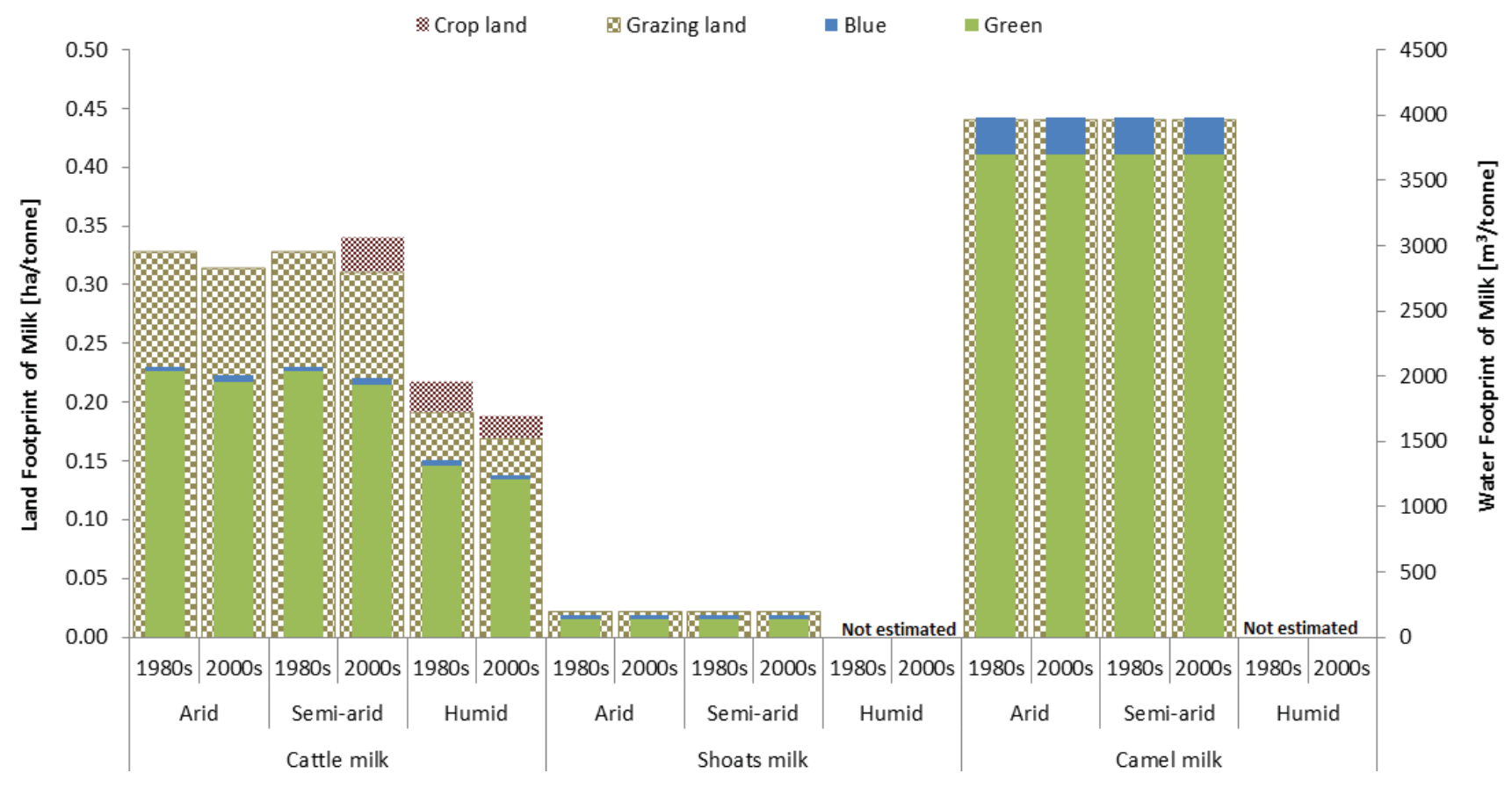

(b)

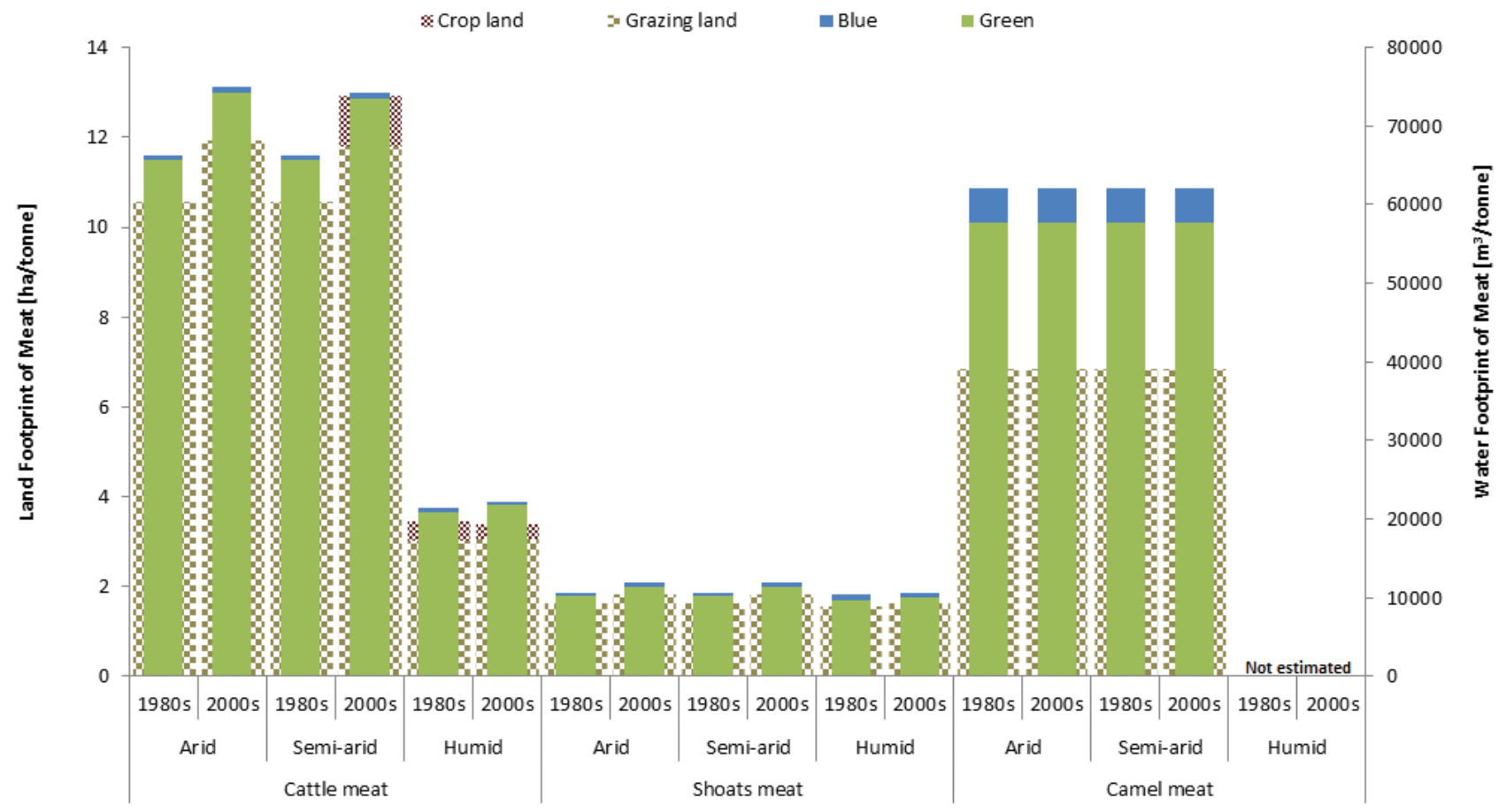


Figure 4: The water and land footprint per tonne of (a) milk and (b) meat produced by cattle, sheep and goats and camels in the arid, semi-arid and humid production systems of Kenya in the 1980s and 2000s.

\subsection{Discussion}

\subsubsection{General limitations of data and scope of conclusions}

This study is the first to quantify changes in ruminant numbers and resource use over a 30-year period in Kenya. The dearth of local literature and relevant data on this subject has posed considerable challenges to the estimation of a number of the important parameters. We therefore only focused on two broad time periods to minimise potential biases associated with any inaccuracies in the data and assumptions we made. Consequently, we restrict our estimates of changes in livestock numbers to the data provided by the DRSRS. Other potential data sources from the government databases were not available to us due to ongoing efforts aimed at quality control and harmonisation of livestock data from various sources (pers. comm). Our livestock population estimates are lower than the national estimates published by the Food and Agriculture Organization (FAOSTAT) and the 2009 Kenya national census livestock estimates. The DRSRS data have been collected consistently using the same counting techniques from 1977 to 2014 and thus cover the entire time span of our study (1977-2012). The reliability of the other available national statistics on livestock has not been quantified and glaring discrepancies were reported following the 2009 census. These other national livestock statistics are also not based on the same and consistent sampling methodology (Dietz et al. 2014, Robinson et al. 2014). The DRSRS data were also amenable to classification into the broad heterogeneous production systems used in this study, but this was not possible to do reliably using the other occasional data sets. Enhancing the consistency, reliability and frequency of the livestock surveys at the national level in Kenya would be necessary to ensure accuracy of future parameter estimates by similar studies looking at long term changes in the livestock production systems. We assumed that the extent of the production systems remained effectively unchanged over the 30-year study period. This assumption may have been partially violated if agro-climatic changes in some of the production systems were sufficient to engender substantial transitions in pastoral livelihood strategies (Jones and Thornton 2009). Although quantifying and incorporating such changes in the production 
systems in our analysis would be desirable, doing so would add a layer of considerable complexity to the analysis and take us beyond the scope of this study. Additionally, our assumption of limited change over the 1977-2012 study period is consistent with the use of 1970-2000 as the base period for defining the livestock production systems (Robinson et al. 2011).

Our analysis focused on the biophysical processes underlying resource use and did not consider economic aspects. Additionally, the lack of consistent data sources on the changes in such parameters as feed composition and carcass and milk yields precluded computing yearly estimates of freshwater and land use.

\subsubsection{Combining water and land footprints to enhance assessment of resource demands for milk and meat production}

Similar patterns and developments were found for the green and blue water and the grazing and cropland footprints in meat and milk production. The reason is that water and land requirements largely go together. As a rule we can expect and we observed indeed that greater land requirements are accompanied by greater green water consumption. With a shift towards more supplement and compounded feed, we can expect a shift towards greater cropland footprint and, in case of irrigated crops, a greater blue water footprint. We did not observe such development for the historical period studied, because intensification of livestock in Kenya hardly occurred.

\subsubsection{Decline in cattle numbers and increased importance of shoats and camels for subsistence.}

The increase in the number of shoats and concurrent decline in the number of cattle between the 1980s and 2000s, whatever its cause, points to the growing importance of small stock to the livelihoods of the Kenyan pastoral communities. The decline in cattle numbers in the arid and semi-arid production systems is reflected in the significant decrease in both the total water and land footprints of cattle production between the 1980s and 2000s. In the same vein, the increase in the number of shoats was accompanied by an increase in the total water and land footprints for shoats between 1980s and 2000s. This indicates an upsurge in the importance of shoats as a source of meat and milk. Despite their continued increase in numbers, shoats still have the lowest demand on water and land resources. This finding is both interesting and important, especially when considering options for reducing pressure on potentially scarce resources, which would favour a shift towards shoat products. The decrease in the total land and water footprint of 
milk and meat production by camel in the arid production system and increase in the semi-arid production system is indicative of increasing adoption of this drought resistant species by farmers in the semi-arid system. The livestock declines, especially of cattle, are linked to an increase in the frequency and severity of droughts between the 1980s and 2000s (Jones and Thornton 2009). The increase in the number of sheep and goats, both of which use less water and land resources than cattle, in the arid and semi-arid production system, offers the livestock producers the opportunity to continue meeting their meat and milk production goals in the prevailing more arid climatic conditions.

\subsubsection{Dominance of cattle in freshwater and land use towards milk and meat production}

Despite their decline in total numbers, cattle still contribute most to the total meat and milk production and total water and land footprints of meat and milk production in the three Kenyan production systems. This highlights the overall importance of cattle in resource use for meat and milk production in Kenya. The trends observed in water and land use by cattle are, however, not uniform across the systems. For instance, in the semi-arid production system, the cropland footprint associated with the production of a tonne of beef and milk by cattle, is much larger than that for the humid system. However, given that the quality and composition of the diet of cattle in the humid production system tends towards intensification of production by the introduction of compounded and supplemental feeds, we expect a larger cropland footprint in the future and possibly a larger blue water footprint in this system. The poor diets in the semiarid system between the two periods, combined with the declining trend in feed conversion efficiency for meat are the main causes of this apparent larger demand for cropland. The livestock farmers focus on enhancing yield by upgrading their breeds but not also concurrently investing in feed improvement, so that feeds continue to constrain milk and meat production in the three production systems.

\subsubsection{Effect of productivity changes on water and land footprints}

Table 3 shows the proportion of green and blue water footprint per tonne of milk and meat produced and compares this to the work by Mekonnen and Hoekstra (2012). Our estimates for arid and semi-arid systems can best be compared to the estimates for grazing systems in Mekonnen and Hoekstra (2012), and our estimates for the humid system with their estimate for mixed systems. Our estimates of the water footprints of milk production are similar to the estimates by Mekonnen and Hoekstra (2012).Beef production showed the largest difference in values between the two, primarily due to differences in the 
assumed feed conversion efficiency and feed composition. We used detailed local and regional data that are a factor of two or larger than those used by Mekonnen and Hoekstra (2012). In both studies, green water was the predominant water footprint component. A larger proportion of blue water in the total water footprint with this improved productivity would be associated with the inclusion of a cropland footprint for irrigated feed production. If such improved productivity were to be realized, then the resultant increases in blue water footprints and cropland footprints for livestock production would potentially enhance competition for natural resources required for feed and food production. Our study did not include data on the industrial livestock production system in Kenya as it was deemed quantitatively negligible at the national scale of this study. The industrial production system reported in Mekonnen and Hoekstra (2012) has a water footprint of an order of magnitude lower than any of the production systems we examined. However, if it were to become prevalent, it would require more cropland than any of the systems considered in this study, with a potential increase in the blue water footprint as well.

Our results show that poor feed conversion efficiency has a large impact on the efficiency with which freshwater and land resources are utilized, in accord with other studies (Herrero et al. 2013). Beef production has larger water and land footprints per tonne than shoats and camel due to higher conversion efficiencies for the latter two species. Diet composition and quality also determine the magnitude of the water and land footprints of meat and milk production. Improved diets translate to better feed conversion and, eventually, to more efficient use of freshwater and land. This is demonstrated by cattle in the humid system. Their slightly better feed conversion efficiency in the 2000s relative to the 1980 s mirrors the increase in the proportions of cross and pure bred cattle and of compounded and supplemental feeds. Nonetheless, the productivity of the improved cattle breeds in the humid production system is still relatively low because cattle diets have not correspondingly improved in Kenya to levels approximating those recommended for optimal yields. 
Table 3: The estimated green, blue and grey water footprint per tonne of milk and meat produced by cattle, shoat and camel compared to the estimates by Mekonnen and Hoekstra (2012).

\begin{tabular}{|c|c|c|c|c|c|c|c|c|c|c|c|}
\hline \multirow{2}{*}{\multicolumn{2}{|c|}{$\begin{array}{l}\text { Parameters } \\
\text { Production system }\end{array}$}} & \multicolumn{10}{|c|}{ Production system } \\
\hline & & Grazing & & \multirow{2}{*}{\multicolumn{2}{|c|}{$\begin{array}{c}\text { Arid and Semi-Arid } \\
\text { Current study }\end{array}$}} & \multicolumn{2}{|c|}{ Mixed system } & \multicolumn{2}{|c|}{ Humid } & \multicolumn{2}{|c|}{ Industrial } \\
\hline \multirow[t]{2}{*}{ Kenya } & & \multicolumn{2}{|c|}{ Mekonnen and Hoekstra 2012} & & & Mekonnen and & 2012 & Curren & study & Mekonnen and & 2012 \\
\hline & Water footprint $\mathrm{m}^{3} /$ tonne & Meat & Milk & Meat & Milk & Meat & Milk & Meat & Milk & Meat & Milk \\
\hline \multirow[t]{4}{*}{ Cattle } & Green & 38370 & 1300 & 74300 & 2000 & 10760 & 900 & 21800 & 1200 & 3200 & \\
\hline & Blue & 180 & 40 & 700 & 50 & 190 & 100 & 500 & 30 & 100 & \\
\hline & Grey & 0 & 0 & 0 & 0 & 0 & 0 & 0 & 0 & 0 & \\
\hline & Total & 38540 & 1300 & 75000 & 2000 & 10940 & 1000 & 22300 & 1240 & 3300 & 0 \\
\hline \multirow[t]{4}{*}{ Shoats } & Green & 11200 & & 11500 & 100 & 5170 & & 10000 & & 2400 & \\
\hline & Blue & 400 & & 600 & 0 & 400 & & 600 & & 400 & \\
\hline & Grey & 0 & & 0 & 0 & 540 & & 0 & & 0 & \\
\hline & Total & 11600 & 0 & 12000 & 0 & 6110 & 0 & 10600 & 0 & 2800 & 0 \\
\hline \multirow[t]{4}{*}{ Camel } & Green & & & 57740 & 3700 & & & & & & \\
\hline & Blue & & & 4440 & 300 & & & & & & \\
\hline & Grey & & & 0 & 0 & & & & & & \\
\hline & Total & & & 62180 & 4000 & & & & & & \\
\hline
\end{tabular}

\subsection{Conclusion and recommendations}

The demand for water and land for meat and milk production is mainly determined by the total numbers, feed conversion efficiency and diet composition of livestock. For cattle milk and meat, the study revealed that the humid production system had the smallest water and land footprints per tonne. Furthermore, the study showed that the water and land footprints for milk and meat from sheep and goats are much smaller than for cattle and camels.

There are many opportunities to improve the water and land use efficiency in meat and milk production in the arid and semi-arid production systems. Interventions such as rangeland rehabilitation to improve biomass availability and diet quality and breeding to increase growth rates and carcass yields can enhance the feed conversion efficiency and, in turn, lead to efficiency gains in natural resources use. Lower water and land requirements by milk production in these systems, may support the conclusion that it is better to produce milk and not meat in the arid and semi-arid systems. However, milk production in the arid and semi-arid systems is mainly constrained by political, social and environmental impediments such as limited access to markets and inputs, including high quality feeds. Production in the humid system is the most resource efficient way to produce both cattle meat and milk. The proximity to markets and crossbreeding with exotic animals has favoured the focus on milk production. Diet quality has however not developed in tandem with the improvement in breeds, thus constraining the feed conversion efficiency. 
Using fodder crops that can be intercropped, and crop residues that do not compete directly with food production is one way to improve the livestock diets in the humid system with low potential for conflicts. There is thus a pressing need for research focusing on advancing our understanding of the factors constraining the uptake of better feeding strategies and more investment in improved feed production.

Although cattle meat and milk in the humid system are more resource efficient than in the arid and semiarid systems, there are many competing claims to the available land and water resources. On the other hand, in arid and semi-arid systems, there are fewer competing demands other than setting areas aside for wildlife conservation and emergence of some cropping in the semi-arid regions. We therefore think that meat production should be carried out in the arid and semi-arid areas insofar possible without conflict with crop production where viable and wildlife protection. Drought and disease resistance associated with the indigenous livestock breeds in the arid and semi-arid systems provides an added advantage to the focus on meat production in these areas. Meat production would also limit the competition with biodiversity conservation by minimizing land use changes and indigenous species losses (Renwick et al. 2014). In addition, the livestock production in the rangelands has other attendant benefits such as wealth accumulation and other cultural roles that are not captured by the purely biophysical assessment we carried out. If these alternative attributes of livestock production are incorporated, then there should be a potential further reduction in the water and land use for meat production in these systems. Finally, an understanding of the sustainability of the current meat and milk production practices and implications of attempts to optimise interaction of the production parameters governing resource use efficiency in each system would enrich our capacity to develop the most resource efficient production practices.

Using both water and land footprints as indicators can deepen our appreciation of the interplay between the management of the two key resources demanded by livestock production-land and water. Additionally, we provide empirical evidence that can enhance our understanding of the key constraints to improving the efficiency of livestock production in Kenya. Finally, our results can guide efforts aimed at improving freshwater and land use efficiency for the specific production systems we studied and possibly other similar systems elsewhere. 


\title{
3 Meat and milk production scenarios and the associated land footprint in Kenya. $^{2}$
}

\begin{abstract}
Increasing demands for meat and milk in developing countries and the associated production growth are driving the expansion of agriculture at the expense of environmental conservation and other land uses. While considerable attention has been directed at improving crop yields to alleviate the pressure on land, there has been far less attention on the implications of the expected intensification of livestock production. Here, we present and analyse the land availability and land footprints of livestock intensification for five scenarios representing various degrees of intensification of meat and milk production by cattle, sheep, goats and camels in arid, semi-arid and humid production systems in Kenya. The first three scenarios are defined by increasing levels of input and management, ranging from low (scenario S1), intermediate (S2) to high (S3) input feed crop cultivation and livestock production. Reference scenario S1 has production practices and output of meat and milk similar to current production practices. In scenarios S2 and S3, the total land used for livestock production remains the same as in S1. Two additional scenarios, S4 and S5, explore opportunities for lessening environmental pressure through reduction of the land footprint of meat and milk production. For each scenario, we quantify the potential availability of grassland and cropland for meat and milk production by cattle, sheep, goats and camel in the arid, semi-arid and humid production systems. A resource use indicator, land footprint (ha), is used to assess changes in land use associated with livestock production. We estimate that the potential increase in production due to intensification from scenario S1 to S2 is 51\% for milk and $71 \%$ for meat. The potential increase due to improving production from scenario S1 to S3 is $80 \%$ for milk and $113 \%$ for meat. The area of grazing land, as a percent of the total potentially available grazing land, decreases from $10 \%$ to $6 \%$ as productivity increases from scenario S1 to S5. Cropland usage increases from $4 \%$ in scenario S1 to $11 \%$ in S5. Reduced land demand in scenarios S4 and S5 indicates the possibility that intensification may help

${ }^{2}$ Published as Bosire et al. (2016b)
\end{abstract}


reduce the pressure on land and hence promote environmental conservation. Overall, the results suggest that it is possible to increase production to meet increasing demands for meat and milk while also gaining land for environmental conservation through intensification. Realizing the potential presented by the intensification scenarios will be contingent upon successfully establishing and operationalizing enabling policies, institutional arrangements and markets and ensuring that relevant information, services, inputs, and other essential requirements are available, accessible and affordable to herders and farmers. 


\subsection{Introduction}

Livestock production has significant land, water and carbon footprints. Agriculture appropriates about $40 \%$ of the global terrestrial surface (Foley et al. 2005). Livestock production alone accounts for $70 \%$ of the total agricultural land use, representing one third of all croplands and vast grazing areas (Steinfeld et al. 2006b). The total feed biomass used by the livestock sector is considerable and amounts to about 4.7 billion tons (dry matter) per year, with about half being grasses and one fourth each being grains and occasional feed and stover (Herrero et al. 2013). Besides its extensive land footprint and significant biomass use, livestock rearing also accounts for almost one third of the agricultural water footprint (Mekonnen and Hoekstra 2012) and about 15\% of the anthropogenic greenhouse gas emissions (FAO 2013). In some regions, continued horizontal expansion is a key factor in deforestation (Bilsborrow and Ogendo 1992, Angelsen 1995) and in others overgrazing causes severe land degradation (Steinfeld et al. 2006b). Not surprisingly, the livestock sector is considered to be one of the leading contributors to the increase in environmental degradation (Steinfeld et al. 2006b, Pelletier and Tyedmers 2010).

Global meat and milk consumption is expected to grow significantly by 2030 (Steinfeld et al. 2006b). This growth will be particularly pronounced in developing countries where the demand for meat and milk will more than double. The increase in consumption of animal products is driven primarily by population growth, increased purchasing power, and changes in dietary preferences favouring more animal source foods (ASFs), notably meat and milk (Delgado 2003, Kastner et al. 2012). In addition, efforts to decrease undernourishment globally are also driving the demand for ASFs (Randolph et al. 2007).

In view of the already very large global natural resource use and environmental concerns related to livestock production, many researchers believe a doubling of production in developing countries will need to be met by a sustainable intensification (Pretty et al. 2011, Tarawali et al. 2011). Many developing countries still practice low input agriculture that relies on natural processes and expansion into forested lands, even in high-potential humid regions (Jankhe 1982, Godfray et al. 2010). This is true for many countries in Africa, where low-input agriculture is still widespread, partly due to limited, or slow uptake of modern production technologies, leading to poor levels of meat and milk production per animal (Headey and Jayne 2014). Because of poor yields and production for subsistence, production levels in most developing countries are insufficient to meet their domestic demands (Place et al. 2006). 
Consequently, large differences exist in livestock productivity between the developed and the developing world, implying a huge untapped efficiency potential in the developing countries, particularly in Africa. Though many interventions have focused on bridging this productivity gap (Tilman et al. 2002), there is a growing realisation that the processes involved in intensification of production of ASFs often overlook environmental impacts (Tscharntke et al. 2012). Studies that assessed these impacts have mainly focused on the implications of increasing yields in croplands on the alleviation of the pressure on the available land (Foley et al. 2005, Koh and Lee 2012). Very few studies have analyzed the consequences of reduced demand for land through increased productivity in both crop and livestock production (Wirsenius et al. 2010, Tilman et al. 2011).

The production and consumption of livestock commodities in Kenya is a case in point. The demand for livestock commodities is on the rise, and will likely continue to rise in the near future (Omore et al. 1999). Several studies have assessed farmer responses to increasing demand and showed how these are closely linked to the wider institutional, social and cultural context and how they relate to economic factors, which differ across farming systems (Feder and Umali 1993, Marra et al. 2003, Owen et al. 2012). However, the availability of and demand for land to meet livestock production needs across the various farming systems has not been quantified for Kenya. Additionally, the implications of both cropland and livestock productivity improvements for various production systems have not been quantitatively analysed and documented. Understanding of these issues is essential for the development and deployment of sound policies and practices that ensure that increased livestock production through intensification is in synergy with other critical targets such as biodiversity conservation and improved nutrition in Kenya. This paper aims to enhance our understanding of land use and availability by examining the intensification potential of meat and milk production by four ruminant species, namely cattle, shoats (sheep and goats) and camels in Kenya. The specific objectives of this paper are two-fold: (1) assess the availability and suitability of land for meat and milk production in three production systems, and; (2) explore options for intensification to either expand production of meat and milk or relieve pressure on existing lands in Kenya.

\subsection{Methods and data}

In this paper we assess land availability, suitability and livestock production and the gains in land savings that can be expected from increasing the production of four ruminant livestock species under three 
intensification scenarios in Kenya as illustrated schematically in Fig. 1. We do not consider meat production from poultry and pigs as they currently constitute a minor proportion of the total meat production in Kenya relative to ruminants (Bett et al. 2012).

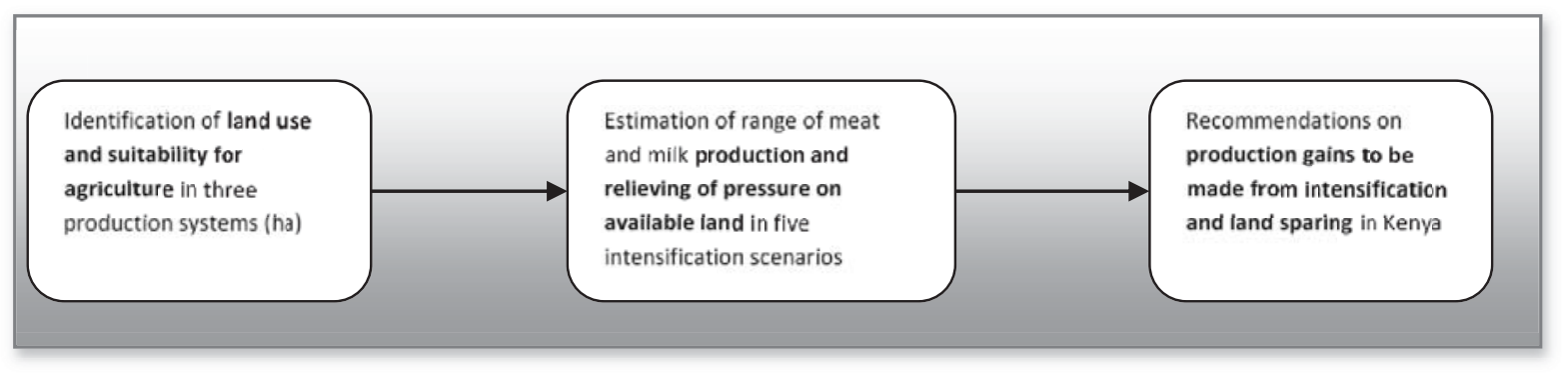

Figure 1. Steps involved in the assessment of land availability, suitability and potential for livestock production under five intensification scenarios.

\subsubsection{Identification of land available for livestock production}

\subsubsection{Selection and characterisation of analysis unit}

We analyse the production systems for four ruminant species, namely cattle, shoats, and camels in Kenya. Each production system is characterized by specific agro-ecological factors (Pratt and Gwynne 1977, Grandin 1988, Rege 2001). Land available for livestock production is estimated for each of the three agroclimatic regions, i.e. humid, semi-arid and arid. Each of these three distinct geographical regions is referred to as a production system.

The humid production system is located in areas with high potential for crop, fodder and livestock production, due to fertile soils, annual rainfall averaging over $800 \mathrm{~mm}$, and modest pest and disease problems. It covers large parts of Central Kenya, the Central Rift Valley, Western Kenya and most of the Coastal strip (Ouma et al. 2000). The semi-arid production system has a medium potential for plant growth and livestock production, an average annual rainfall of $600-800 \mathrm{~mm}$ and a high prevalence of trypanosomiasis. This production system covers parts of Eastern Kenya, neighbouring the highland production systems to the north and south, and the coastal strip to the west. The arid production system has the lowest potential for biomass and livestock production. This system is characterised by an average annual rainfall of less than $600 \mathrm{~mm}$, high variability in rainfall amount in both the wet and dry seasons, 
and high prevalence of various livestock diseases (Grandin 1988, De Leeuw and Rey 1995, Ndambi et al. 2007). The arid and semi-arid systems cover about $83 \%$ of the total land area of Kenya and are home to about 35\% of Kenya's population. In contrast, the humid system covers only about 17\% (Ruigu 1988).

\subsubsection{Land available for agriculture}

The land area directly available for ruminant production in the three production systems in Kenya includes grazing lands, for grazing and browsing livestock, and feed crop areas, for cultivation of fodder and feeds. However, the potential land available for livestock production also includes grasslands suitable for crop production and currently used for grazing. The land currently available for livestock and crop production in each of the delineated production systems was estimated by masking the land use systems raster obtained from FAO (2010) by the production systems polygon (Robinson et al. 2011). The detailed classification systems used in Robinson et al. (2011) are reclassified into the three agro-climatic zones above as described in Bosire et al. (2015). Figure 2 illustrates the estimates of land area currently available for livestock and crop production in each of the three production systems under each of three production scenarios.

The total area of land $L_{\text {total }}[s]$, constituting production system $s$ (arid, semiarid, humid) can be partitioned into the total grassland area ( $L_{\text {grassland }}[S]$ ) plus other environmentally valuable areas, such as forests and other protected areas with restricted access for livestock rearing $L_{e n v}[s]$, cropland used for food and feed production $L_{c r o p}[s]$, and unproductive areas, including built-up, degraded and bare areas that are unsuitable for agricultural production $\left(L_{\text {unprod }}[s]\right.$ ). Therefore, the total land area for livestock and crop production in each production system $L_{\text {agric }}[S]$ is determined by:

$L_{\text {agric }}[S]=L_{\text {grassland }}[S]+L_{\text {crop }}[S]$

The cropland used for feed production $L_{\text {feedcrop }}[s]$ quantifies the feed-crop land footprint (Bosire et al. $2015)$ and is calculated as the proportion of cropland $L_{\text {crop }}[S]$ that is specifically used for feed crops, forages such as alfalfa and Napier grass. Likewise, the grassland used by livestock quantifies the grassland 
footprint $L_{\text {grazing }}[S]$. By adding the feed cropland and grassland footprints we get the total land use footprint for livestock $L_{\text {livestock }}[S]$.
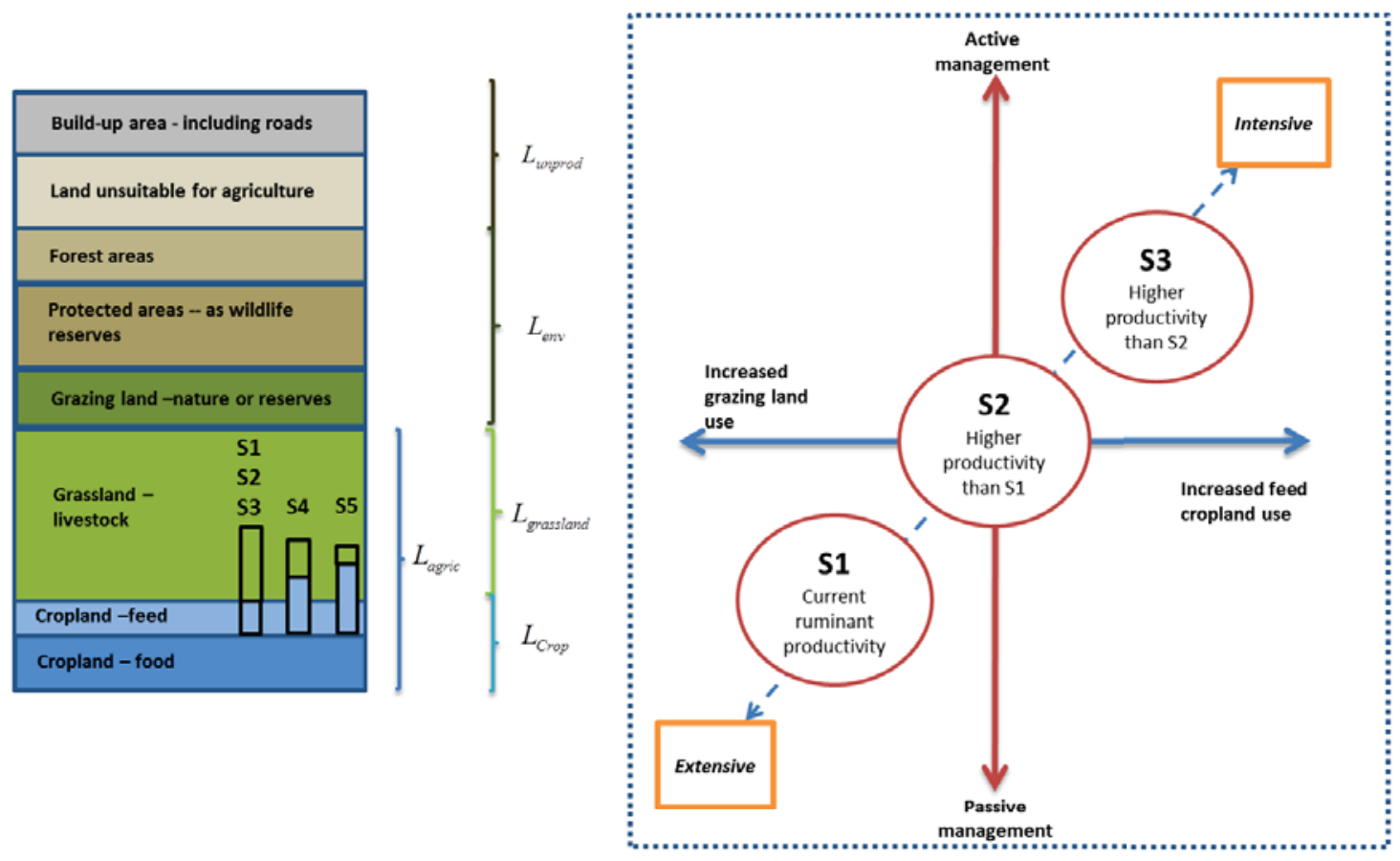

Figure 2: Subdivision of the total land area of Kenya into the six land use/cover categories referred to in the text. The schematic illustration depicts the differences in management and land use intensification between the five livestock production scenarios (S1-S5). The differences between the land uses under the five scenarios are indicated across the three agricultural land areas.

\subsubsection{Land suitability estimation}

Under intensified production, livestock dietary composition increasingly includes higher proportions of feed crops. We thus determine the extent of land suitable for the production of both food and feed crops in section 2.2.1 and outline five scenarios of intensification of livestock production in Kenya in section 2.2.2.

3.2.2.1 Land suitability for food and feed crop cultivation 
Intensification of ruminant livestock production systems is generally correlated with an increase in the fraction of supplemental and compounded feeds in the animal diets (Herrero et al. 2013) and thus with increased use of cropland for feed crop production. We consider only grassland suitable for cultivation (Figure 3) as available for conversion into land for feed production in the semi-arid and humid systems (S2 and S3) (Figure 2). The baseline scenario (S1) for land available for livestock production corresponds to the current pattern of land used for grazing and feed crop cultivation as described in Bosire et al. (2015).

Global grazing and cropland suitability maps (van Velthuizen et al. 2007) were used to determine the land potentially available for feed crops within the land areas currently available for pasture or crop production. In these maps, land suitability is provided for pasture or crop production for 2.2 million grid cells of 5 by 5 arc minute, classified as either rainfed or irrigated, and distributed across three input and management levels, i.e. low, intermediate and high.

A crop suitability index (CSI) can be derived for a combination of crop types, under both rainfed and irrigated conditions, and at the three levels of input and management. CSI is defined as the proportions of maximum yields of crops that can be achieved in a grid cell under appropriate management (van Velthuizen et al. 2007). Crop suitability indices range from 0 to 100, with 0 representing not suitable and 100 very high suitability. We consider lands with CSI between 0 and 50 (medium suitability) as unfit for feed crop cultivation and thus exclude them from the subsequent analyses (Section 2.1.2). Land with CSI values of 51-100, ranging from medium, high to very high suitability, are included as potentially available areas for feed cultivation under scenarios S1 to S3. 


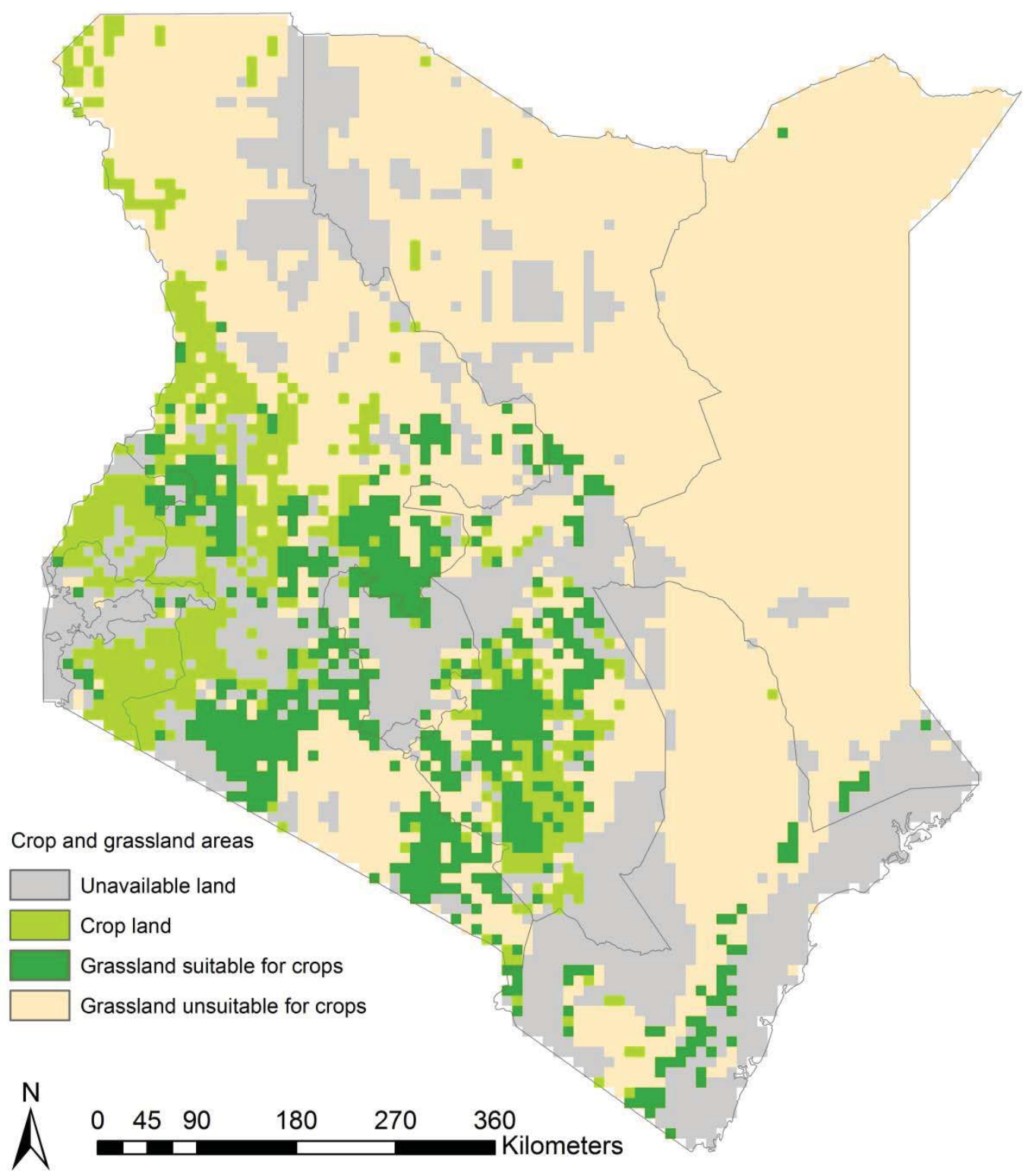

Figure 3: A map of Kenya showing the distribution of cropland, the land unavailable for agriculture, the grasslands and their suitability for crops.

\subsubsection{Intensification: quantifying the maximum production potential with current livestock numbers}

We define five intensification scenarios using a set of assumptions relating to land availability for livestock production and the potential production of meat and milk by cattle, shoats and camels in each of the three preceding production systems. We distinguish three levels of input and management, ranging from low input rainfed to high input irrigated cultivation defined by van Velthuizen et al. (2007). 
The first scenario, S1, is the baseline scenario and represents low production of meat and milk. For the baseline it is assumed that livestock is produced under conditions of low inputs and traditional management. Livestock production is also assumed to be primarily for subsistence and not markets. Furthermore, it is assumed that the production system is not mechanized, no fertilizers or chemicals are used to control pests or diseases and that no measures are taken to prevent land degradation. As agricultural production in Kenya is predominantly carried out by smallholder farmers, with little farmland under irrigation (about 0.07\%) (Ngigi 2002), these characteristics are typical of the current livestock production practice in Kenya.

Scenarios S2 and S4 assume intermediate production of meat and milk under both rainfed and irrigated agriculture, with intermediate inputs and intermediate management. Manual labour and animal traction are used, some fertilizer is applied and some chemicals are used for pest or disease control. There are fallow periods and certain measures are taken to prevent land degradation. In scenario S2 the total land footprint of livestock production is kept constant, with increasing milk and meat outputs, while in scenario S4 milk and meat outputs are kept constant, with a decreasing total land footprint of livestock production (Table 1).

Scenarios S3 and S5 represent high production of meat and milk, under both rainfed and irrigated agriculture, characterized by the use of high inputs and advanced management. Agricultural production is mechanized and improved high-yielding feed crop varieties are widely used. In scenario S3, the total land footprint of livestock production is kept constant, with increasing milk and meat outputs, while in scenario S5 milk and meat outputs remain constant, with decreasing total land footprint of livestock production.

\subsubsection{Eight factors determining production under the five scenarios}

The following eight factors determine the production potential for meat and milk in the five scenarios: 1) types of land used, 2) feed composition, 3) land productivity, 4) feed conversion efficiency, 5) livestock productivity, 6) ratios of the different livestock species, 7) livestock breeds, and 8) ratios of meat and milk produced. For meat production we analyse the role of all these factors for all four livestock species in each of the three production systems. We similarly evaluate the influence of these factors on milk production 
except for shoats and camels in the humid production system where they are not typically reared for milk production.

Table 1 Summary of factors determining production intensification under the five scenarios. For details and references on each factor refer to the text.

\begin{tabular}{|c|c|c|c|c|c|}
\hline \multicolumn{2}{|c|}{ Scenario constraints } & \multicolumn{2}{|c|}{$\begin{array}{l}\text { Increase in production while } \\
\text { keeping land footprint of livestock } \\
\text { production constant in all } \\
\text { production systems }\end{array}$} & \multicolumn{2}{|c|}{$\begin{array}{l}\text { Reduction in land footprint of } \\
\text { livestock production while keeping } \\
\text { meat and milk production } \\
\text { constant in all production systems }\end{array}$} \\
\hline $\begin{array}{l}\text { Factors of } \\
\text { production }\end{array}$ & $\begin{array}{l}\text { Scenario S1 } \\
\text { (reference) }\end{array}$ & $\begin{array}{l}\text { Scenario S2 } \\
\text { (Intermediate } \\
\text { intensification) }\end{array}$ & $\begin{array}{l}\text { Scenario S3 } \\
\text { (high } \\
\text { intensification) }\end{array}$ & $\begin{array}{l}\text { Scenario S4 } \\
\text { (Intermediate } \\
\text { intensification) }\end{array}$ & $\begin{array}{l}\text { Scenario S5 } \\
\text { (high } \\
\text { intensification) }\end{array}$ \\
\hline Land use & $\begin{array}{l}\text { Grazing land } \\
\text { and minimal } \\
\text { cropland use }\end{array}$ & $\begin{array}{l}\text { Grazing land } \\
\text { and conversion } \\
\text { of suitable } \\
\text { grazing land } \\
\text { into feed } \\
\text { cropland }\end{array}$ & $\begin{array}{l}\text { Grazing land } \\
\text { and conversion } \\
\text { of suitable } \\
\text { grazing land } \\
\text { into feed } \\
\text { cropland }\end{array}$ & $\begin{array}{l}\text { Grazing land } \\
\text { and conversion } \\
\text { of suitable } \\
\text { grazing land } \\
\text { into feed } \\
\text { cropland }\end{array}$ & $\begin{array}{l}\text { Grazing land } \\
\text { and conversion } \\
\text { of suitable } \\
\text { grazing land } \\
\text { into feed } \\
\text { cropland }\end{array}$ \\
\hline $\begin{array}{l}\text { Feed } \\
\text { composition }\end{array}$ & $\begin{array}{l}\text { Mainly pasture } \\
\text { with minimal } \\
\text { fodder and } \\
\text { compounded } \\
\text { feeds }\end{array}$ & $\begin{array}{l}\text { Mainly pasture } \\
\text { and higher } \\
\text { proportion of } \\
\text { crop based } \\
\text { feeds than in S1 }\end{array}$ & $\begin{array}{l}\text { Pasture and } \\
\text { higher } \\
\text { proportion of } \\
\text { crop based } \\
\text { feeds than in S2 }\end{array}$ & $\begin{array}{l}\text { Mainly pasture } \\
\text { and higher } \\
\text { proportion of } \\
\text { crop based } \\
\text { feeds than in S1 }\end{array}$ & $\begin{array}{l}\text { Pasture and } \\
\text { higher } \\
\text { proportion of } \\
\text { crop based } \\
\text { feeds than in S4 }\end{array}$ \\
\hline $\begin{array}{l}\text { Land } \\
\text { productivity }\end{array}$ & current & + & ++ & + & ++ \\
\hline $\begin{array}{l}\text { Feed } \\
\text { Conversion } \\
\text { Efficiency }(\mathrm{FC}\end{array}$ & current & + & ++ & + & ++ \\
\hline $\begin{array}{l}\text { Livestock } \\
\text { productivity }\end{array}$ & current & + & ++ & + & ++ \\
\hline
\end{tabular}

\subsection{Land use}

We classify agricultural land use into either grazing or cropland and make assumptions on their availability to livestock based on where they occur in each of the production systems. For the arid production system we assume that there is no cropland available for feed cultivation.

We assume that an increase in meat and milk production is associated with a higher fraction of compounded and supplemental feeds in the diet. This is consistent with the observed increase in the amount of feed crops in the diets of ruminants as the production output per animal increases from the arid to the humid production system. Thus, the three productivity scenarios represent distinct stages along a gradient of increasing intensification, dependent on expansion of feed crop cultivation onto 
grasslands suitable for crop production. The expansion of feed crops can be expected to directly compete with food production because both require arable land. Even so, we still chose to assign additional land to meet increased feed demand for ruminant production by converting arable grazing land feed crop cultivation (Figure 2).

The five production scenarios also differ with respect to restrictions placed on expansion of land cultivated for feed crops. Under scenario S1, feed cultivation is not allowed to expand and the entire livestock production enterprise only occurs on grazing land and minimal cropland. Feed cultivation can expand but only onto grazing land in scenarios S2 to S5. Recall that only grazing land of medium to high suitability for crop production can be converted to cropland in the semi-arid and humid production systems.

\subsection{Feed composition}

We assume that a higher output of meat and milk can be achieved by including crop residues and compounded and supplemental feeds in the livestock diet. Such an improved feed composition, blending grains, cereals and minerals rich in energy and low in fibre, makes it possible to meet production objectives centred on improved animal growth, weight gain, milk output, and general health.

For scenario S1, we assume the current diet composition, including minimal crop residue, compounded and supplemental feeds in the diets, i.e. the current application levels in the semi-arid and humid production systems (Bosire et al. 2015). For scenarios S2 and S4, we specify an improved diet containing higher proportions of fodder, crop residues and compounded and supplemental feeds. Scenarios S3 and S5 assume current diets containing the highest possible levels of compounded and supplemental feeds for meat and milk producing livestock in Kenya based on values reported by case study farms and by Bouwman et al. (2005).

\subsection{Breed of livestock and Feed conversion efficiency}

Both improved breeds and higher feed conversion efficiency (FCE) contribute to increasing productivity. Indigenous breeds, mixed breeds (Guernsey, Jersey, Ayrshire and Friesian dairy stock, crosses between these European breeds, and crosses between the European breeds and Zebu type cattle typically kept in the humid production system), pure or exotic breeds in the production systems are associated with low, intermediate and high meat and milk output, respectively. FCE is defined as feed use per unit of output 
produced by each species and in each of the three production systems. It is expressed in terms of dry weight of feed intake per fresh weight of meat or milk produced. Improved FCE is assumed to be the main driver for increasing the productivity of the four ruminant species. We base the FCE calculations on Bouwman et al. (2005), calibrated with values derived from field visits to case study farms representing different stages of intensification of meat and milk production in Kenya.

Scenario S1 represents mainly indigenous breeds in the arid and semi-arid systems and mixed breeds in the humid system characterised by comparatively low productivity per animal due to low FCE and poor diets. Although the indigenous breeds have certain qualities, such as drought and disease tolerance, that make them more suitable for production under the conditions assumed in scenario S1, we focus only on their inherent productivities. In scenarios S2 and S4, productivity improvement is achieved by crossbreeding the indigenous and exotic species, leading to breeds with improved FCE derived from the exotic breeds and disease and drought resistance traits inherited from the indigenous breeds. Livestock breeds in Scenarios S3 and S5 have the highest FCE, usually associated with the exotic or pure breeds, such as the Boran cattle.

\subsection{Livestock productivity}

Livestock productivity (meat and milk production per animal) is a function of the FCE, breed and the diet composition. We determine animal productivity in the five scenarios in Kenya based on values reported by case study farms and by Bouwman et al. (2005) for all scenarios except scenario S1 in which values are the same as those in Bosire et al. (2015).

\subsection{Land productivity}

Land productivity is a function of the amount of precipitation, soil type, crop and level of input. We consider the minimum, mean and maximum productivity of the grass, fodder crops, maize and wheat for grazing and croplands to represent the three scenarios (Ouda 2001, Mekonnen and Hoekstra 2011b). Maize and wheat are included in the analyses because they constitute a large proportion of the compounded and supplemental feeds in Kenya (ILRI 2010). Under scenarios S2 to S5, we consider the land productivities under the grazing land conversion option presented in section 2.2.3.1. 


\subsection{Ratios of ruminant species and ratio of meat to milk production}

For all scenarios, we assume that the production systems have settled at an equilibrium based on the prevailing climate, market systems and other factors determining production practices. Therefore, we keep the livestock number constant and maintain current proportions of meat and milk production distributed over the three species in the arid, semi-arid and humid production systems in Kenya. These factors are a proxy for economic drivers of livestock production and quantify the ratio of usage of products of animals of each species based on the prevailing market access infrastructure.

\subsubsection{Maximum production potential with current total land use}

Intensification can make it possible to increase production and meet rising demand for ASFs without increasing the amount of land used. To estimate the production increase with intensification, we maintain the total land used for milk and milk production as in scenario S1 and estimate the expected quantities of milk and meat produced with increased productivity for scenarios S2 and S3. The highest potential production of meat and milk by species $a$ in production systems $s$, considering improved land productivity in S2 and S3, $P P_{\text {meat\&milk }}[a, s]$ (tonne), is estimated as the total land used to produce meat

and milk, $L L U_{\text {meat } / \text { milk }}[a, s]$ (ha), by species $a$ in production systems $s$, divided by $L_{\text {livestock }}[a, s]$, the land footprint (ha/tonne) for species $a$ in production system $s$

$$
P P_{\text {meat } / \text { milk }}[a, s]=\frac{L L U_{\text {meat } / \text { milk }}[a, s]}{L_{\text {livestock }}[a, s]}
$$

\subsubsection{Estimating land use for livestock production}

To understand how the anticipated trajectory of intensification will affect demand for land we estimate land use under intensification as outlined in Figure 2. We keep the total land use for milk and meat production constant and equal to the estimates reported in Bosire et al. (2015) in scenarios S1, S2 and S3. Total land use for production under scenarios S4 and S5 is derived with equation 2, keeping the total meat and milk production constant.

Due to the difficulty of acquiring some of the relevant data for sheep, goats and camel production we make certain simplifying assumptions for each species across the five scenarios. For sheep and goats, only 
improvements in meat production are calculated, while milk productivity is assumed to be static. The productivity of both milk and meat by camels is also assumed to be static.

\subsubsection{General limitation of data and methods}

Estimating the total potential livestock production requires detailed information on all the ruminant and monogastric species in each production system. This was not always possible because reliable long-term information on several species such as chicken and pigs was not available. As we were unable to find evidence for improved productivity for camel using ground truthing in the case study farms, we assumed no intensification of camel production under the three scenarios of improved management. Therefore, in estimating the total potential output of ruminants in Kenya, we assume that the camel output is maintained at the current levels of management to circumvent this limitation. However, camel production is quite small relative to cattle and shoats, about $9 \%$, and so the overall results should be largely unaffected by this assumption and representative of the different scenarios.

Available data on livestock numbers for the three production systems selected for this study are also limited. We therefore used data from aerial surveys conducted by the Kenya Directorate of Resource Surveys and Remote Sensing (DRDRS) from 2000 to 2012 to estimate the numbers of livestock in each of the three production systems. Our values for milk and meat production for Kenya, especially for cattle, therefore differ from those used by the Food and Agriculture Organization (FAOSTAT) and Behnke and Muthami (2011), derived from the 2009 national census data. Inconsistencies in spatial layers used to infer land suitability, crop yields and land availability can potentially add a level of inaccuracy in estimates

of key parameters used in this study. Such a mismatch was, however, not encountered when down-scaling the global availability, suitability and crop yield estimates to the national production system level.

\subsection{Results}

We first present the results on land use and production potential. Tables 3-6 summarise the results on major land uses whereas Figures 3-5 depict the findings on the production parameters. 


\subsubsection{Total agricultural land and suitability for crop production}

Assessment of the total land available for agricultural production showed that 12,912,300 hectares (ha) (23\%) of Kenya's total land area is unavailable for livestock production (Figure 2 and Table 2). The remaining 43,679,900 ha (77\%) of Kenya's land area that qualifies as agricultural lands consists of grasslands (68\%) and croplands (9\%). The arid production system covers nearly 34,307,400 ha (79\%) of the national agricultural land, and consists mainly of vast grasslands. The semi-arid and humid systems cover $3,843,700$ ha $(8 \%)$ and $5,528,800$ ha (13\%) of the remaining total agricultural land, respectively.

The suitability analysis shows that $12 \%$ of the total agricultural land can be classified as land with medium to very high suitability for cropping (Table 1 ). However, the precise percentage coverage of this category varies widely across the different production systems, from $42 \%$ in the semi-arid system to $64 \%$ in the humid production system. No suitability estimates were made for the arid production system as crop cultivation is not currently practiced in this system. Land of low suitability for crop production is highest in the semi-arid production system, comprising $58 \%$ of the total agricultural land in this production system.

When considering only grasslands, the humid production system displays the highest share (69\%) of the land suitable for crop production. In contrast, about $34 \%$ of the grasslands in the semi-arid production system appear to be suitable. Strikingly, $36 \%$ of the cropland currently cultivated in all the three production systems in Kenya fall into the medium to very high suitability categories. For both the humid and the semi-arid systems the fraction of land that is suitable for crops and used for crop cultivation is about $60 \%$. 


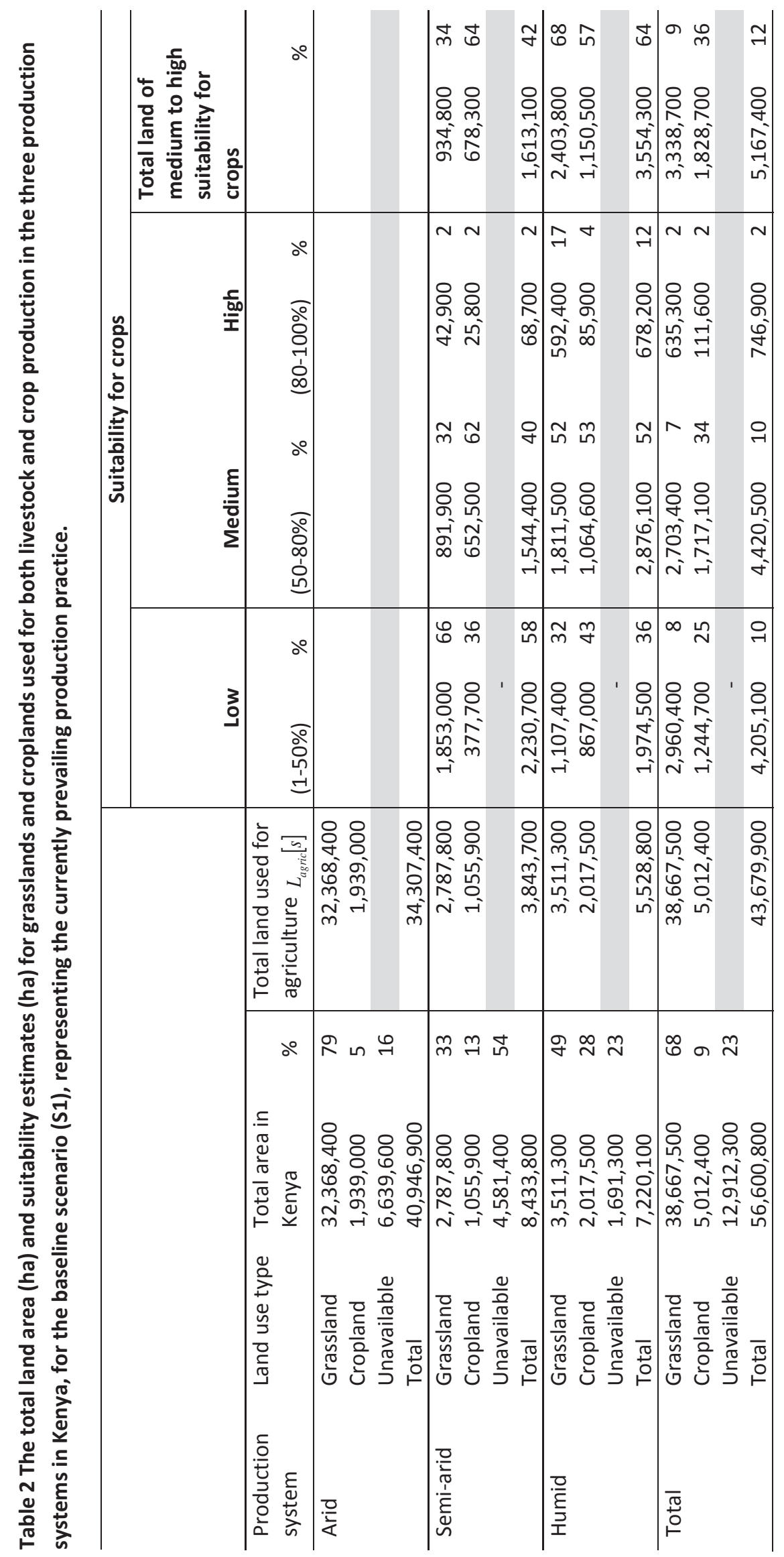




\subsubsection{Land available for agriculture in Kenya}

Table 3 shows the estimates of land used for both livestock and crop production and the land currently used for agriculture. As we consider only the land for agriculture, the estimate for the total land used for agriculture is lower than that potentially available for agricultural production by $3 \%$ due to the exclusion of cropland from the arid system. Grasslands in the arid system constitute most (88\%) of the land used for agriculture. The humid and semi-arid systems have the second largest (13\%) and smallest (9\%) fractions, respectively, of land that can be used for agricultural production. Overall, about $9 \%$ of grassland in Kenya is currently used for livestock production. The highest proportion of grassland currently used for livestock production (37\%) is in the semi-arid system. The humid system has $22 \%$ of the grassland currently used for livestock production while $6 \%$ of grassland is used in the arid system. The overall use of feed cropland is $5 \%$ of the total cropland for agriculture. Humid systems have the largest proportion (6\%) of agricultural cropland that is used for feed crop production.

Table 3 The total land area used for agriculture (ha), land currently used for agriculture (ha) in grasslands and croplands for both livestock and crop production and the current land footprint of livestock in three production systems in Kenya.

\begin{tabular}{|c|c|c|c|c|}
\hline $\begin{array}{l}\text { Production } \\
\text { system }\end{array}$ & Land use type & $\begin{array}{l}\text { Total land used } \\
\text { for agriculture } \\
\left(L_{\text {agric }}[S]\right)\end{array}$ & $\begin{array}{l}\text { Current land use for } \\
\text { agriculture } \\
L_{\text {grazing }}[S]_{+} L_{\text {crop }}[S]\end{array}$ & $\begin{array}{l}\text { Current land use for } \\
\text { livestock production } \\
\left(L_{\text {livestock }}[S]\right)\end{array}$ \\
\hline \multirow[t]{3}{*}{ Arid } & Grassland & $32,368,400$ & $1,915,650$ & $1,915,650$ \\
\hline & Cropland & - & - & - \\
\hline & Total & $32,368,400$ & $1,915,650$ & $1,915,650$ \\
\hline \multirow[t]{3}{*}{ Semi-arid } & Grassland & $2,787,800$ & $1,045,000$ & $1,045,000$ \\
\hline & Cropland & $1,055,900$ & $1,055,900$ & 4,850 \\
\hline & Total & $3,843,700$ & $2,100,900$ & $1,049,850$ \\
\hline \multirow[t]{3}{*}{ Humid } & Grassland & $3,511,300$ & 752,100 & 752,100 \\
\hline & Cropland & $2,017,500$ & $2,017,500$ & 132,400 \\
\hline & Total & $5,528,800$ & $2,769,600$ & 884,500 \\
\hline \multirow[t]{3}{*}{ Total } & Grassland & $38,667,500$ & $3,712,750$ & $3,712,750$ \\
\hline & Cropland & $3,073,400$ & $3,073,400$ & 108,200 \\
\hline & Total & $41,740,900$ & $6,786,150$ & $3,850,000$ \\
\hline
\end{tabular}




\subsubsection{Production potential of meat and milk under increasing intensification under current land use}

Scenario S3 represents the configuration of factors that ensures the highest output of milk and meat (Figure 3a). Milk production increases with improved intensification from scenarios S1 to S3 by between $51 \%$ and $80 \%$. The total milk production is consistently higher in the humid production system in all scenarios. The semi-arid system shows the largest increase (99\%) in milk production across all the systems as productivity increases from S1 to S3, mainly associated with improved milk yields by cattle. The humid system has consistently high increase in production as intensification increases from scenario S1 to S3, while the arid system has the lowest increase in production (24\%) with increasing intensification from scenario S1 to S2.

Meat production increases in the arid (99\%) and the semi-arid (290\%) systems as intensification increases from scenario S1 to S3 (Figure 3b). The potential for improving livestock productivity is much larger for cattle in these systems than in the humid system where there is a decline in meat production (14\%) with increasing intensification from scenario S2 to S3. This points to greater constraints to improving cattle yields in the humid system than in the arid and semi-arid systems, leading to smaller productivity increases in the humid system. A better FCE for this scenario would lead to higher meat production in the humid system. Similarly for shoats, the carcass yield increases by $33 \%$ and $50 \%$ in all the production systems as intensification progresses from scenario S1 to S2 and S1 to S3, respectively. This leads to elevated meat production with advancing intensification from scenario S1 to S2 of $31 \%$ and S1 to S3 of $61 \%$. 
". Production ('000 tonne)

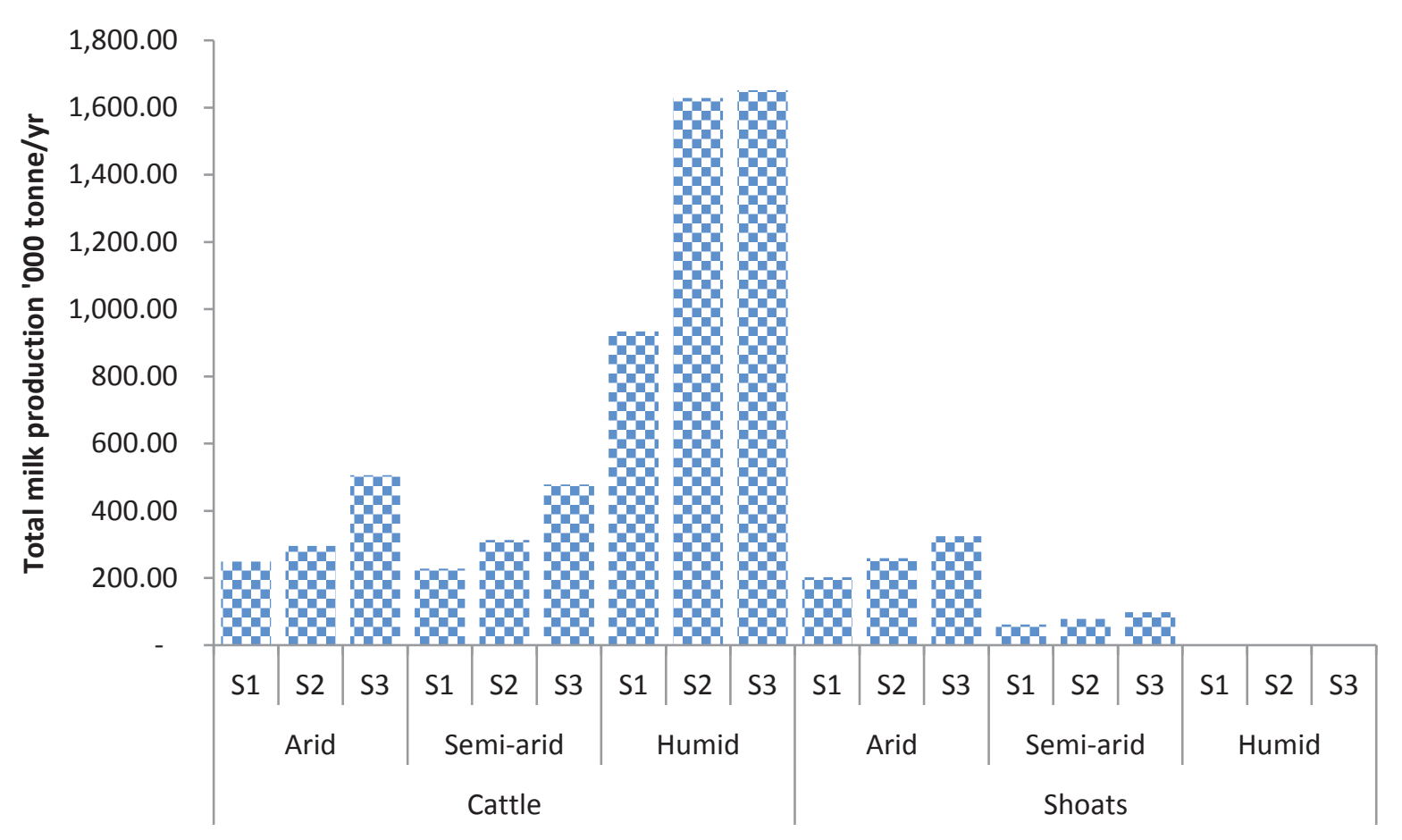

Figure 3a: Milk production potential of three livestock species estimated for each of the three production systems (arid, semi-arid and humid) under scenarios S1 to S3. 
\% Production ('000 tonne)

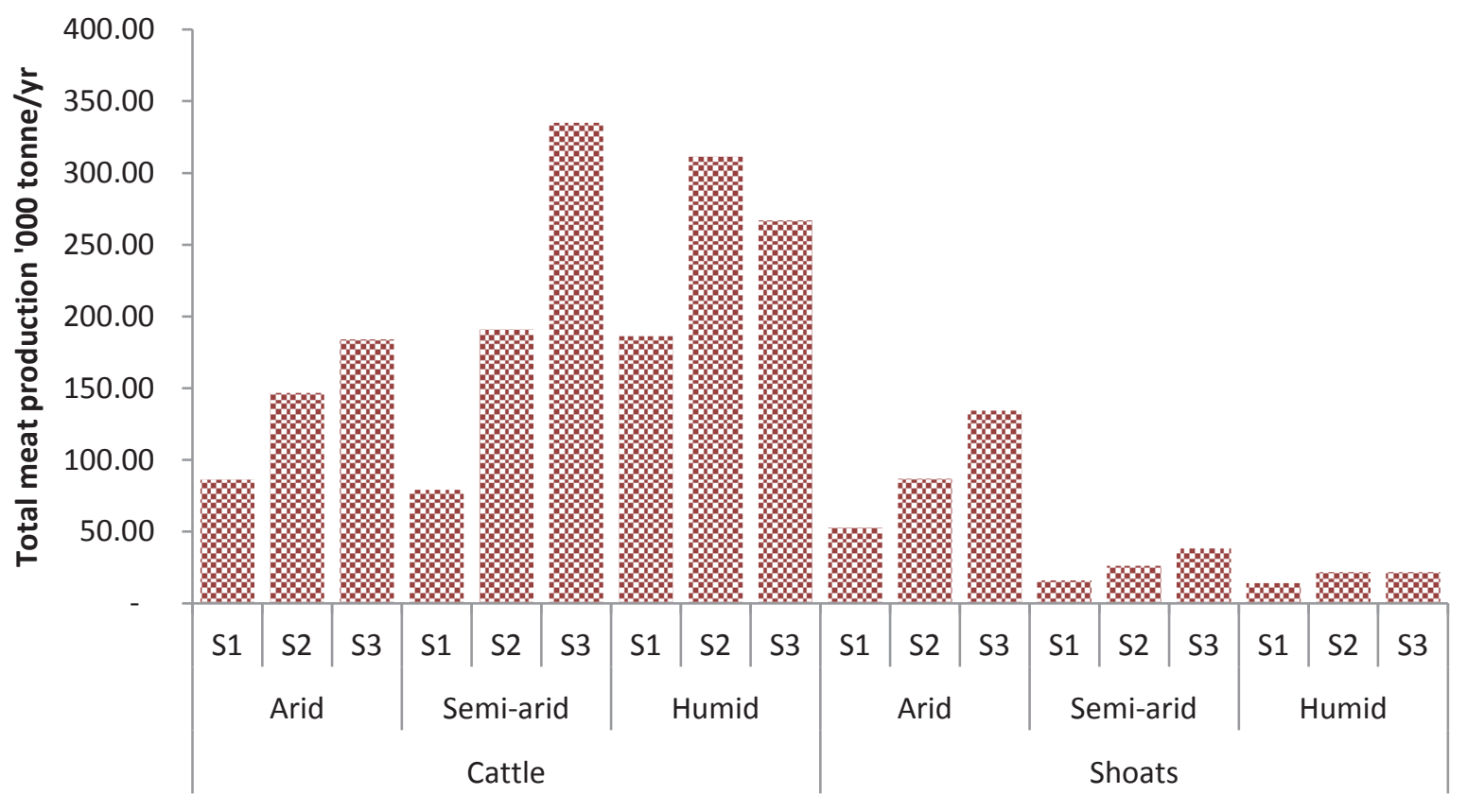

Figure 3b: Meat production potential of three livestock species estimated for each of the three production systems (arid, semi-arid and humid) under scenarios S1 to S3.

\subsubsection{Increase in production potential and growth in per capita supply of milk and meat.}

Milk and meat represent a large proportion of the expenditure of many households (Bett et al. 2012). Here, we only consider milk and meat production per capita after intensification in all the production systems throughout Kenya. The increase in per capita supply of meat and milk from cattle is the highest and ranges between $77 \%$ and $88 \%$ across all the three scenarios. The percentage increase in the per capita supply of beef with advancing intensification from scenario S1 to S3 of 67-72\%, representing 9 to $14 \mathrm{~kg}$ per year, is the largest recorded. Even though the current supply rate is lower than the FAO food balance of national production estimate of $11.3 \mathrm{~kg}$ per capita of beef supply per year for Kenya, our estimated range of increased supply does not deviate much from this estimate.

\subsubsection{Potential for resource savings under increasing intensification}

Table 4 shows that in all systems, there is a general decline in the total land used for livestock production with improved productivity from scenarios S1 to S5. The semi-arid system has the highest overall use of 
available agricultural land for livestock production. However, for the humid system, the total cropland used for livestock production increases from scenario S2 to S3 as the assumed productivity increase requires improving diets with supplemental and compounded feeds, the production of which would require converting about 600,000 ha of land that is currently not used for feed cultivation into croplands. The smallest area of grassland used for ruminant production is in the arid system in scenario S5. By contrast, the largest area of cropland used for livestock production is in scenario S3 in the humid production system. In order to have a comprehensive indication of land potentially available for expansion of feed crop production, we focus on the land currently classified as grasslands and suitable for crop production in section 3.1. In all the scenarios, the demand for cropland to produce feed does not exceed the proportion of grassland that is considered to be of medium to high suitability for crop production. This indicates that improving productivity as proposed in this analysis is unlikely to lead to increased competition between feed and food production on the current cropland.

Table 4 The total land use (ha) for meat and milk production in each production system under the five scenarios, with the total output kept at the baseline production levels (scenario S1).

\begin{tabular}{|c|c|c|c|c|c|c|}
\hline \multirow{3}{*}{$\begin{array}{l}\text { Production } \\
\text { system }\end{array}$} & \multirow{3}{*}{ Land use type } & \multicolumn{5}{|c|}{ Land footprint of livestock production of meat and milk } \\
\hline & & \multicolumn{5}{|c|}{ Scenarios } \\
\hline & & S1 & S2 & S3 & S4 & S5 \\
\hline \multirow[t]{3}{*}{ Arid } & Grassland & $1,915,650$ & $1,915,650$ & $1,915,650$ & $1,122,750$ & 780,500 \\
\hline & Feed Cropland & - & - & - & - & - \\
\hline & Total & $1,915,650$ & $1,915,650$ & $1,915,650$ & $1,122,750$ & 780,500 \\
\hline \multirow[t]{3}{*}{ Semi-arid } & Grassland & $1,045,000$ & 742,500 & 570,600 & 454,750 & 269,300 \\
\hline & Feed Cropland & 4,850 & 307,350 & 479,250 & 11,900 & 5,000 \\
\hline & Total & $1,049,850$ & $1,049,850$ & $1,049,850$ & 466,650 & 274,300 \\
\hline \multirow[t]{3}{*}{ Humid } & Grassland & 752,100 & 422,200 & 209,650 & 387,250 & 167,500 \\
\hline & Feed Cropland & 132,400 & 462,300 & 674,850 & 135,750 & 418,300 \\
\hline & Total & 884,500 & 884,500 & 884,500 & 523,000 & 585,800 \\
\hline \multirow[t]{3}{*}{ Total } & Grassland & $3,712,750$ & $2,783,300$ & $2,197,600$ & $1,964,750$ & $1,217,300$ \\
\hline & Feed Cropland & 137,200 & 765,900 & $1,146,250$ & 147,600 & 423,300 \\
\hline & Total & $3,850,000$ & $3,850,000$ & $3,850,000$ & $2,112,400$ & $1,640,600$ \\
\hline
\end{tabular}

Land use per tonne of product in scenario S3 is the lowest across all the production systems (Figures 4ab) mainly due to the improvement in ruminant productivity of meat and milk and drop in the use of 
grasslands. The converse is the case for the use of cropland, which increases from $0.27 \mathrm{ha} /$ tonne to 0.33 ha/tonne for meat production as the level of intensification advances from scenario S4 to S5 in the humid system. This is despite the increased FCE and carcass yield in S5. The highest rate of land use, $0.3 \mathrm{ha} /$ tonne and $11.9 \mathrm{ha}$ /tonne for milk and meat production, respectively, were recorded for scenario S1 in the arid system. Scenario S5 in the humid production system exhibits the lowest level of land use per tonne, 0.11 ha/tonne for cattle milk and $0.72 \mathrm{ha} /$ tonne for sheep and goat meat, even after allowing for cropland use. Scenario S5 exhibits the largest cropland footprint for both milk and meat, 0.09 ha/tonne and 1.79 ha/tonne, respectively. Overall, land use per tonne of product is highest for cattle due to their poorer feed conversion efficiency relative to that for shoats. We omit the results for camel as we did not analyse the effect of the changes in productivity on camel milk and meat production under the five scenarios.

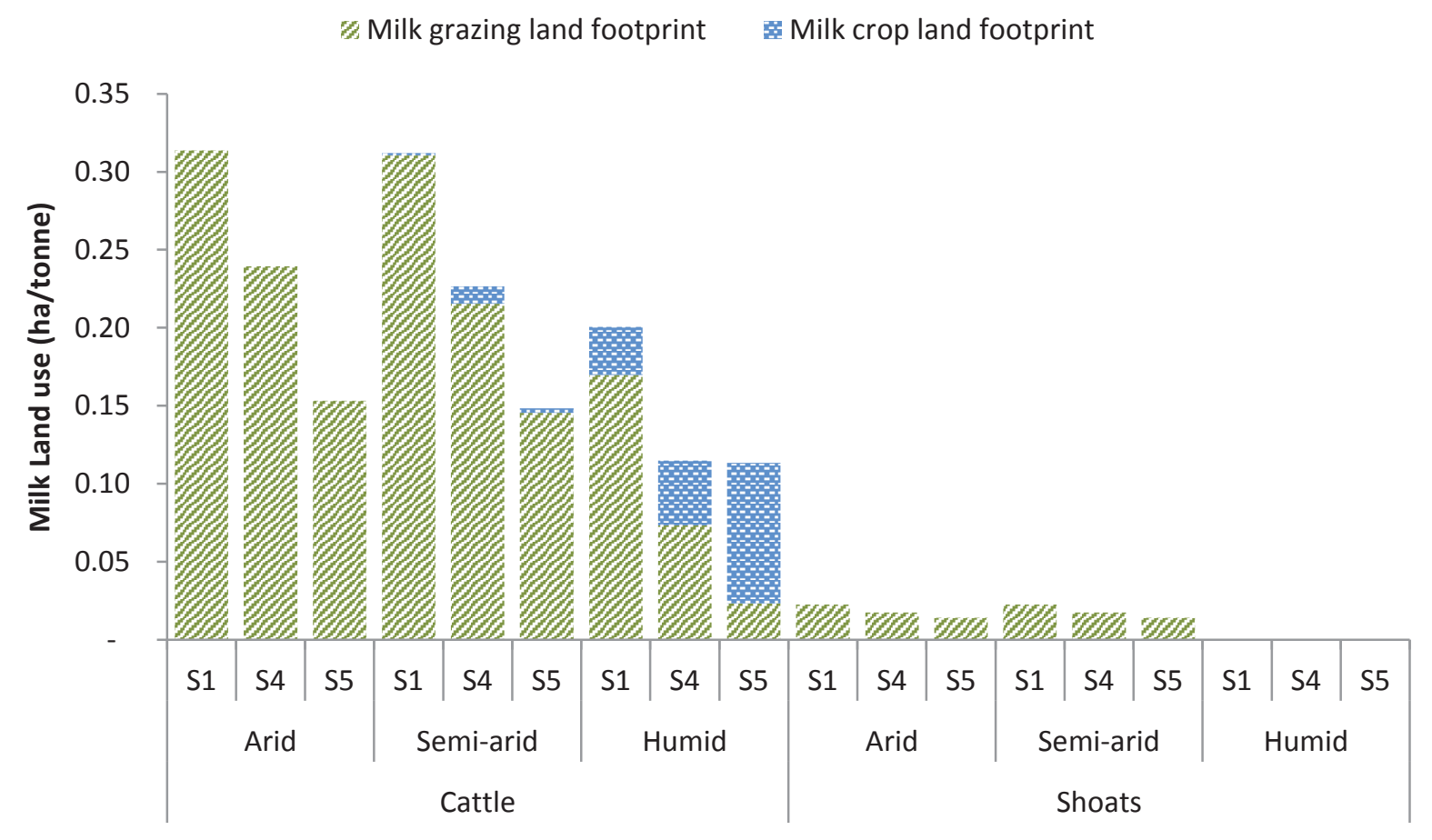

Figure 4a: Land productivity for milk under each of the three production systems (arid, semi-arid and humid) for scenarios S1-S5. 


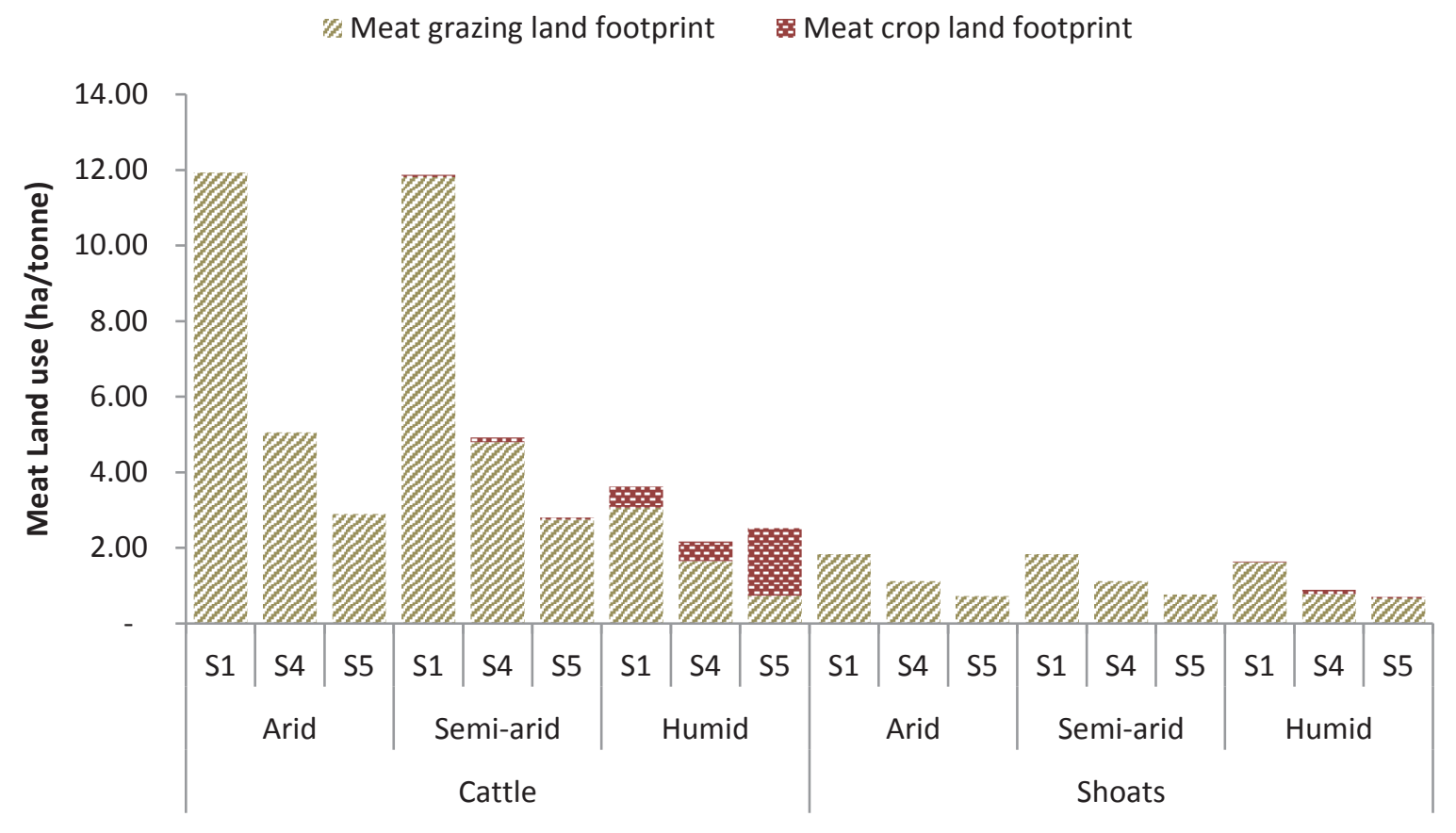

Figure 4b: Land productivity for meat in each of the three production systems (arid, semi-arid, humid) for scenarios S1-S5.

\subsection{Discussion}

In this section we discuss the implications of increased livestock production with intensification on food security in Kenya in sections 4.1 through to 4.2. We then discuss levels of intensification under the five scenarios and how they affect production potential in sections 4.3 through to 4.5 .

\subsubsection{Increased livestock production potential or output}

Recognition of the challenges likely to be posed by the projected growth in demand for livestock products to natural resources has prompted diverse stakeholders to form alliances, such as the multi-stakeholder forum under the Global Agenda of Action, to consider how best to bridge the efficiency gap and improve other aspects of livestock production (FAO 2013). The production scenarios we consider represent possible paths to increasing production within the prevailing land constraints. The increased production under scenarios S2 and S3 is rather large and may seem hard to attain in practice. The absolute improvements in meat and milk production per animal are, from very low levels, about $5 \mathrm{~kg} / \mathrm{cow} /$ day to $20 \mathrm{~kg} / \mathrm{cow} /$ day for milk and about $76 \mathrm{~kg} /$ animal to $216 \mathrm{~kg} /$ animal for carcass yield. In the humid mixed 
crop-livestock systems, there are far more opportunities to improve milk production than in the drier semi-arid and arid systems. Furthermore, dairy production is currently the most economically important livestock production activity in Kenya (Behnke and Muthami 2011). It would therefore be worthwhile exploring how to further improve productivity in this sector within the humid production system, including the development of synergies between crop and livestock production (Tarawali et al. 2011). When considered alongside the exceptional returns on investment realised in the humid system (Nicholson et al. 2004), dairy production in this system shows the greatest promise to improve livestock productivity in Kenya. However, there is increasing realisation that future production improvements will need to be more targeted at the small rural farmer communities, increased efficiency of production and developing more market-oriented systems of both production and supply chains (Headey and Jayne 2014). The current rapid urbanisation in Kenya, with a doubling in urban population size expected by 2050 (UN 2014), will almost certainly accelerate the development of urban markets, and hence increase the flow of products from the farm gate to the urban consumers, and hopefully raise the income of livestock farmers.

In order to make more land available for feed crops, it will be important to sensitize the farmers on the opportunities to meet both food and feed production and benefit from dairy and meat production. This would be achievable if the key elements of intensification embodied in scenarios S2 and S3 are adopted and practiced by farmers. Nevertheless, most farmers will likely not have sufficient resources and technical know-how to make the changes necessary to benefit from the anticipated increase in output from improved management practices and the associated enhanced productivity (Upton 2004). This calls for investment by governments and other development actors to enable farmers acquire the resources and skills needed to improve productivity of the indigenous breeds of cattle and small ruminants in the low-input systems (Klapwijk et al. 2014).

Our results show that opportunities for meat productivity improvements are much larger in the arid and semi-arid systems than in the humid systems. We also show that the increase in production of meat from scenario S2 to S3 expected for cattle in the humid systems is not likely to be realised due to the suboptimal FCE relative to the current high cropland use in scenario S3. In the drier areas, where the common livestock breeds thrive on a diet composed mainly of natural grasses and produce below their potential, there are more opportunities to improve meat production. Hence, we expect large changes in production in these systems as productivity increases from the baseline scenario S1 to scenarios S2 and S3. These 
potential productivity improvements are already being realized in private ranches in these systems. Here, pure breeds, like the Boran, and their crosses with exotic breeds, e.g. Simmental, are reared under exclusive grazing and feed supplementation, making it possible for farmers to obtain relatively high carcass yields (Kahi et al. 2006). In the humid system, there are more constraints on land for livestock production and stronger influences of other factors. For example, better access to markets for the increased output, especially for milk, have led to the adoption of various production intensification strategies (Udo et al. 2011).

\subsubsection{Implications for food security}

Poverty and the associated high levels of malnutrition are a major and persistent challenge for many African countries (FAO et al. 2014). Sustainable intensification of production thus presents a viable pathway to effectively confronting both challenges in a world with finite land resources and a rapidly expanding human population. Although staple crops dominate the diets in many African countries, the domestically generated supply of these cereals is often below per capita requirements. In Kenya, this is linked to continued reliance on relief food in several arid and semi-arid areas. Though this is not always as much a problem of production as it is of food distribution, there is no gainsaying that large parts of Kenya, especially the arid and semi-arid areas that produce most of the meat consumed in Kenya, are currently extremely food insecure. That $40 \%$ of land considered unsuitable for cultivation is currently under cultivation in the semi-arid system is a strong indication of a growing need to contain rising levels of food insecurity and the need to enhance productivity by promoting and encouraging (e.g., through providing incentives) land uses optimal or appropriate for particular production systems or agro-climatic zones.

Increasing the production of milk and meat through intensification would raise the level of food security and enable farmers to increase their incomes from livestock and enhance their ability to purchase food and meet other family needs, like better health care and education. However, allowance needs to be made for the fact that any benefits from intensification of production would need to be adjusted for the various trade-offs of implementing the associated innovations. Accordingly, an analysis that evaluates all the costs and risks associated with intensification for individual farmers would help further clarify and strengthen the argument for increased income to farmers due to intensifying their livestock production enterprises. 
Another pertinent issue to consider is the rate of Kenyan population growth. Although the actual growth rate has slowed down in recent years, projections point to about a $60 \%$ increase in the coming 20 years (UN 2013b). This underscores the extreme importance and urgency of investing in increasing agricultural productivity to meet the projected upsurge in demand. Finally, because it can simultaneously increase production, income and nutritional security of small-scale farming families, and save land for other uses such as conservation, intensification holds the greatest promise to successfully improving livestock production in Kenya.

\subsubsection{Decline in quantity of land used through intensification of production}

Land scarcity is a major constraint to livestock production in the semi-arid and humid production systems. Almost $40 \%$ of the area already cultivated in the semi-arid and humid production systems occupies land not considered as highly suitable for crop production. This indicates a greater demand for cropland than what is currently available. However, both the semi-arid and humid systems have land under pasture, which is classified as highly suitable for crop production, and so could be converted to produce both food and feed. In addition, if the level of intensification were advanced from the current level, S1, to productivity scenarios S4 and S5, more land under pasture could also become available for crop production.

Conversion of suitable grassland to crop production provides the opportunity to meet the twin objectives of increasing both ruminant livestock output and relieving the constraint of unavailability of land for livestock production. This can be accomplished through the cultivation of dual purpose high-yielding crops for both food and feed, such as sweet potatoes (Ipomoea batatas), maize (Zea mays), cowpeas (Vigna unguiculata) and groundnuts (Arachis hypogaea). Such crops are being developed to aid the adoption of improved technologies such as exotic livestock breeds that require more fodder and concentrates to ensure optimal production (Blümmel et al. 2003, Claessens et al. 2008). Conflicts between the production of food and feed crops will remain though. Currently, $36 \%$ of the calories produced by the world's crops are being used for animal feed, but due to conversion losses only $12 \%$ of those feed calories ultimately contribute to the human diet, as meat and other animal products (Cassidy et al. 2013).

The pressure on land for livestock production is highest in the semi-arid system, where land availability for agriculture is lowest. This finding adds a quantitative dimension to and reaffirms similar conclusions 
derived from qualitative analysis carried out by Shiferaw (2002). It is mainly the relatively higher rainfall levels in the semi-arid areas than in the arid system that facilitates crop-livestock interactions and increases land demand in these zones. Land scarcity in this system can be alleviated by adopting production of drought-resistant and yield-improved dual-purpose crops such as sorghum (Sorghum bicolor), thereby improving both farmer nutrition and livestock feed supply (Sutherland et al. 1999, Olembo et al. 2010). Additionally, through the intensification process embodied in scenarios S4 and S5, the consequent land sparing effect would avail more land for maintaining wildlife and other ecosystem goods and services that promote ecosystem health and the resilience of socio-ecological systems (Foley et al. 2005).

For the arid system, there are seemingly vast grasslands for livestock production. Production in this system relies on seasonal access to the grasslands due to large seasonal variability in pasture availability. However, the operation of many biophysical and non-biophysical processes, such as land fragmentation through fencing (Ogutu et al. 2013, Ogutu et al. 2014), and rising conflicts over access rights to water and pasture, hinder production in these systems by putting additional constraints on the availability and use of these vast grasslands for livestock production. Such constraints are hard to capture by the methods we used to assess resource use on these grasslands, so our estimates of the availability of these grasslands for livestock production are probably overestimates. Additionally, the availability of grazing land in this system is likely to be further reduced by the increasing frequency and severity of droughts (Williams et al. 2012), natural resource conflicts (Menkhaus 2015) land degradation (Mundia and Aniya 2006), large scale mining and infrastructure development. Due to these and other constraining factors, the opportunities and prospects for improving production at the crop-livestock interface in these dryland systems are currently very limited (Robinson et al. 2015). Most gains in the livestock sector in this system will thus likely be realized by enhancing production efficiency, increasing resilience to diseases and droughts as envisioned under scenarios S4 and S5. Additionally, due to the high availability of grazing land at the current numbers of livestock, there exists a high potential to increase herd size and total output from cattle, sheep and goats.

A valuable extension of the assessment of land availability for livestock production should entail estimation of the total biomass available for grazing and browsing in each of the production systems. Such biomass estimates corrected for proper use factors and harvestable biomass fraction before 
multiplication with the available land area (De Leeuw and Wilson 1987, De Leeuw and Tothill 1990, FAO 2010), could deliver improved and more accurate estimates of the attainable livestock production increase under different scenarios.

As livestock production practices become more intensified in Kenya, we expect a reduction in the average herd sizes used for production. Currently, herders keep huge herds for a variety of reasons, including coping with risks and cultural reasons, such as prestige, and not necessarily due to economic considerations per se. Consequently, the expectation of a reduction in the average herd size with advancing intensification implicitly assumes huge changes in the behaviour of hundreds of thousands of farmers and herders and that the relevant and enabling policies, institutional arrangements, markets, supporting information, services, inputs, and other essential requirements will be made available, accessible and affordable in order to realize the potential of the contemplated intensification (Biggs 2007). The reduction in herd sizes with increasing intensification would be expected to be more pronounced in the arid and semi-arid areas than in the humid areas where herd sizes are already small. Furthermore, even though the reduction in herd sizes following intensification would mirror that associated with the change from pastoralism to settled agro-pastoralism, the farmers would likely derive greater benefits from the few herds than do agro-pastoralists, if intensification would increase livestock productivity beyond the levels achievable under agro-pastoralism. Although the anticipated meat and milk yields under the most productive scenario, S3, are quite modest relative to the yields realized under similar climatic conditions, for example in Australia, the decline in land use due to intensification from scenario S1 to S5 is quite high, approximately $100 \%$ overall. Decreased demand on land associated with advanced intensification would reduce the pressure on land, allowing rotational grazing and fallow periods. Reduced pressure on land would also free up land for the preservation and conservation of biodiversity and ecosystem services, reduce habitat degradation, which is currently widespread in Kenya (Bai and Dent 2006), and allow for recovery of the already degraded habitats (Georgiadis et al. 2007, Navarro and Pereira 2012).

\subsection{Conclusion}

Our findings highlight the potential for intensifying livestock production in Kenya and the associated tradeoffs, which can be summarized as follows. 
1. It is potentially possible to expand the production of meat by $71 \%$ and of milk by $51 \%$ in Kenya using the currently available cropland. Meat production could even be increased by as much as $113 \%$ and milk production by up to $80 \%$ by increasing ruminant productivity and availing additional cropland for livestock production. However, both scenarios have costs and risks associated with intensification of production on the available cropland which would need to be taken into account.

2. The competition between the production of feed crops required to support production under the anticipated intensification, and production of food crops, biofuels as well as space for the rapidly expanding human settlements, is likely to be intense because the land area currently under feed crops would need to be expanded by 50-300\%, at the expense of the other competing land uses. Increasing the role of crop residues and other food by-products in livestock diets would help ease the pressure to expand croplands for exclusively producing livestock feeds.

3. The arid systems have the greatest potential to increase overall meat production under improved management practices in Kenya. But milk production by cattle in the humid system possesses the highest potential for increasing production to meet the projected increase in demand and ensure self-sufficiency in milk supply in Kenya. It is noteworthy, however, that challenges presented by diseases and pests along with other social and cultural constraints (e.g. free-ranging goats limiting intensification efforts; the women who are responsible for many livestock activities having limited decision-making power and accessibility to the income earned) in the lowland humid areas are huge, and have severely slowed the adoption and development of profitable dairy enterprises unless promoted by big external donor funded projects.

4. Increasing productivity of livestock, food and feed crops would reduce the demand for even more land for production and hence avail more land for environmental conservation, settlements, infrastructure development and other uses. Environmental conservation can be enhanced by confining livestock to less land using, for example, zero-grazing as is currently practiced in the humid system. As the zero-grazed animals are stall fed, cultivation of feed can be carried out in a manner that ensures little degradation of landscapes and that degraded landscapes are restored through appropriate cultivation practices. 


\section{Urban consumption of meat and milk and its green and blue water footprints - patterns in the 1980s and 2000s for Nairobi, Kenya ${ }^{3}$.}

Abstract

The problem. Various studies show that the developing world experiences and will continue to experience a rise in consumption of animal proteins, particularly in cities, as a result of continued urbanization and income growth. Given the relatively large water footprint (WF) of animal products, this trend is likely to increase the pressure on already scarce water resources. Aim. We estimate, analyse and interpret the changes in consumption of meat and milk between the 1980s and 2000s for three income classes in Nairobi, the ratio of domestic production to imports, and the WF (the volume of freshwater consumed) to produce these commodities in Kenya and abroad. Results. Nairobi's middle-income class grew much faster than the overall population. In addition, milk consumption per capita by the middle-income group grew faster than for the city's population as a whole. Contrary to expectation, average meat consumption per capita across all income groups in Nairobi declined by $11 \%$. Nevertheless, total meat consumption increased by a factor 2.2 as a result of population growth, whilst total milk consumption grew by a factor 5. As a result, the total WF of meat consumption increased by a factor 2.3 and the total WF of milk consumption by a factor 4.2. The increase in milk consumption was met by increased domestic production, whereas the growth in meat consumption was partly met through imports and an enlargement of the footprint in the countries neighbouring Kenya. Discussion and conclusion. A likely future rise in the consumption of meat and milk in Nairobi will further enlarge the city's WF. Given Kenya's looming blue water scarcity, it is anticipated that this WF will increasingly spill over the borders of the country. Accordingly, policies aimed at meeting the rise in demand for meat and milk should consider the associated environmental constraints and the economic implications both nationally and internationally.

\footnotetext{
${ }^{3}$ Published as Bosire et al. (2016a).
} 


\subsection{Introduction}

Urbanization is one of the three major processes driving the "livestock revolution" currently underway in many developing countries (Delgado et al. 1999). Advancing urbanization together with growing human populations and continued economic growth, engender rising food requirements and a change in dietary preferences towards more livestock intensive diets, consisting of more meat, milk and eggs (Crosson and Anderson 1994, van der Zijpp 1999, Ndambi et al. 2007). Not surprisingly, both the production and consumption of animal source foods (ASFs) in developing countries are projected to increase (FAO 2016). The anticipated increase in ASF consumption will likely lower the prevailing high levels of undernutrition (FAO et al. 2015), which have been associated with inadequate consumption of protein (Ayele and Peacock 2003, Narrod et al. 2011). Yet, despite the rising consumption of ASFs, there are major differences in consumption patterns among different income classes, with the middle and upper income classes consuming predominantly more ASFs, particularly from supermarkets (Thornton et al. 2007).

By 2014 about $54 \%$ of the global population was estimated to live in urban areas, compared to $30 \%$ in 1950. There is a huge difference in the level of urbanization between industrialized and developing countries, with around 75\% living in urban areas in North America, Latin America and Europe, 48\% in Asia and $40 \%$ in Africa. Up till 2050, the number of global urban dwellers is projected to increase by 2.5 billion and reach a total of 6.3 billion; $90 \%$ of this increase is projected to take place in Asia and Africa. When only the urban population in sub-Saharan Africa for the period 2015-2030 is considered, future prognoses indicate that the number of people transitioning from rural to urban life is estimated to increase by $115 \%$ in 15 years, from 170 to 360 million (UN 2015).

Feeding urban populations requires large quantities of food to be transported into cities from surrounding areas (Liu et al. 2013). With progressing urbanization, urban centres develop tele-connectivity and a lengthening of food supply chains. Initially, agricultural products are supplied from only a few kilometres away. As urbanization continues, distances become larger, extending from local to national, to regional and finally to food imports from the global market. The highest degree of globalization is found in the most advanced countries, where urban areas are based on service and industrial sectors, which provide enough revenues to sustain long supply chains. In contrast, rural areas typically have lower population density and enough land per capita to produce food for both the rural inhabitants and adjacent and remote urban populations (Seto et al. 2012). 
The environmental impacts of livestock production represent a major challenge and source of concern (Steinfeld et al. 2006a, de Vries and de Boer 2010, Gerber et al. 2013), and are expected to rise given the projected expansion of the livestock sector in developing countries in the coming decades (Alexandratos and Bruinsma 2012b). There is thus a pressing need to safeguard ecosystems and natural resources in these countries, most of which are already experiencing considerable and varied pressures (Herrero et al. 2010a, Herrero and Thornton 2013). Following the fact that the majority of future consumers of livestock products will be urban dwellers, a deeper understanding of the link between urbanisation and consumption of livestock products, on the one hand, and natural resource use and its environmental impacts, on the other, become increasingly important.

Consumption patterns and their associated socio-economic correlates have been widely studied and form the basis for projections of future demand for food (Delgado 2003, Narrod et al. 2011, Msangi and Rosegrant 2012). However, the relationships of these patterns to resource use, though highly intertwined, have only recently began to be intensively analysed (Gerbens-Leenes and Nonhebel 2002, Rockström et al. 2007, De Fraiture et al. 2010, Falkenmark and Lannerstad 2010, Molden et al. 2010, Fischer et al. 2011, Gerten et al. 2011, Mekonnen and Hoekstra 2012), largely due to an increasing recognition of the growing scarcity of water and land, which severely constrains agricultural production (Costa 2007, Molden 2007, Hoekstra and Wiedmann 2014). Most of these studies have mainly focused on understanding the environmental implications of food consumption in developed countries and their findings form the basis for recommendations to reduce environmental footprints. However, the results from these studies are seldom fully representative for developing countries. In Africa, studies of the relationship between resource use and consumption patterns have focused almost exclusively on crops (Chouchane et al. 2015, Pahlow et al. 2015). Consequently, there is an enhanced understanding of improved agricultural productivity of crops (Conceição et al. 2016) and its implications for natural resource demand.

An important aspect of the environmental implication of consumption that has attracted relatively little attention thus far is how urban growth and the associated increase in consumption of animal source foods (ASFs) affects natural resource appropriation in Africa. As a result, more focused studies into the relationship between resource use and consumption patterns in Africa are needed as a basis for developing sound strategies for limiting adverse environmental impacts of the rapidly expanding and changing consumption patterns. 
This paper aims to contribute to advancing our understanding of consumptive water use linked to the consumption of animal sourced foods and its environmental consequences in an example developing country. More precisely, it focuses on Kenya and the linkages between the premier urban area in Kenya, Nairobi, and the use of water resources to produce the meat and milk consumed by its population. The metropolis of Nairobi functions as a financial, political and infrastructural hub for the East African region (Kearney 2012). Its population increased from about 140,000 in 1950 to 3.9 million in 2015, raising the percentage of the total Kenyan population living in the capital city from $2.3 \%$ to $8.4 \%$ (UN 2015). The fraction of Kenya's population living in the four largest urban areas during the same period increased from $4.3 \%$ to $12.2 \%$ (CBS 2010), underscoring the rising importance of urban areas in Kenya (Obudho 1997).

Nairobi City is highly segmented, with pockets of affluent neighbourhoods, with people spending at least 50 US dollars a day, surrounded by informal settlements dominated by urbanites living at, or below, the poverty line and spending about two dollars a day (Syagga et al. 2001, K'Akumu and Olima 2007). This wealth inequality is reflected in the consumption of livestock products, with the poor households consuming far lower levels than their affluent counterparts (Gamba 2005). Overall, about a quarter of the meat supply in Kenya is imported, with livestock from the neighbouring countries of Tanzania, Uganda, Somalia and Ethiopia constituting 22\% of the total consumption (Muthee 2006, Tempia et al. 2010). The rapid urban population growth in Nairobi and the associated changes in consumption levels of meat and milk make this city a good case for analysing temporal trends and spatial differentiation in consumption of animal source foods, and its associated water resource use.

The objective of this paper is to determine the sphere of influence exerted by the consumption of animal products in Nairobi City, by quantifying the per capita and total amount of meat and milk consumed by its residents (Section 2.2), assessing the fractions of these livestock products with domestic and foreign origins (Section 2.2), and comparing the patterns for the 1980s and 2000s to show temporal change (Section 3). The green and blue water footprints associated with meat and milk consumption are estimated (Section 2.3), contextualized in terms of their domestic and imported components, and viewed in relation to blue water scarcity in Kenya (Section 4). Thus, the study evaluates the geographic reach of Nairobi's externalized footprint.

\subsection{Method}


Figure 1 shows the analytical steps followed in this study. We consider the change in urban population in Nairobi between the 1980s (1980-1989) and 2000s (2000-2009). The city's population is disaggregated into three income classes: low, middle and high. Meat and milk consumption quantities are estimated per income class. We consider meat from cows, goats, sheep and camels and milk from cows; we exclude poultry and pork as their reported quantities in the diets are very low (Gamba 2005). We determine the per capita and aggregate green and blue water footprints associated with meat and milk consumption in Nairobi per income class per period (1980s vs 2000s). We distinguish between footprints within the country and outside, thus visualizing the foreign water dependency ratio. Finally, the blue water footprint of livestock production in Kenya is viewed in the context of blue water scarcity in the country.

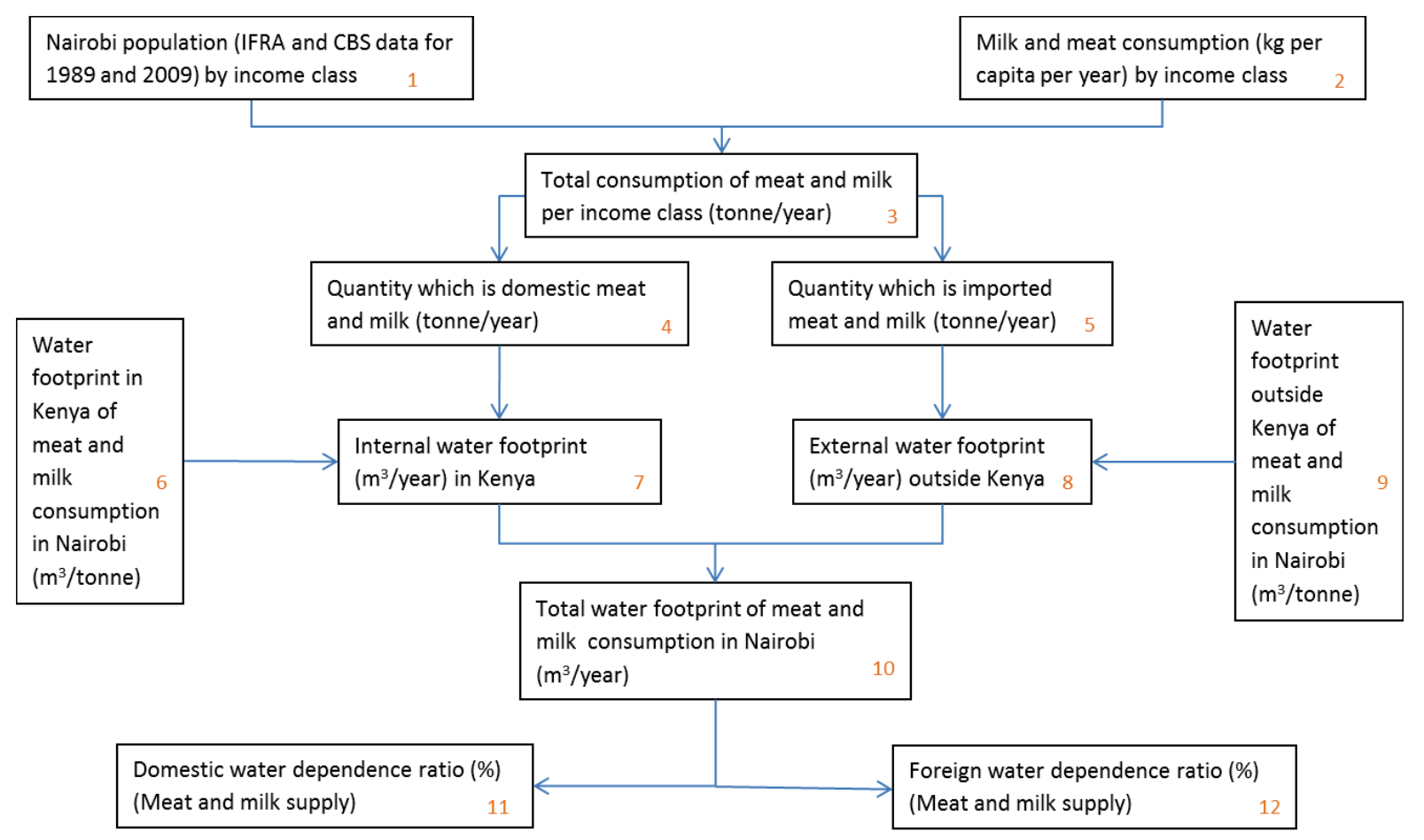

Figure 1: The analytical steps followed in estimating the water footprint and sphere of influence of meat and milk consumption in Nairobi between the 1980s and 2000s.

\subsubsection{Study area}

Nairobi is situated at the southern tip of the Kenyan Highlands, an area of high agricultural potential. After Kenya's independence in 1963, Nairobi changed status from provincial Kenyan district to one of the eight administrative provinces. After the promulgation of the New Kenyan Constitution in 2010 the area 
became one of Kenya's 47 counties. Today, Nairobi County consists of nine districts, namely Kamukunji, Starehe, Makadara, Langata, Dagoretti, Westlands, Kasarani, Embakasi and Njiru. In addition to these administrative changes, the actual area of Nairobi has almost doubled during the last century, from 384 $\mathrm{km}^{2}$ in 1910 to $695 \mathrm{~km}^{2}$ currently.

\subsubsection{Population and meat and milk consumption data (Steps1-5)}

We use census data from 1989 and 2009 from the Central Bureau of Statistics of Kenya (CBS), recently renamed the Kenya National Bureau of Statistics (KNBS), as a proxy for the total population of Nairobi in the 1980s (1980-1989) and 2000s (2000-2009) (GOK 2010). For each period we subdivide the number of inhabitants into three groups: high, middle and low income classes. For the 2000s, we extracted population data from Ledant (2011), whose estimates are based on the premise that the urban space is highly segregated according to levels of affluence. Ledant (2011) uses three analytical steps, including residential polygons, satellite data and household surveys, to generate sub-location polygons for seven income classes. To divide the population in the 2000s into the three income groups, we firstly used the residential polygons from Ledant (2011), satellite data and household surveys, to spatially delineate seven income groups into the sub-location polygons. Secondly, we aggregated these into the three prescribed classes: the first two low income groups in Ledant (2011) were classified as low, the next three were classified as middle and the last two were classified as high income. This new proportional representation was verified against the proportions reported by Odhiambo (2004). The two did not differ, thus confirming the applicability of the reclassification approach used. Figure 2 shows the distribution of the population in Nairobi into three income classes as described above. To estimate the population size for the 1980s, we used the 1989 CBS census data at the sub-location level (the lowest administrative level used in the Kenyan census). To estimate the proportions of the three income groups, we applied the proportions for Nairobi estimated by Muwonge (1980). 


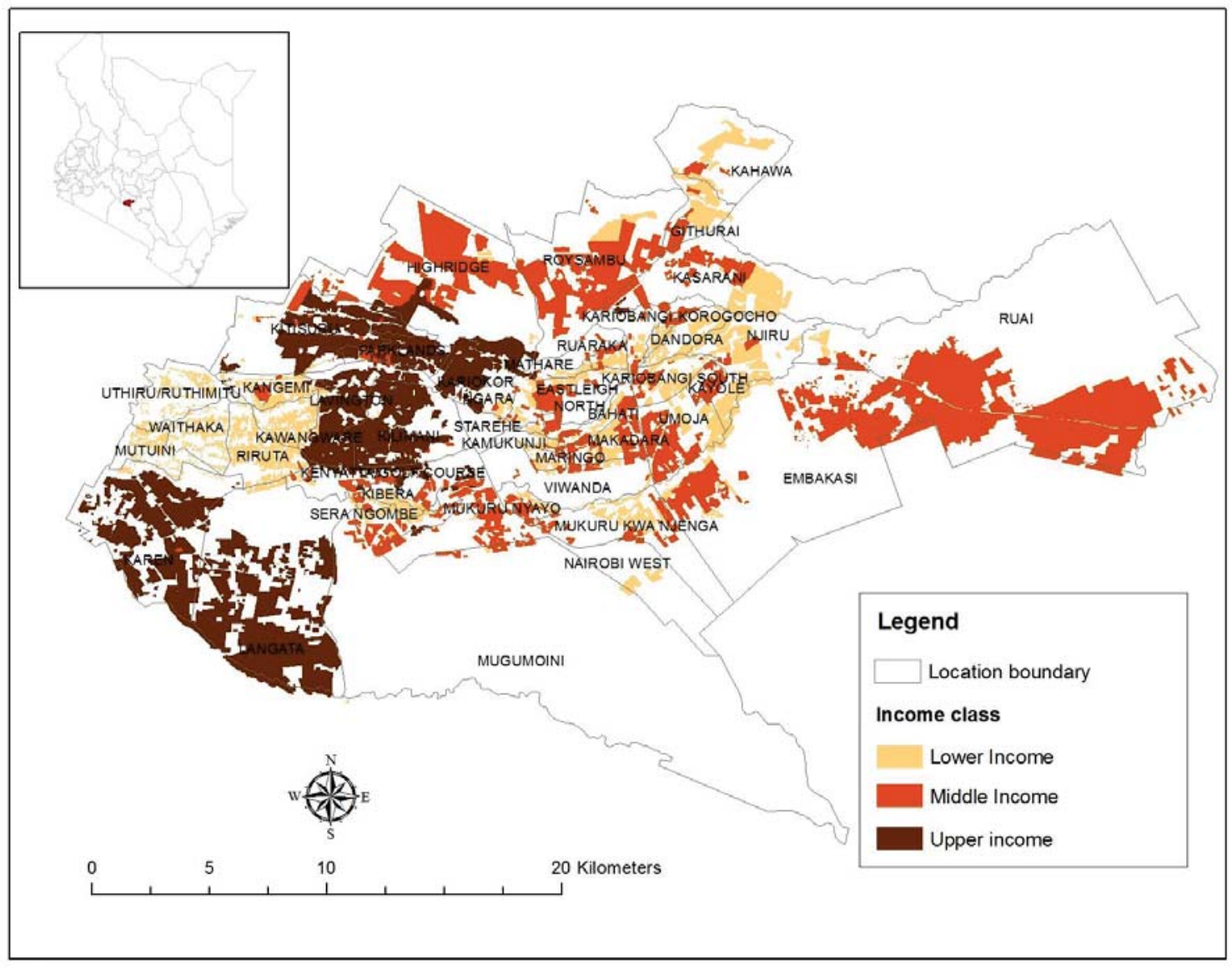

$W F_{\text {cons }}=\sum_{p}\left(C[p] \times W F_{\text {prod }}^{*}[p]\right)$

Figure 2: Income-class distribution for Nairobi in the 2000s, across the nine districts of Nairobi by sub-location and residential type. Source: adapted from Ledant (2011)

We use a bottom-up approach to estimate the total amount of meat and milk consumed in Nairobi, i.e. the "food end-use" (Wirsenius et al. 2010). This refers to quantities purchased by consumers. The information about quantities of milk and meat consumed by different income groups in Nairobi in the 1980s and 2000s were collated from a wide range of sources (Shah and Frohberg 1980, Ouma et al. 2000, Argwings-Kodhek et al. 2005, Gamba 2005, Njarui et al. 2011). We linked the relative affluence to milk and meat consumption by assigning the quantities of milk consumed to the three income classes. Higher income levels are generally linked to higher consumption levels of ASFs, leading to larger environmental footprints. By disaggregating data by income class it is possible to account for variations in affluence and environmental footprints. Meat and milk consumption are summed across the livestock species 
considered. Thus, we assume that the preferences associated with individual residents are implicitly captured (Juma et al. 2010).

We assessed which fractions of Nairobi's meat and milk consumption come from domestic production and import based on the national ratio of total production to total import for these two product categories, taking data from various sources (Muthee 2006, EADD 2008, Tempia et al. 2010). This allows for an evaluation of the dependence of the city's consumption on national production versus imports. The precise sources of meat and milk consumed are determined from stock and supply routes for the live animals and unprocessed milk sold in the Nairobi markets, respectively.

\subsubsection{Assessing the water footprint of milk and meat consumption (Steps 6-12)}

The water footprint of a product is the total amount of freshwater used to produce the good (Hoekstra et al. 2011). It consists of three components. The green water footprint refers to consumptive water use of rainfed soil moisture, the blue water footprint to the consumptive water use of groundwater and surface water, and the grey water footprint to the volume of water required to dilute pollution (Hoekstra et al. 2011). In this study we focus on analysing the green and blue water footprints.

A water footprint can have both a domestic and foreign component. For the urban consumption of meat and milk in Nairobi, the former refers to the consumptive freshwater use in Kenya to produce meat and milk for Nairobi's citizens while the latter refers to the consumptive water use in other countries to produce meat and milk consumed in Nairobi. We use the bottom-up approach to estimate the green and blue water footprints of consumption $W F_{\text {cons }}$ in Nairobi as follows:

$W F_{\text {cons }}=\sum_{p}\left(C[p] \times W F_{p r o d}^{*}[p]\right)$

where $C[p]$ is the consumption of product $p$ by consumers in Nairobi (tonne/yr) and $W F^{*}{ }_{p r o d}[p]$ the water footprint of this product ( $\mathrm{m}^{3} /$ tonne). Since a quantity of product $p$ consumed in Nairobi will generally originate in part from within the country and in part from other countries, the average water footprint of a product $p$ consumed in Nairobi is calculated as in Mekonnen and Hoekstra (2011): 


$$
W F_{p r o d}^{*}[p]=\frac{P[p] \times W F_{p r o d}[p]+\sum_{n_{e}}\left(T_{i}\left[n_{e}, p\right] \times W F_{p r o d}\left[n_{e}, p\right]\right)}{P[p]+\sum_{n_{e}} T_{i}\left[n_{e}, p\right]}
$$

in which $P[p]$ represents the production quantity of product $p$ in Kenya, $T_{i}\left[n_{e}, p\right]$ the imported quantity of product $p$ from exporting nation $n_{e}, W F_{\text {prod }}[p]$ the water footprint of product $p$ when produced in Kenya and $W F_{\text {prod }}\left[n_{e}, p\right]$ the water footprint of product $p$ as in the exporting nation $n_{e}$. The assumption made here is that the total consumption volume originates from domestic production and imports according to their relative volumes (Mekonnen and Hoekstra 2012). This assumption would be problematic if huge price differentials or clear preferences existed between the meat and milk derived from the domestic and foreign sources and when this would affect Nairobi's buyer decisions differently than those in other parts of Kenya. We are not aware of any compelling evidence that this is the case.

For the water footprint of imported products $\left(W F_{\text {prod }}\left[n_{e}, p\right]\right)$ we use the data from Mekonnen and Hoekstra (2012). For domestically produced products we used the weighted average of the water footprint from three production systems (arid, semi-arid and humid systems) from which the meat and milk consumed originate as described in Bosire et al. (2015) for both time periods. The main determinants of water footprint of meat and milk that we considered include the composition of the livestock feed, water use efficiency in feed crop production and the feed conversion efficiency of the animal. The main temporal trend in these systems is towards higher efficiency in the production of meat and milk in the humid system but a lower efficiency in the arid and semi-arid systems. This has lowered the water footprint per tonne of product in the humid system, but raised it in the arid and semi-arid systems. For the imported milk and meat, we use import proportions from Aklilu et al. (2002) for meat and from (EADD 2008) for milk imports in the 2000s. We assume no imports for the 1980s, consistent with FAO estimates of meat and milk imports into Kenya in the 1980s (FAO 2016).

The foreign water dependency of Nairobi's meat and milk consumption is defined as the ratio of the water footprint of Nairobi's meat and milk consumption outside Kenya to the total water footprint of Nairobi's meat and milk consumption. The domestic water dependency is calculated as the domestic divided by the total water footprint of Nairobi's meat and milk consumption. 


\subsection{Results}

\subsubsection{Population changes in Kenya and Nairobi between the 1980s and 2000s}

Kenya's population increased by $70 \%$ between the 1980 s and 2000 s (Table 1). During this period the rural population grew by $38 \%$ and the urban population by about $240 \%$. The population of Nairobi grew slower than the total Kenyan urban population, and increased by about $150 \%$, from 1.3 to 3.1 million. In the 1980s, Nairobi represented one third of the national urban population; this was one fourth in the 2000s. Nairobi's middle-income class showed the greatest rate of increase, quadrupling its size between the 1980s and 2000s. The low-income class doubled, while the high-income class showed the lowest growth, about one and half times. Although all three income classes increased substantially between the 1980s and the 2000s, the residential settlement pattern associated with the three income groups in the 2000s (Figure 2) was not much different from the 1980s.

\subsubsection{Consumption of meat and milk in Kenya and Nairobi between the 1980s and 2000s}

Between the 1980s and 2000s, per capita consumption of meat and milk in Kenya increased by $9 \%$ and 17\%, respectively (Table 2). The rural population had consistently lower meat consumption per capita than the urban population. For the rural population, meat consumption per capita did not change discernibly, but for the urban population it increased. Overall, the total consumption of meat in Kenya increased over this period and the largest contributor to the increase in meat consumption in Kenya was the total urban consumption, which almost quadrupled. In contrast, the rural population's consumption of meat only increased by $38 \%$.

However, in Nairobi, per capita meat consumption declined over this period. Among the income classes, the largest decline in meat consumption was in the high-income class. The doubling of meat consumption in Nairobi was mainly a result of population increases; most pronounced was the $255 \%$ increase in the total consumption of meat by the middle-income class. 
Table 1 Population and meat and milk consumption in the 1980s and 2000s for Kenya and Nairobi City.

\begin{tabular}{|c|c|c|c|c|c|c|c|c|c|c|}
\hline \multirow[t]{2}{*}{$\begin{array}{l}\text { Consumer } \\
\text { group }\end{array}$} & \multicolumn{2}{|c|}{$\begin{array}{l}\text { Population } \\
\text { (thousand) }\end{array}$} & \multicolumn{2}{|c|}{$\begin{array}{c}\text { Per capita } \\
\text { meat consumption } \\
\text { (kg/yr) }\end{array}$} & \multicolumn{2}{|c|}{$\begin{array}{c}\text { Total } \\
\text { meat consumption } \\
\text { (tonne/yr) }\end{array}$} & \multicolumn{2}{|c|}{$\begin{array}{c}\text { Per capita } \\
\text { milk consumption } \\
(\mathrm{kg} / \mathrm{yr})\end{array}$} & \multicolumn{2}{|c|}{$\begin{array}{c}\text { Total } \\
\text { milk consumption } \\
\text { (tonne/yr) }\end{array}$} \\
\hline & $1980 \mathrm{~s}$ & $2000 \mathrm{~s}$ & 1980s & $2000 s$ & 1980s & $2000 s$ & 1980s & $2000 s$ & 1980s & $2000 s$ \\
\hline \multicolumn{11}{|l|}{ Kenya } \\
\hline Rural & 18,930 & 26,100 & 13 & 13 & 239,470 & 330,450 & 49 & 58 & 921,330 & $1,504,670$ \\
\hline Urban & 3,700 & 12,500 & 18 & 21 & 69,050 & 263,990 & 42 & 48 & 155,630 & 599,390 \\
\hline Total & 22,700 & 38,600 & 16 & 17 & 352,810 & 652,330 & 45 & 53 & $1,023,630$ & $2,038,610$ \\
\hline \multicolumn{11}{|l|}{ Nairobi } \\
\hline Low income & 950 & 2,000 & 13 & 12 & 12,490 & 23,710 & 34 & 60 & 32,670 & 119,430 \\
\hline Middle & 240 & 950 & 24 & 21 & 5,670 & 20,150 & 44 & 94 & 10,540 & 89,260 \\
\hline \multicolumn{11}{|l|}{ Income } \\
\hline High Income & 60 & 170 & 29 & 25 & 1,790 & 4,170 & 66 & 126 & 4,160 & 21,090 \\
\hline Total & 1,300 & 3,100 & 22 & 19 & 27,400 & 60,340 & 48 & 93 & 60,550 & 290,980 \\
\hline $\begin{array}{l}\text { Nairobi's } \\
\text { share in Kenya }\end{array}$ & $6 \%$ & $8 \%$ & & & $8 \%$ & $9 \%$ & & & $6 \%$ & $14 \%$ \\
\hline
\end{tabular}

Kenyan milk consumption per capita increased by $17 \%$, in rural areas by $18 \%$ and in urban areas by $15 \%$. Per capita consumption of milk was larger in rural than urban areas in both the 1980 s and 2000s. For Nairobi, the consumption of milk per capita increased by $93 \%$ between the 1980 s and 2000 s. This increase was not even across all income classes: the middle income class more than doubled their per capita milk consumption, while the low income class increased their consumption by $74 \%$.

Total consumption of milk in Kenya increased by $95 \%$, and was mainly due to a quadrupling of the total urban population's milk consumption. Nairobi's consumption of milk increased five-fold between the 1980s and 2000s, with the highest increase, almost nine-fold, realized by the middle-income class. The high-income class increased their total consumption almost five-fold between the 1980s and 2000s, while the low income class increased their consumption three-fold. 
Table 2 Percentage changes in human population size, meat and milk consumption for Kenya and Nairobi between the 1980s and 2000s.

\begin{tabular}{|c|c|c|c|c|c|}
\hline Consumer group & $\begin{array}{l}\text { Change in } \\
\text { population }\end{array}$ & $\begin{array}{l}\text { Change in per } \\
\text { capita meat } \\
\text { consumption }\end{array}$ & $\begin{array}{c}\text { Change in total } \\
\text { meat consumption }\end{array}$ & $\begin{array}{l}\text { Change in per } \\
\text { capita milk } \\
\text { consumption }\end{array}$ & $\begin{array}{l}\text { Change in total } \\
\text { milk consumption }\end{array}$ \\
\hline \multicolumn{6}{|l|}{ Kenya } \\
\hline Rural & $38 \%$ & $0 \%$ & $38 \%$ & $18 \%$ & $63 \%$ \\
\hline Urban & $234 \%$ & $14 \%$ & $282 \%$ & $15 \%$ & $285 \%$ \\
\hline Total & $70 \%$ & $9 \%$ & $85 \%$ & $17 \%$ & $99 \%$ \\
\hline \multicolumn{6}{|l|}{ Nairobi } \\
\hline Low income & $110 \%$ & $-10 \%$ & $90 \%$ & $74 \%$ & $266 \%$ \\
\hline Middle Income & $300 \%$ & $-11 \%$ & $255 \%$ & $112 \%$ & $747 \%$ \\
\hline High Income & $166 \%$ & $-13 \%$ & $133 \%$ & $90 \%$ & $407 \%$ \\
\hline Total & $149 \%$ & $-11 \%$ & $120 \%$ & $93 \%$ & $381 \%$ \\
\hline
\end{tabular}

Total supply in Kenya of both meat and milk increased between the 1980s and 2000s (Table 3). Though domestic supply of meat in the 2000 s was $35 \%$ higher than in the 1980 s, imports grew to account for $27 \%$ of the total supply in the 2000s. Domestic supply of milk in the 2000 s was $97 \%$ higher than in the 1980 s and milk imports only accounted for $1 \%$ of the total milk supply in Kenya in the 2000 s.

Table 3 Domestic and imported shares of meat and milk in the 1980s and 2000s for Kenya.

\begin{tabular}{|c|c|c|c|c|c|c|}
\hline & \multicolumn{2}{|c|}{ Meat supply (tonne/yr) } & \multirow[t]{2}{*}{$\%$ Change } & \multicolumn{2}{|c|}{ Milk supply (tonne/yr) } & \multirow[t]{2}{*}{ \% Change } \\
\hline & $1980 \mathrm{~s}$ & $2000 s$ & & $1980 s$ & $2000 s$ & \\
\hline Domestic & 352,810 & 476,200 & 35 & $1,023,630$ & $2,018,220$ & 97 \\
\hline Import & - & 176,130 & - & - & 20,390 & \\
\hline Total & 352,810 & 652,330 & 85 & $1,023,630$ & $2,038,610$ & 99 \\
\hline$\%$ change in import & - & 27 & & - & 1 & \\
\hline
\end{tabular}

\subsubsection{Water footprint of milk and meat consumption per income group}

\subsubsection{Per capita water footprint of milk and meat consumption}

Figure 3 shows the water footprint of meat and milk consumption per capita per income class for the 1980s and 2000s. The 2000s had a consistently lower per capita water footprint associated with meat consumption than the 1980s, mostly because of a decline in the per capita consumption of meat in the 2000 s across all income groups. The high-income group had the highest per capita meat footprint in both periods, which is consistent with the relatively high consumption of meat by this group. 
In the 2000s, the water footprint of milk consumption per capita was larger than in the 1980s for all income groups, though the magnitude of the difference is not commensurate with the increased per capita consumption of milk. This is mainly due to an increased efficiency of milk production in the humid production system and the accompanying reduction in the weighted average water footprint in the 2000s.

The meat and milk water footprints were dominated by the green water footprint, which contributed $96 \%$ to the total water footprint for milk consumption and $98 \%$ for meat consumption.

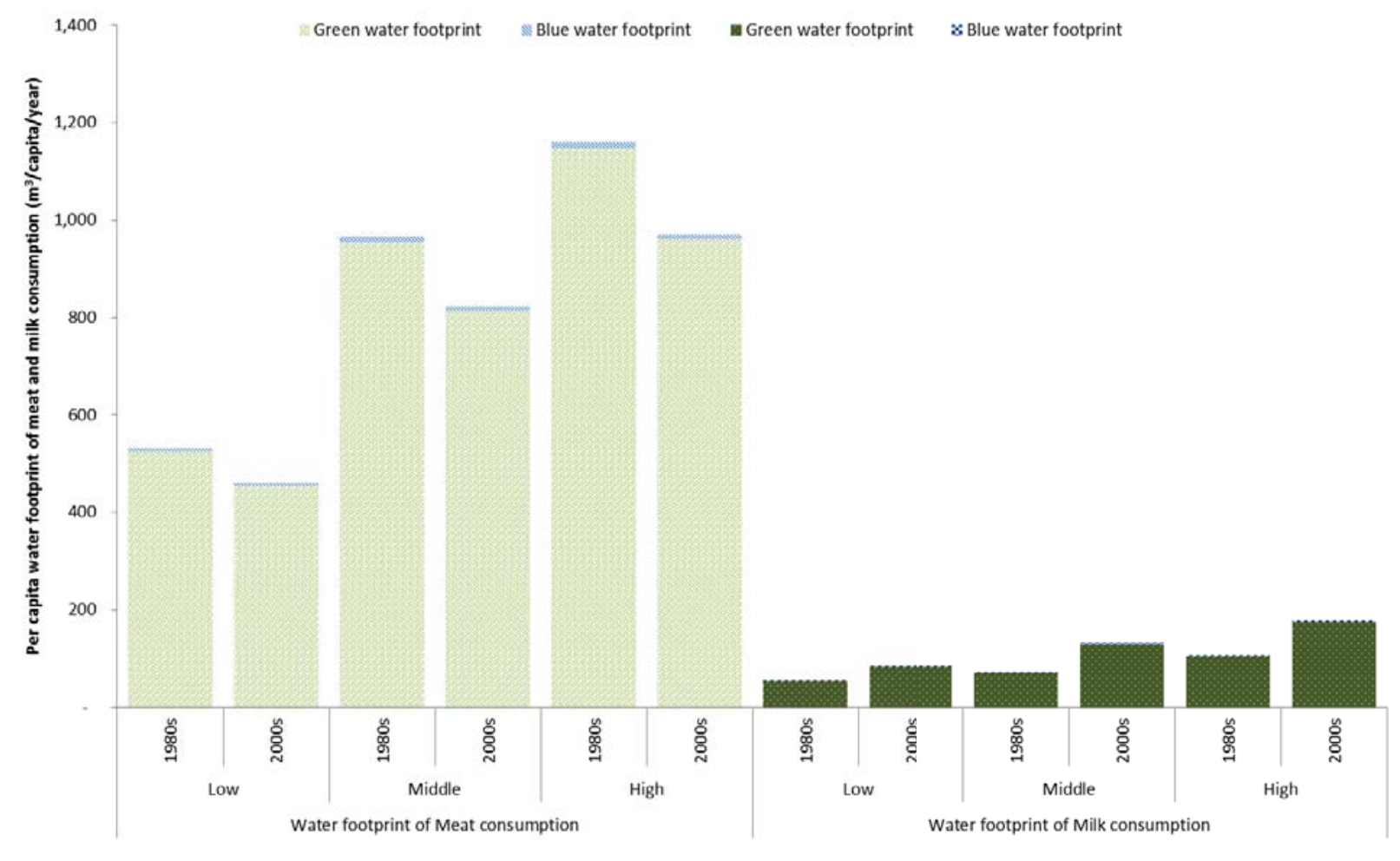

Figure 3: The water footprint of meat and milk consumption per capita by low, middle and high-income class in Nairobi City, in the 1980s and 2000s. 


\subsubsection{Total green and blue water footprint of milk and meat consumption}

The total green and blue water footprint of meat and milk consumption in the 2000s was larger than in the 1980 s, due to the increased population of Nairobi. The largest total water footprint of consumption was that for meat consumption by the low-income group in the 2000s (Figure 4). The middle-income group had the second largest water footprint recorded for meat consumption in the 2000s, whereas the high-income group had the smallest footprint for meat consumption in both the 1980s and 2000s, due to the comparatively small size of this income group. The total water footprint of milk consumption showed a similar pattern as observed for meat consumption, being largest for the low-income class. This is associated with the higher numbers for the low-income group in the 1980s and 2000s, as well as an increase in the per capita consumption of milk by this income class in the 2000 s.

The total water footprint of meat consumption in Nairobi more than doubled between the 1980s and 2000s, while the total water footprint of milk consumption in Nairobi quadrupled (Table 3). The blue water footprint associated with meat consumption doubled between the 1980s and 2000s. The emergence of a blue water footprint of consumption of milk in the $2000 \mathrm{~s}$ is associated with the inclusion of compounded and supplemental feeds in the livestock diets in this period. Nevertheless, the green water footprint was the largest component of the total water footprint in both the 1980s and 2000s because production of livestock feeds was primarily through rain-fed cultivation and rarely depended on irrigation. 


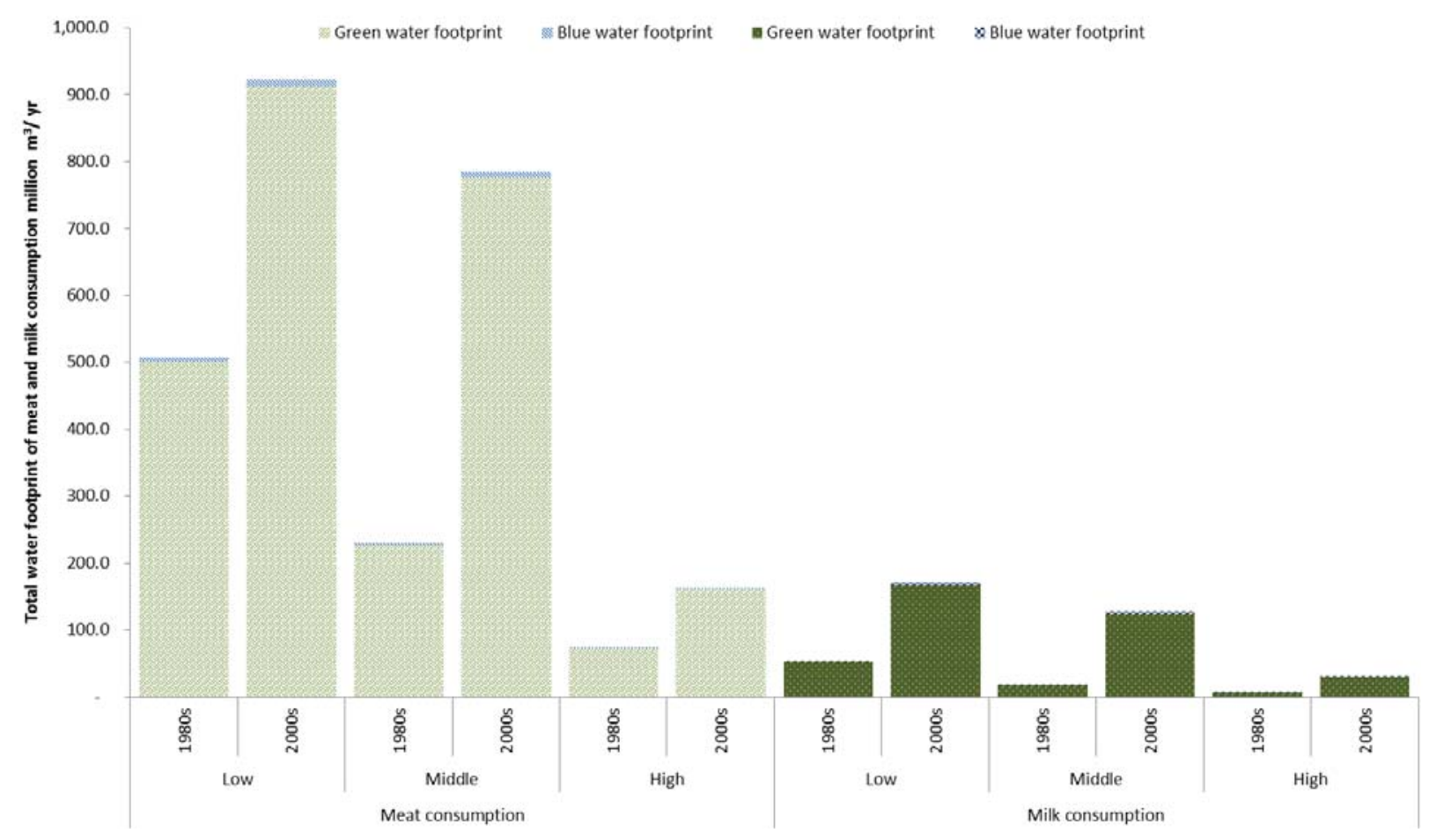

Figure 4: The total water footprint of meat and milk consumption by low, middle and high-income class in Nairobi City, in the 1980s and 2000s.

\subsubsection{Domestic and foreign water dependence of meat and milk consumption in Nairobi.}

The domestic water dependence of meat consumption in Nairobi declined from $100 \%$ in the 1980 s to $61 \%$ in the 2000s and the foreign water dependence rose from zero to $39 \%$ (Table 4). Milk consumption remained almost entirely dependent on domestic water resources. The proportion of the water footprint of Nairobi's meat and milk consumption to the total water footprint of meat and milk consumption in Kenya increased from $6.5 \%$ to $8 \%$ for meat and from $4.4 \%$ to $11 \%$ for milk between 1980 s and 2000 s. 
Table 4 Total water footprint of Nairobi's meat and milk consumption in the 1980 s and 2000s, specified into domestic and foreign components, and the associated dependence ratios.

\begin{tabular}{|c|c|c|c|c|c|c|c|c|c|c|}
\hline \multirow[t]{2}{*}{ Water footprint } & \multicolumn{2}{|c|}{$\begin{array}{c}\text { Total water } \\
\text { footprint of } \\
\text { Nairobi } \\
\text { consumption } \\
\text { (million } \mathrm{m}^{3} / \text { year) }\end{array}$} & \multicolumn{2}{|c|}{$\begin{array}{l}\text { Domestic water } \\
\text { footprint of } \\
\text { Nairobi } \\
\text { consumption } \\
\text { (million } \mathrm{m}^{3} / \text { year) }\end{array}$} & \multicolumn{2}{|c|}{$\begin{array}{c}\text { Foreign water } \\
\text { footprint of } \\
\text { Nairobi } \\
\text { consumption } \\
\text { (million } \mathrm{m}^{3} / \text { year) }\end{array}$} & \multicolumn{2}{|c|}{$\begin{array}{l}\text { Domestic water } \\
\text { dependence of } \\
\text { Nairobi } \\
\text { consumption } \\
\text { (\%) }\end{array}$} & \multicolumn{2}{|c|}{$\begin{array}{l}\text { Foreign water } \\
\text { dependence of } \\
\text { Nairobi } \\
\text { consumption } \\
\text { (\%) }\end{array}$} \\
\hline & 1980s & $2000 s$ & $1980 \mathrm{~s}$ & $2000 \mathrm{~s}$ & $1980 \mathrm{~s}$ & $2000 \mathrm{~s}$ & 1980s & $2000 \mathrm{~s}$ & $1980 \mathrm{~s}$ & 2000s \\
\hline \multicolumn{11}{|l|}{ Meat } \\
\hline Green & 810 & 1,860 & 810 & 1,130 & - & 730 & 100 & 61 & - & 39 \\
\hline Blue & 10 & 20 & 10 & 10 & - & 10 & 100 & 65 & - & 35 \\
\hline Total & 820 & 1,880 & 820 & 1,140 & - & 740 & 100 & 61 & - & 39 \\
\hline \multicolumn{11}{|l|}{ Milk } \\
\hline Green & 80 & 340 & 80 & 330 & - & 4 & 100 & 99 & - & 1 \\
\hline Blue & - & 10 & - & 10 & - & 0 & 100 & 99 & - & 1 \\
\hline Total & 80 & 350 & 80 & 350 & - & 5 & 100 & 99 & - & 1 \\
\hline
\end{tabular}

\subsection{Discussion}

\subsubsection{Consumption of meat and milk in Kenya and Nairobi}

The average meat consumption per capita estimated for Kenya in this study is $17 \mathrm{~kg}$ per year for the 2000s, which is higher than the $13 \mathrm{~kg}$ per year reported by FAO (2016). The per capita beef/mutton/chevron consumption level of $17 \mathrm{~kg}$ per year for Kenya is much lower than in many other countries, like for example Australia, Brazil and the USA, estimated to $52 \mathrm{~kg}$ per year, $40 \mathrm{~kg}$ per year, and $37 \mathrm{~kg}$ per year, respectively. When poultry and pork are also included in the per capita meat consumption estimates, there is an even greater difference in the meat consumption estimates between Kenya and some other countries. With the addition of pork and poultry, meat consumption per capita is the highest at $120 \mathrm{~kg}$ per year in Australia, followed by $116 \mathrm{~kg}$ per year in the USA, and $92 \mathrm{~kg}$ per year in both Brazil and Canada. The inclusion of poultry and pork in the Kenyan average per capita meat consumption only adds a mere $0.8 \mathrm{~kg}$ to the annual consumption, which leaves per capita meat consumption in Kenya at about one fifth of the figures for the largest meat consumers.

In this study we have established that rural and urban consumption of meat and milk in Kenya show different developments between the 1980s and 2000s. While the urban meat consumption per capita increased, rural meat consumption did not change. In contrast to the increase in per capita meat consumption across all urban areas in Kenya, the per capita meat consumption in Nairobi declined, which 
may relate to the combination of general price increases in Nairobi and a decrease in overall livestock production in Kenya over this period (Gamba 2005, Bosire et al. 2015).

The average meat consumption per capita in Nairobi is slightly higher than in Kenya as a whole and mimics the general rural-urban dichotomy of Kenya's meat consumption pattern. Per capita meat consumption in the low-income class was similar to the rural consumption in both the 1980s and 2000s. This may be explained by the fact that recent migrants to Nairobi maintain their rural diets. Most rural migrants first settle into the low-income class residential areas and may maintain this residence throughout their stay in the urban areas. The largest annual per capita meat consumption is associated with the high-income group. This consumption level is about three times the average consumption of meat estimated for Africa, which is $9 \mathrm{~kg}$ per capita (FAO 2016). When compared with the estimates for the neighbouring countries, the high-income class's annual per capita meat consumption is twice as high as the average consumption in Sudan and nearly four times higher than the average consumption in Ethiopia.

Price is a main driver of access to ASFs by Nairobi's residents, leading to the varied consumption patterns observed among the different income groups. Differences in the price and availability of milk and meat are determined by the level of processing and the livestock species from which they originate (Ouma et al. 2000, Gamba 2005). The consumption of beef, in particular, provides clear evidence for differentiation along the affluence gradient as beef is one of the key livestock products consumed across all the urban income classes (Gamba 2005). Among the various meat products produced in Kenya, beef ranks among the most common at about $77 \%$ of total production (Aklilu et al. 2002). Sheep and goat meat are not as widely consumed and are mainly consumed by the middle and high-income groups as roasted meat, commonly referred to as "nyama choma" (Juma et al. 2010). Most low-income earners minimise their consumption of non-home prepared foods, at restaurants and kiosks, as this requires a shift to a price level only affordable to higher socio-economic levels (van 't Riet et al. 2003).

Milk consumption per capita in rural Kenya is about $10 \mathrm{~kg}$ per year higher than the urban consumption rate. This is mainly the result of access to milk and direct consumption at home. Urban consumption involves purchase, which may hinder access. Additionally, most milk in urban areas is consumed in the form of tea with milk, which reduces the consumption quantities (Njarui et al. 2011). The national milk consumption level of $53 \mathrm{~kg}$ per year per capita is much lower than the FAO estimate of $99 \mathrm{~kg}$ per year. This is partly a result of the difference in approach, with the current study using a bottom-up approach 
whereas the FAO uses a top-down assessment method. The average per capita milk consumption in Nairobi is however about twice as large as the national average milk consumption. This is indicative of the increase in consumption of animal source foods (ASFs) associated with urban growth. The purchasing power of Nairobi residents is also much higher than that in the other urban areas (Argwings-Kodhek et al. 2005) and may contribute to the larger consumption per capita. Compared to some of the large milk drinkers in the world, such as the USA (256 kg/yr/capita) and Europe (219 kg/yr/capita), the consumption in Nairobi by the low, middle and high income classes (60, 94 and $126 \mathrm{~kg} / \mathrm{yr} /$ capita, respectively) is rather low (FAO 2016). The gap in consumption between the high and low-income groups in Nairobi is quite large. This persisted from the 1980 s to the 2000 s and the low-income class still consumed milk at the rates characteristic of rural consumption. This finding is similar to that reported for milk and meat consumption in Kerala, India (Renuka et al. 2009). The consumption of milk associated with Nairobi is mainly due to good access facilitated by the close proximity to the milk production areas and to the fact that a large quantity of milk is consumed unprocessed, allowing for affordable pricing for all the income classes.

Total milk and meat consumption changes in Nairobi between the 1980s and 2000s are a function of population increase and changes in per capita meat and milk consumption. The $300 \%$ increase of the size of Nairobi's middle-income class contributed most to the increase in total meat and milk consumption. The low consumption level in the low-income class is associated with a high incidence of undernutrition and especially protein deficiency (Mboganie-Mwangi and Foeken 1996, Black et al. 2013).

\subsubsection{Sources of meat and milk consumed in Nairobi}

The sphere of influence of Nairobi's meat and milk demand has grown with the increase in its population size since the 1980s. The growth in Kenya's GDP has not been rapid enough to lead to a dramatic increase in the demand for meat per capita (WB 2015). Despite a stagnation in demand for meat per capita, there is a large increase in total demand because of the growing population and a significant increase in the quantities of meat imported from the neighbouring countries (Muthee 2006, Tempia et al. 2010). The 22\% increase in the import of live animals in the 2000s (Aklilu et al. 2002) was probably a response to the decline in supply of livestock in Kenya. The stock routes for live cattle, sheep and goats showed that the largest flow of these animals was directed towards Nairobi and Mombasa, with Nairobi receiving the bulk of this livestock import (Tempia et al. 2010). 
In the 1980s, most of the ASFs and other perishable agricultural products consumed in Nairobi were sourced from farmers in the highland areas to the north and some ranches to the south of the city. On the contrary, cereals and other not highly perishable farm products were mainly ferried from rural areas as far away as western Kenya. Immigration of a large number of people from regions farther away from Nairobi increased the import of these cereals and vegetables (K'Akumu and Olima 2007). Housing schemes such as the Umoja and Kariobangi schemes also pushed the dairy and ranching systems farther away from areas within the early boundaries of Nairobi, thereby increasing the average distance from which these products were sourced (Huchzermeyer 2007).

Milk imports have not constituted a large proportion of the total consumption in Nairobi and Kenya as a whole. Milk imported from countries such as New Zealand, constitutes about $0.5 \%$ of the total milk supply to the Kenyan market, and is mainly in the form of powdered milk, that can be reconstituted into liquid milk by the processors (EADD 2008), or sold in small packages, as small as 10 grams, to low income groups (Olok-Asobasi and Sserunjogi 2001). The imported milk is mostly used in the dry seasons. Sudan and Kenya jointly have the largest dairy herds in sub-Saharan Africa (Karanja 2003), yet Sudan provides about twice the quantities of milk per capita, compared to Kenya. Adopting a more resource-efficient production of meat and milk would enable Kenya to reduce the reliance on external sources for ASFs. This is especially important in light of the contemporary and projected growth of cities in Kenya.

\subsubsection{Influence of income on water footprint of milk and meat consumption in Nairobi}

As expected, our results show that the water footprint of milk and meat consumption in Nairobi is linked to the socio-economic standards of the population. This finding reaffirms findings of other studies that have documented dietary changes in response to changes in income and those that have looked at resource use for countries with different income levels (Benjelloun 2002, Delgado 2003, Hoekstra and Chapagain 2007). The water footprint in Nairobi changed as result of a combination of three factors: changes in total population, changes in consumption of milk and meat per capita and changes in the average footprint of production per unit of product (Bosire et al. 2015). The water footprint per unit of meat increased over time following the decline in efficiency and productivity. The water footprint per unit of milk, however, was reduced as a result of increases in productivity. 
The differences in the per capita water footprint of milk consumption between the high, middle and lowincome classes are slightly higher than the differences in the water footprints associated with meat consumption. The large difference in the water footprints between the high and low-income residents of Nairobi is due to a large difference between the quantities of milk consumed by the two income classes, which relates to differences in access. Overall, the relatively large water footprint associated with meat consumption is because meat generally has a large water footprint in comparison to milk (Bosire et al. 2015). In addition, the source areas for the local and imported meat are mainly classified as arid and semiarid regions and the breeds of livestock reared are mainly indigenous, low meat yielding breeds.

\subsubsection{The domestic and foreign water footprints of milk and meat consumption in Nairobi}

Between the 1980s and 2000s there is a substantial increase in the total import of meat but only a very slight increase in the import of milk (Aklilu et al. 2002, EADD 2008). This leads to a much larger growth in the domestic water footprint of Nairobi's milk consumption than in the domestic water footprint of the city's meat consumption. The increase in the domestic water footprint of milk consumption in Nairobi indicates a continued reliance on the domestic water resources for milk production despite an increase in the total milk consumption. This is made possible due to an improvement in the milk production over this period in Kenya. The domestic water footprint of meat consumption in Nairobi also increased between the 1980s and 2000s. We observe an increased reliance on foreign water resources to meet the increase in total meat consumption in Nairobi. The reliance on foreign water to meet the city's meat consumption is associated with a decline in livestock productivity between the 1980s and 2000s and partly explained by depressed investments in the livestock sector especially in the arid and semi-arid production systems (Bosire et al. 2015).

The green water footprint dominates both the domestic and foreign water footprint of Nairobi's meat and milk consumption in the 2000s. Generally, there is lower competition for green water than blue water resources. The externalization of the water footprint of Nairobi's meat and milk consumption to other countries, through imports, frees the domestic water resources to be used for other purposes than livestock production. It reduces the potential conflict arising from the use of limited domestic water resources towards livestock production rather than for food crop production. On the other hand, it increases dependence on foreign water resources, which are likely to become scarcer as well, particularly 
given that most imports come from neighbouring countries that face the problem of limited water resources as well.

\subsubsection{Urban growth, the resultant water footprint increase and the implications for blue water scarcity}

Any assessment of water footprints from increased food demand by urbanizing populations should take into account the availability of and potential competition for water with the other sectors of the economy. This is especially pertinent for developing countries, such as Kenya where the growth of urban areas is expected to accelerate following the establishment of county governments in 2013. Blue water scarcity can thus be expected to present a persistent and growing problem. Already, agriculture contributes as much as $86 \%$ to the total blue water footprint in Kenya (Table 5). The municipal and industrial sectors contribute only $13 \%$ and $1 \%$, respectively. Although the blue water footprint constitutes a minor proportion of the current total water footprint of animal source products (given the much larger green water footprint), the blue water footprint of livestock production stands for as much as $31 \%$ of the total domestic blue water footprint. In the humid production system, which represents an area of increased efficiency and improved animal diets, where additional blue water consumption is associated with feed crops in the livestock diets, livestock production is responsible for more than $43 \%$ of the blue water footprint. In both the arid and semi-arid production system, livestock production contributes about $26 \%$ to the total blue water footprint. Blue water consumption here is restricted to drinking and servicing water.

Blue water scarcity in Kenya's production systems is classified significant to severe (Mekonnen and Hoekstra 2016). The blue water scarcity is considered severe in the arid system, while the semi-arid and humid systems both exhibit significant blue water scarcity. 
Table 5. The blue water footprint (million $\mathrm{m}^{3} / \mathrm{year}$ ) in the 2000 s and blue water scarcity in three production systems in Kenya.

\begin{tabular}{|c|c|c|c|c|c|c|c|c|}
\hline \multirow[b]{2}{*}{$\begin{array}{l}\text { Production } \\
\text { system }\end{array}$} & \multicolumn{6}{|c|}{$\begin{array}{l}\text { Blue water footprint of production } \\
\qquad \text { (million } \mathrm{m}^{3} / \text { year) }\end{array}$} & \multirow{2}{*}{$\begin{array}{l}\text { Livestock } \\
\text { production } \\
\text { share of } \\
\text { total blue } \\
\text { WF in } \\
\text { Kenya }\end{array}$} & \multirow{2}{*}{$\begin{array}{l}\text { Avg. } \\
\text { blue } \\
\text { water } \\
\text { scarcity }\end{array}$} \\
\hline & $\begin{array}{l}\text { Food-crop } \\
\text { production }\end{array}$ & $\begin{array}{l}\text { Feed-crop } \\
\text { production }\end{array}$ & $\begin{array}{l}\text { Livestock } \\
\text { services }\end{array}$ & Household & Industry & $\begin{array}{l}\text { Kenya } \\
\text { total }\end{array}$ & & \\
\hline Arid & 107.3 & 0 & 41.8 & 10.3 & 1.1 & 160.5 & $26 \%$ & 3.51 \\
\hline Semi-arid & 56.1 & 0 & 26.3 & 16.8 & 1.8 & 101.0 & $26 \%$ & 1.86 \\
\hline Humid & 46.3 & 17.0 & 34.1 & 19.7 & 2.1 & 102.2 & $43 \%$ & 1.52 \\
\hline Others & 0.8 & 0 & & 0.1 & 0 & 0.9 & $0 \%$ & \\
\hline Total & 210.5 & 17 & 102.2 & 47 & 5 & 381.7 & $31 \%$ & \\
\hline
\end{tabular}

Sources: blue water footprint data from Hoekstra and Mekonnen (2012); blue water scarcity data from (Mekonnen and Hoekstra 2016). Livestock production shares concern both feed and service water footprints. Scale for blue water scarcity: low blue water scarcity $<1$, moderate blue water scarcity $=1-1.5$, significant blue water scarcity $=1.5-2$, and, severe blue water scarcity $>2$.

The domestic water footprint of milk consumption associated with Nairobi is mainly in the humid production system. This production system is classified as significantly blue water scarce. There are large competing claims to the blue water resources in this system that precludes the use of the blue water resources for cultivation of feed for milk production. Given the high level of blue water scarcity and the competing claims for water, there is a need to enhance water use efficiency in milk production and to consider alternative source areas for milk or less water-intensive protein sources than milk.

Meat is mainly sourced from the arid and semi-arid production systems, which jointly cover the largest area of Kenya. The severe blue water scarcity, large water footprint for livestock production in the arid system and increased total demand for meat may explain the strong rise in meat imports and foreign water dependence. Also in the case of meat production, water use efficiency needs to be increased or more water-efficient protein-rich meat alternatives could be considered.

\subsection{Limitations and assumptions of the study}

We have focused on the bottom-up approach to estimating consumption of meat and milk and not on the supply of food at the wholesale level as is often done. The approach we use allocates consumption quantities to different income groups. Our ability to estimate the consumption of meat and milk in Nairobi was limited by the large diversity of diets and the large sample sizes needed to have accurate estimates 
of the consumption of these products. To minimize potential biases in the estimated consumption of meat and milk, we relied on quantities documented by multiple household budget surveys (Shah and Frohberg 1980, Argwings-Kodhek et al. 2005, Gamba 2005, Njarui et al. 2011). We assumed that these data sources were representative of the diverse quantities consumed by the highly socio-economically segregated Nairobi population and both the rural and urban populations. We excluded poultry and pork from the study as the pertinent data were difficult to gather at this scale, there was no consistent analysis of consumption of these two products in the available literature, and the proportion of these two products in the diets was low according to existing data (Gamba 2005). Consumption of poultry and pork are projected to increase in developing countries and so both sources of meat should be given consideration in future dietary analyses (Alexandratos and Bruinsma 2012a, Herrero et al. 2013).

The diets are linked to incomes, yet there are often massive differences in incomes quoted by different studies, for example by Argwings-Kodhek et al. (2005) and Ledant (2011). The annual incomes for Nairobi residents reported by Ledant (2011), are much lower, merely US\$ 691, than the over US\$1,440 reported for the high-income class by Argwings-Kodhek et al. (2005) (1 US\$ = 69.44 KES at the 2009 exchange rate). Ledant (2011) acknowledges that responses by interviewees about their income amounts were often inaccurate. This discrepancy with the income classification done by the Central Bureau of Statistics of Kenya was corrected for in their methodology through the classification of residence types to more accurately reflect income classes, using such factors as monthly rental rates, type of material used for construction and area of land occupied by the residence. We assume that this correction negates the wide discrepancy in the incomes assigned to the various income classes.

The scale of the income class disaggregation was not similar for the 1980 s and 2000 s, further limiting the household-scale analysis of the changes associated with segregation patterns between the two periods. We thus focused on the sub-location level which is consistent for both periods from the census reports for Kenya for 1989 and 2009 and show no differences in the sub-location classification as low, middle or high income regions. We represent the urban income class segregation using the spatial scale of Ledant (2011), a baseline scale recommended for use in future consumption studies for Nairobi. 


\subsection{Conclusion}

Between the 1980s and 2000s the population in Nairobi increased by 150\%, from 1.3 to 3.1 million, which was twice the rate of the $70 \%$ population growth for entire Kenya. The rapid population increase in Nairobi is the main reason behind the increased consumption of both meat and milk during these decades, with 120 and $380 \%$, respectively. This shows that across all income groups there was a marked relative shift from meat to milk. Out of the three income classes, it is the middle-income class that stands out with a total consumption increase of more than $250 \%$ for meat and $750 \%$ for milk. However, taking the rapid population increase into account, the per capita consumption displays a quite different pattern, with a per capita meat consumption decline of $11 \%$ and milk consumption increase of $17 \%$.

The water footprints of total meat and milk consumption in Nairobi were fully met by domestic water resources in the 1980s. This had changed in the 2000s when the foreign water footprint of meat production was $39 \%$. The reliance on foreign water resources to meet the consumption of meat may be viewed as a means to relieve pressure on the already scarce water resources in Kenya. At the national level, animal production by the 2000 s contributes $30 \%$ to total consumptive blue water use in Kenya. This large contribution by livestock to the use of blue water will potentially increase with increased consumption of meat and milk unless measures are put in place to improve efficiency of livestock production.

Given the water scarcity levels in the areas of the three production systems, the Kenyan government should be cautious in formulating and implementing policies aimed at increasing the proportion of meat and milk in the diet. Careful consideration should be given to measures to improve the resource efficiency of meat and milk production and the potential of increasing import from other more resource-endowed countries. 


\title{
5 The effect of changing meat and milk consumption on future water and land footprints in Kenya. ${ }^{4}$
}

\begin{abstract}
Population growth and rising affluence increase the demand for agricultural commodities, while urbanization and globalization enlarge consumer-producer distances. The associated growth in trade in agricultural products results in increasing dependence on natural resources in the producing regions. This study assesses the impact of changing meat and milk consumption on natural resources use in Kenya, considering two socio-economic development scenarios, namely the Business As Usual (BAU) and Kenya Vision 2030 (S2030) scenarios. Two resource use indicators, water footprint and land footprint, are used to represent human appropriation of water and land resources for meat and milk production, trade and consumption in 2030. Overall meat and milk production and consumption are projected to be higher in the S2030 than in the BAU scenario. The fraction of imported meat in total meat consumption is expected to grow between 2009 and 2030 from 37\% to 45\% in both scenarios. The fraction of imported milk in total milk consumption will remain at $13 \%$ in the S2030 scenario but grow towards $20 \%$ in the BAU scenario. From 2009 to 2030, the water and land footprints of meat production will grow by $93 \%$ and $91 \%$ in BAU and by $45 \%$ and $23 \%$ in $\mathbf{S} 2030$. The water and land footprints of milk production will both grow by $59 \%$ in BAU and by $18 \%$ and $14 \%$ in S2030. The use of water and land for producing meat and milk in Kenya will thus grow under both scenarios, but less in S2030 than in BAU, despite the stronger growth of meat and milk consumption per capita in S2030, which can be explained by the smaller population growth in the S2030 scenario and the greater improvements in water and land productivities in the S2030 scenario. The Vision 2030 strategy for improving livestock production in Kenya is of great importance to reduce the speed with which the environmental footprint of the sector will increase, but it will be insufficient to stabilize or even reduce the sector's footprint. Besides, reducing the dependency on foreign land and water resources would require a yet more ambitious policy.
\end{abstract}

\subsection{Introduction}

${ }^{4}$ Submitted to Food Policy (Bosire et al. Submitted) 
Human population has increased globally from an estimated 2.5 billion people in 1950 to the current 7 billion (UN 2013a). Population growth has been most rapid in the developing world where the growth rate is spurred by high fertility rates (Spence et al. 2009). Alongside the population increase is a trend towards diets that include more highly nutritive and resource-demanding livestock products. This so called demand-driven livestock revolution (Delgado 2003) has been realized mostly in developing regions, especially in Asia. Animal source foods such as milk and meat require more freshwater than crop-based foods (Rockström et al. 2009, Mekonnen and Hoekstra 2012). Satisfying the increasing demand for animal source foods is therefore constrained by the amount of water and land resources available for agricultural production (Wirsenius et al. 2010, Stroosnijder et al. 2012).

While other countries may have a competitive advantage in other economic sectors, in sub-Saharan Africa agriculture remains the pillar of many economies and the main driver of economic growth (De Fraiture et al. 2010). Consequently, there have been repeated calls to develop and intensify agricultural production in general and the livestock sector in particular as envisioned in initiatives such as the Comprehensive Africa Agriculture Development Programme. However, agricultural intensification can have adverse effects on the environment, as has been documented for the livestock sector, particularly intensified dairy and pig production in developed regions (van der Zijpp 1999, Gerber et al. 2005). These negative outcomes of agricultural intensification agendas point to a disconnection between policies that focus on enhancing livestock production on the one hand and natural resource management on the other (Otte et al. 2012). This realization has spurred the development of scientifically sound environmental indicators that provide quantitative metrics for empirically monitoring and evaluating the environmental footprints of human consumption (Hoekstra and Wiedmann 2014, Bruckner et al. 2015). The water and land footprints are two such key indicators that are used to assess the impacts of human consumption on the appropriation of freshwater and land.

In Kenya, the national vision for development, officially referred to as Kenya Vision 2030, outlines strategies to be used by the national government to achieve middle-income status by 2030 . The economic pillar of Vision 2030 aims at an annual gross domestic product (GDP) growth rate of 10\% from the year 2012 to 2030, while the social pillar seeks to establish a just and equitable society living under a secure and clean environment. The political pillar aims at entrenching and nurturing a democratic system that respects the rule of law and protects the freedom of every Kenyan. Increased prosperity in Kenya as 
envisioned by Vision 2030 will almost certainly result in increased consumption, especially of animal source foods. The increased consumption will aggravate the pressure on the water and land resources needed to meet the growing demand.

This study aims to understand how the policies on population fertility rates, livestock production and dairy consumption, as formulated in Kenya's Vision 2030, will affect land and water resources use, both within and outside Kenya. This is achieved through the quantification and evaluation of the environmental resources demand linked to the consumption of meat and milk in Kenya projected to the year 2030, the anticipated end date of Kenya's Vision 2030 strategy.

\subsection{Method and data}

We formulated two scenarios for Kenya towards 2030: the Business as Usual (BAU) scenario, which assumes the continuation of current policies into the future, and the S2030 scenario, which assumes the full implementation of Kenya's Vision 2030 strategy. The scenarios are described in terms of changes in population, total meat and milk production, water and land use efficiency in feed production, feed conversion efficiency of animals, and consumption of meat and milk per capita. We consider total meat and milk from ruminants (cattle, sheep, goats), leaving out meat from pigs and chicken as well as meat and milk from camels. For both scenarios we use outputs from the Kenyan Threshold 21 (T21) model to obtain future estimates for population and meat and milk production. The T21 model was specifically developed to forecast the impacts of agricultural strategies and national development plans in Kenya and was made suitable to assess the impacts of implementing Kenya's Vision 2030 strategy (Züllich et al. 2015). To date, the model has been used for climate change adaptation and comprehensive national development planning in Kenya, analysis of green economy investment options, as well as for assessment of alternative national strategies for malaria eradication (Pedercini et al. 2011, Züllich et al. 2015). Consumption patterns and the usage of water and land resources are not included in the T21 model and related variables in the two scenarios are assumed as described in the following section. Based on the description of the two scenarios we estimate water and land footprints of meat and milk production, assess the economic productivities of water and land use in meat and milk production, and estimate the water footprint of meat and milk consumption, showing which parts of these footprints lie within Kenya and which parts outside the country. 


\subsubsection{Description of scenarios}

Several issues are addressed in the Kenya Vision 2030 strategy. We focus here on population growth and the production and consumption of meat and milk. Table 1 shows the status of a number of relevant variables in the base year (2009) and assumed changes between the base year and 2030 under the BAU and S2030 scenarios, assuming full implementation of the policies pertinent to each scenario. Figure 1 further shows total meat and milk production, consumption and net import in 2009 and in 2030 for the two scenarios.

The BAU scenario assumes the continuation of the current trends in population, production and consumption growth up to 2030, full implementation of the currently existing legislation and no fundamental deviation from the current policies between now and 2030. Population size is estimated based on decadal national censuses and projections based on fertility rates for the year 2009 (GOK 2010c, 2012). The BAU scenario assumes similar meat and milk consumption rates as those documented by Gamba (2005) and Argwings-Kodhek et al. (2005) for Kenya today. Production parameters for meat and milk are taken from Bosire et al. (2015) for the period 2000-2012. Trade in meat and milk is quantified based on the food balance approach. Current trade is estimated based on figures for the year 2009.

The S2030 scenario assumes full realization of the Vision 2030 strategic goals. In this scenario, the population growth rate is assumed to be based on halving the fertility rate between 2009 and 2030 (GOK 2012). The scenario is further characterised by a high economic growth rate, which translates into a higher rate of consumption of animal source foods. The S2030 scenario assumes a $184 \%$ increase in total meat consumption between 2009 and 2030 and a 121\% increase in total milk consumption (GOK 2010b, Alexandratos and Bruinsma 2012a). In this scenario, the projected growth in production is based on an increased public investment in agriculture of up to $10 \%$ of the national budget and an average annual growth rate of at least $6 \%$ in agricultural production as outlined in the Comprehensive Africa Agriculture Development Programme (CAADP) from the African Union agreement. The overall goal of CAADP is to eliminate hunger and reduce poverty through agriculture. The S2030 scenario assumes the adoption of technologies and management practices that improve production. Trade in meat and milk is quantified based on the food balance approach.

Table 1. The status of variables in the base year (2009) and assumed changes between the base year and 2030 under the Business as Usual and S2030 scenarios. 


\begin{tabular}{|c|c|c|c|}
\hline & \multirow{2}{*}{$\begin{array}{r}\text { Base year }{ }^{1} \\
\text { (2009) }\end{array}$} & \multicolumn{2}{|c|}{ Scenario for the year $2030^{2}$} \\
\hline & & $\begin{array}{r}\text { Business as usual } \\
\% \text { change } \\
\end{array}$ & $\begin{array}{r}\text { S2030 } \\
\text { \% change } \\
\end{array}$ \\
\hline Population & $38,610,100$ & $+63 \%$ & $+29 \%$ \\
\hline $\begin{array}{l}\text { Consumption of ruminant } \\
\text { products per capita }(\mathrm{kg})\end{array}$ & $\begin{array}{l}\text { Meat: } 17 \\
\text { Milk: } 53\end{array}$ & $\begin{array}{r}\text { Meat: }+23 \% \\
\text { Milk: }+10 \%\end{array}$ & $\begin{array}{r}\text { Meat: }+101 \% \\
\text { Milk: }+77 \%\end{array}$ \\
\hline $\begin{array}{l}\text { Production of ruminant } \\
\text { products (tonnes) }\end{array}$ & $\begin{array}{r}\text { Meat: } 374,840 \\
\text { Milk: } 1,831,870\end{array}$ & $\begin{array}{r}\text { Meat: }+93 \% \\
\text { Milk: }+59 \%\end{array}$ & $\begin{array}{r}\text { Meat: }+147 \% \\
\text { Milk: }+122 \%\end{array}$ \\
\hline Meat WF (m³/tonne) & & & \\
\hline $\begin{array}{l}\text { Green } \\
\text { Blue }\end{array}$ & $\begin{array}{r}32,069 \\
501\end{array}$ & $\begin{array}{l}0 \% \\
0 \%\end{array}$ & $\begin{array}{l}-42 \% \\
-38 \%\end{array}$ \\
\hline Total & 32,570 & $0 \%$ & $-41 \%$ \\
\hline Meat LF (ha/tonne) & & & \\
\hline Grazing & 4.86 & $0 \%$ & $-62 \%$ \\
\hline Crop & 0.36 & $0 \%$ & $+105 \%$ \\
\hline Total & 5.22 & $0 \%$ & $-50 \%$ \\
\hline Milk WF (m³/tonne) & & & \\
\hline Green & 1,139 & $0 \%$ & $-47 \%$ \\
\hline Blue & 31 & $0 \%$ & $-39 \%$ \\
\hline Total & 1,170 & $0 \%$ & $-47 \%$ \\
\hline Milk LF (ha/tonne) & & & \\
\hline Grazing & 0.17 & $0 \%$ & $-65 \%$ \\
\hline Crop & 0.02 & $0 \%$ & $+63 \%$ \\
\hline Total & 0.19 & $0 \%$ & $-49 \%$ \\
\hline
\end{tabular}

${ }^{1}$ Sources: base year data on population from (GOK 2010c); WF and LF data from (Bosire et al. 2015); consumption of meat and milk per capita from (Argwings-Kodhek et al. 2005, Gamba 2005)

${ }^{2}$ Sources: estimated changes of population, and total production of meat milk are taken from the output of the T21 model; changes in WF and LF per tonne of product are taken from Bosire et al., (2016); changes in consumption of meat and milk per capita from Erb et al. (2009) and (GOK 2010b), respectively. 

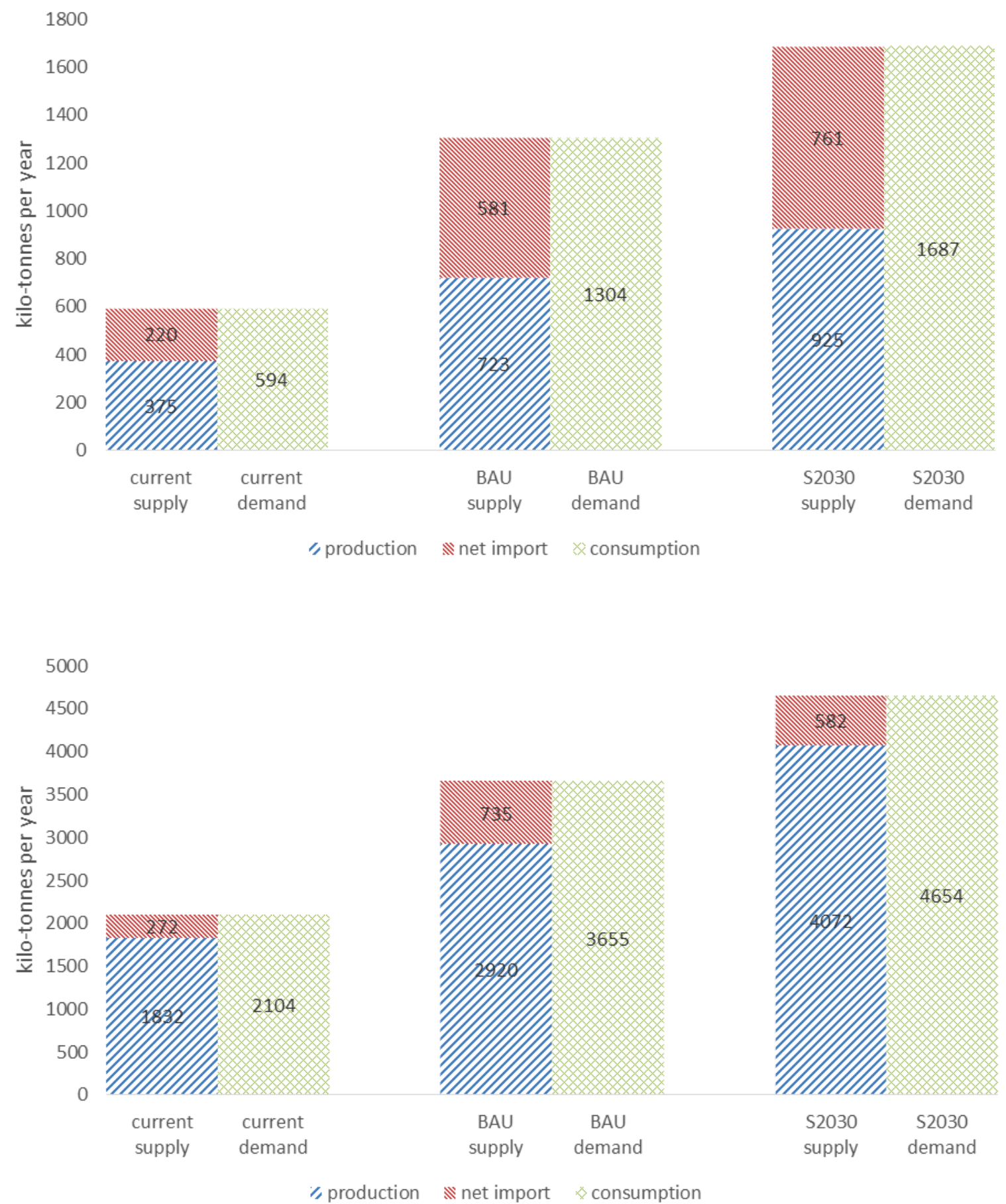

Figure 1. The production, consumption and net import of meat (upper graph) and milk (lower graph) in 2009 and in $\mathbf{2 0 3 0}$ for the BAU and $\mathbf{S 2 0 3 0}$ scenarios. 


\subsubsection{Population}

Population growth is determined by birth and mortality rates. In the BAU scenario, population growth is presumed to continue under the current high fertility rate of 4.6 children per woman, resulting in a population growth of 63\% between 2009 and 2030 (GOK 2012). The S2030 scenario is based on a reduction of the fertility rate towards 2.1 children per woman in 2030, resulting in a population growth of 29\%. Achieving the lower population growth as assumed under the $\$ 2030$ scenario presupposes increasing the effective contraceptive use rate from $27 \%$ under the BAU scenario to $40 \%$ under the S2030 scenario.

\subsubsection{Production of meat and milk}

The agricultural sector in Kenya has seen annual growth rates varying between $0.7 \%$ and $5.3 \%$ in the $1990 \mathrm{~s}$ (Ndung'u et al. 2011). In the BAU scenario, meat and milk production are assumed to continue growing and become $93 \%$ and 59\% larger than the current production, respectively, by 2030 . For the S2030 scenario we use production growth rates assuming increased budgetary allocation as described in Züllich et al. (2014). Meat and milk production under the S2030 scenario are assumed to grow between the base year and 2030 by $147 \%$ and $122 \%$, respectively. This assumption is motivated by the second and fourth strategies in the agricultural sector improvement plan in the Vision 2030 document. The second strategy aims to increase productivity of crops and livestock while the fourth strategy focuses on preparing new lands for cultivation by strategically developing irrigable areas of arid and semi-arid lands for both crops and intensified livestock production.

For the BAU scenario we assume that the prevailing feed crop yields remain unchanged and therefore that the water and land footprints per unit of feed crop stay at their current levels. In the S2030 scenario, we assume improvements in feed crop yields according to the "good" water productivity improvement percentage in Ercin and Hoekstra (2014). The water and land footprints per unit of meat and milk associated with improved livestock productivity under technology improvements are derived from scenario S1 in Bosire et al. (2016b) for the BAU scenario and from scenario S3 for the S2030 scenario. The relative distribution of production over the arid, semi-arid and humid production systems is assumed to remain the same as in the base year. 
Overall, the average water and land footprints per tonne of meat and milk are lower for the S2030 than the BAU scenario (Table 1). As we assumed no technological improvements in production in the BAU scenario, there is no difference in the water and land footprints per tonne of meat and milk between the BAU scenario and base year. In S2030, however, the water footprints per tonne of meat and milk will get reduced by $41 \%$ and $47 \%$, respectively. The land footprint per tonne of meat and milk will decrease in this scenario by $50 \%$ and $49 \%$, respectively. However, the overall smaller land footprint of meat and milk production in the S2030 scenario is the net result of large decreases in the grazing land footprint, but very substantial increases in the cropland footprint, related to the increased fraction of feed crops in the diet of the animals in this scenario.

Due to large discrepancies in the various data sets on livestock production in the base year (2009), we use the meat and milk production values from Bosire et al. (2015) and project production to 2030 using the production growth rates from Züllich et al. (2014). The large discrepancies are brought about by the inaccuracies inherent in the country level data prior to the 2009 livestock census. The estimates from Bosire et al. (2015) are based on consistent livestock censuses by the Kenya Directorate of Resource Surveys and Remote Sensing (DRDRS) covering the period 1977 to 2012.

\subsubsection{Consumption of meat and milk}

For the baseline year 2009 we used the data on consumption of meat and milk from Gamba (2005) and Argwings-Kodhek et al. (2005). Since consumption of livestock products has not yet been developed in the T21 model, changes in consumption had to be determined outside the model. Per capita meat and milk consumption in the BAU scenario is assumed to grow with the same growth rates as were calculated for the period 1980-2009 (Shah and Frohberg 1980, Argwings-Kodhek et al. 2005, Gamba 2005). The growth of meat and milk consumption per capita in the S2030 scenario was estimated assuming full implementation and realization of the Vision 2030 strategy.

Total consumption of meat and milk in the BAU scenario are projected to grow by $119 \%$ and $74 \%$, respectively (Alexandratos and Bruinsma 2012a). Due to lack of country-specific projections, total meat consumption under the $\mathbf{S} 2030$ scenario is assumed to grow by $184 \%$ to meet the "less meat" scenario for Sub-Saharan Africa described in Erb et al. (2009b). The less meat scenario has been selected because it is the most plausible scenario for Kenya's meat consumption into the future as opposed to the other 
scenarios in Erb et al. (2009b) which give as high as $400 \%$ increase in per capita meat consumption. Total milk consumption in the $\mathbf{S} 2030$ scenario is projected to more than double, as targeted under Kenya's dairy development strategy (GOK 2010b), with an increase of $121 \%$ by 2030 relative to the base year.

\subsubsection{Food balance analysis}

In the Kenya Agricultural Sector Development Strategy, the government advocates self-sufficiency through maintaining a balance between demand and supply of livestock products (GOK 2010a). However, in neither of the two scenarios does the expected growth in production of meat and milk keep up with the expected growth in consumption. To understand the implications of changes in consumption and production on food self-sufficiency, we use a food balance approach (subtracting total production from total consumption) to determine required imports of meat and milk by 2030.

\subsubsection{Assessment of water and land footprints of livestock production and consumption}

The water and land footprints of livestock production in the two scenarios are estimated following the same method as in Bosire et al. (2015). The water footprint is an indicator of appropriation of freshwater, from either a production or consumption perspective (Hoekstra et al. 2011). We consider here both the blue water footprint, the consumption of blue water resources (groundwater and surface water), and the green water footprint, the consumption of green water resources (rainwater in the soil). The land footprint is defined here as the actual land used from either production or consumption point of view (Erb 2004). We will distinguish between two components in the land footprint: grazing land and cropland.

For both meat and milk, we calculate the water footprint of production and consumption as:

$W F_{\text {prod }}[p]=P[p] \times W F_{\text {prod }}[p]$

$W F_{\text {cons }}[p]=C[p] \times W F_{\text {cons }}[p]$

whereby $P[p]$ is the production of product $p$ in the country (tonne/yr), $C[p]$ is the consumption of product $p$ (tonne/yr), $W F_{\text {prod }}[p]$ is the average water footprint of the product produced in the country $\left(\mathrm{m}^{3} /\right.$ tonne), and $W F_{\text {cons }}[p]$ is the average water footprint of the product consumed in the country. The products are meat and/or milk from cattle, sheep and goats and camel. Whereas $W F_{\text {prod }}[p]$ depends on the water footprint of production in the country (averaged over different regions and production systems), $W F_{\text {cons }}[p]$ 
depends on the water footprint of production in the country and on the water footprint of the production in other countries for imported products.

Similarly, we calculate the land footprint of production and consumption as:

$L F_{\text {prod }}[p]=P[p] \times L F_{\text {prod }}[p]$

$L F_{\text {cons }}[p]=C[p] \times L F_{\text {cons }}[p]$

The dependency of Kenya's consumption of meat and milk on domestic versus foreign freshwater and land resources is derived from the ratios of domestic production versus imports.

\subsubsection{Assessment of economic water and land productivity of meat and milk production}

Economic water and land productivities of meat production in Kenya are estimated by dividing the total value of meat production (Kshs/y) by the total water and land footprint associated with meat production, respectively, and similarly for milk production. The values of meat and milk production are derived by multiplying the unit price of meat and milk and their total production. Prices of milk and meat are assumed to be constant. Although we expect increases in milk and meat prices during the projection period, we assumed no price changes, since we are interested in comparing the two scenarios for each livestock product. Additionally, the difference in price between meat and milk is consistent with the conclusions of Syrstad (1993). The price of $1 \mathrm{~kg}$ of beef ranges between three to five times that of $1 \mathrm{~kg}$ of milk.

\subsection{Results}

\subsubsection{Water and land footprints of meat and milk production in Kenya by 2030}

Compared to the base year, the total water footprint of meat production increases by $93 \%$ in the BAU scenario and $45 \%$ in the $\mathrm{S} 2030$ scenario. The total water footprint of milk production increases by $59 \%$ in BAU and decreases by $18 \%$ in S2030 (Table 2). The total land footprint shows a similar trend: the total land footprint of meat production increases over the period $2009-2030$ by $93 \%$ in the BAU scenario and $23 \%$ in the $\mathbf{S} 2030$ scenario. The total land footprint of milk production grows by $59 \%$ under the BAU scenario and by $12 \%$ in $\mathrm{S} 2030$. 
Between 2009 and 2030, the economic value of meat production increased by $93 \%$ and $147 \%$, whilst the economic value of milk production increased by $59 \%$ and $122 \%$ under the BAU and S2030 scenarios, respectively. Both meat and milk production had higher economic water productivity under the S2030 than the BAU scenario. Though the economic water productivity of meat production is smaller than in milk production, the water productivity in both sectors grows by more or less the same rate in the S2030 scenario. Economic water productivity of milk in 2030 is higher in S2030 (148 Kshs/m³) than in BAU (78 $\mathrm{Kshs} / \mathrm{m}^{3}$ ) scenario. Economic land productivity grows fast (by 100\%) for meat production in the S2030 scenario.

Table 2 Water and land footprints and water and land productivity of meat and milk production at present and by 2030 under the BAU and $\mathbf{5 2 0 3 0}$ scenarios.

\begin{tabular}{|c|c|c|c|}
\hline & Base (2009) & BAU & S2030 \\
\hline WF of meat production (million $\mathrm{m}^{3} /$ year) & 12,210 & 23,540 & 17,640 \\
\hline WF of milk production (million $\mathrm{m}^{3} /$ year) & 2,140 & 3,420 & 2,520 \\
\hline LF of meat production $\left(10^{3}\right.$ ha/year) & 1,960 & 3,770 & 2,410 \\
\hline LF of milk production ( $10^{3} \mathrm{ha} /$ year) & 350 & 560 & 400 \\
\hline Economic value of meat (million Kshs) & 174,300 & 336,070 & 430,290 \\
\hline Economic value of milk (million Kshs) & 167,520 & 267,060 & 372,400 \\
\hline Economic water productivity of meat (Kshs $\left./ \mathrm{m}^{3}\right)$ & 14 & 14 & 24 \\
\hline Economic water productivity of milk (Kshs/m $\mathrm{m}^{3}$ ) & 78 & 78 & 148 \\
\hline Economic land productivity of meat (Kshs/ha) & 89,080 & 89,080 & 178,240 \\
\hline Economic land productivity of milk (Kshs/ha) & 475,540 & 475,540 & 940,850 \\
\hline
\end{tabular}

\subsubsection{Water and land footprints of meat and milk consumption in Kenya by 2030}

The water footprint of meat consumption per capita is about 5\% smaller in the $\mathbf{S} 2030$ scenario than in the BAU scenario despite the fact that the milk consumption per capita is more than $60 \%$ larger (Figure 2 ). Similarly, the water footprint of milk consumption per capita is $16 \%$ smaller in the $\$ 2030$ scenario than in the BAU scenario. The land footprint of meat consumption per capita is $22 \%$ smaller in the $\mathrm{S} 2030$ scenario than in the BAU scenario. The largest difference in land footprint per capita is between the per capita cropland footprint for milk in the S2030 scenario and the BAU scenario. The cropland footprint in the S2030 scenario almost quadruples relative to the base year for meat consumption because of the increased use of feed crops in livestock production. 


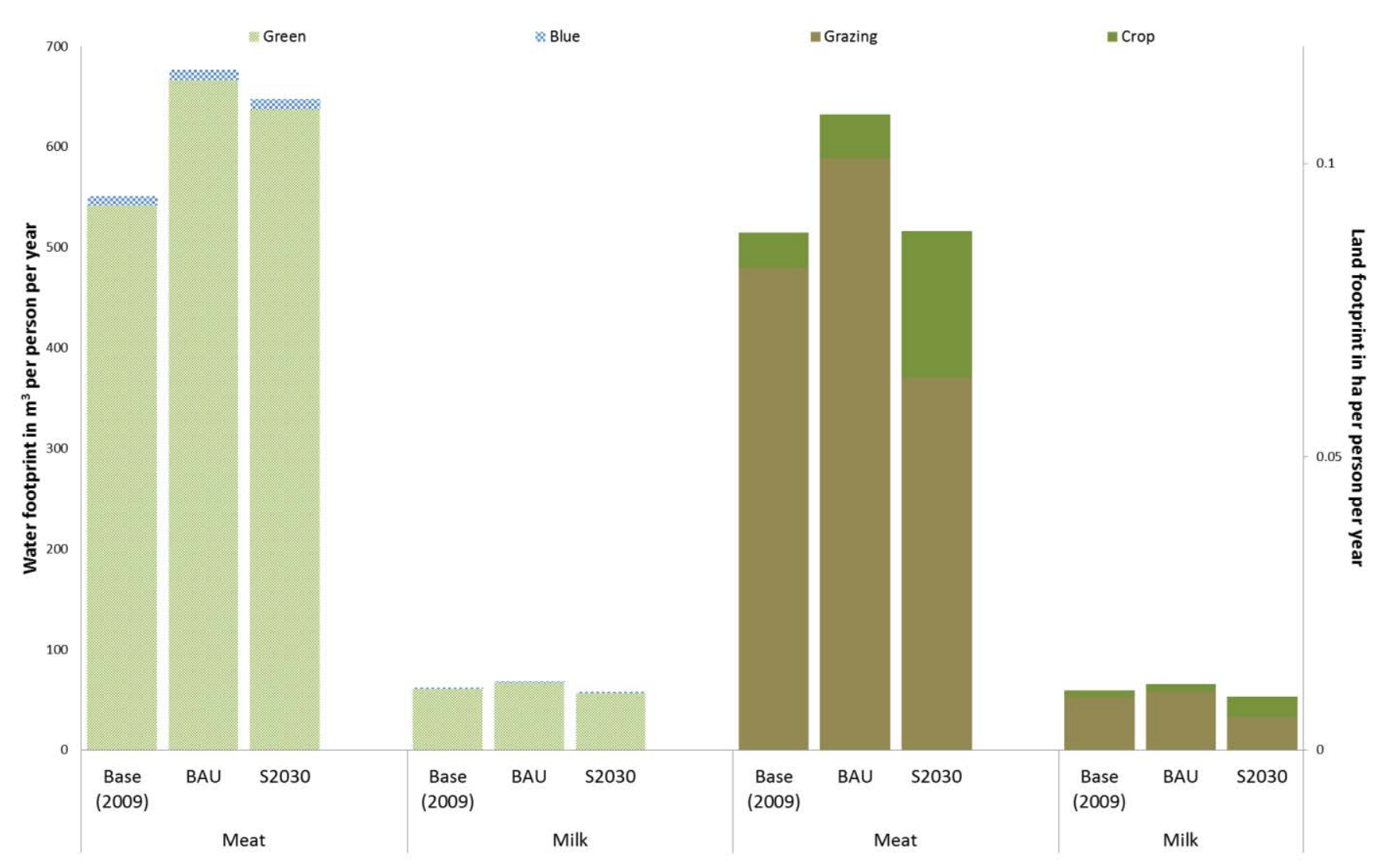

Figure $\mathbf{2}$ Water and land footprints per capita for meat and milk consumption in $\mathbf{2 0 3 0}$ for the BAU and S2030 scenarios.

Table 4 shows the domestic and foreign water footprints of meat and milk consumption in Kenya under the two scenarios. The ratios of the domestic and foreign water footprints of meat consumption in the base year differ slightly from that in the BAU and S2030 scenarios. The ratios of the domestic and foreign water footprints of both meat and milk consumption in the BAU and S2030 scenarios in 2030 are similar. Under the base year (2009) there is a 43\% dependence on foreign water resources to meet the meat demand as opposed to a $45 \%$ consumptive use of foreign water resources under the BAU and S2030 scenarios. Consumption of milk however shows greater dependence on foreign water resources under the BAU scenario (20\%) than under the S2030 scenario (12\%).

Table 5 shows the domestic and foreign land footprints of meat and milk consumption in Kenya under the two scenarios. In both scenarios, the foreign land dependence of meat consumption marginally grows from $43 \%$ in the base year to $45 \%$ in 2030 . Milk consumption relies more strongly on domestic land 
resources, both in the base year and the future, although the foreign land dependence will grow in both scenarios. 


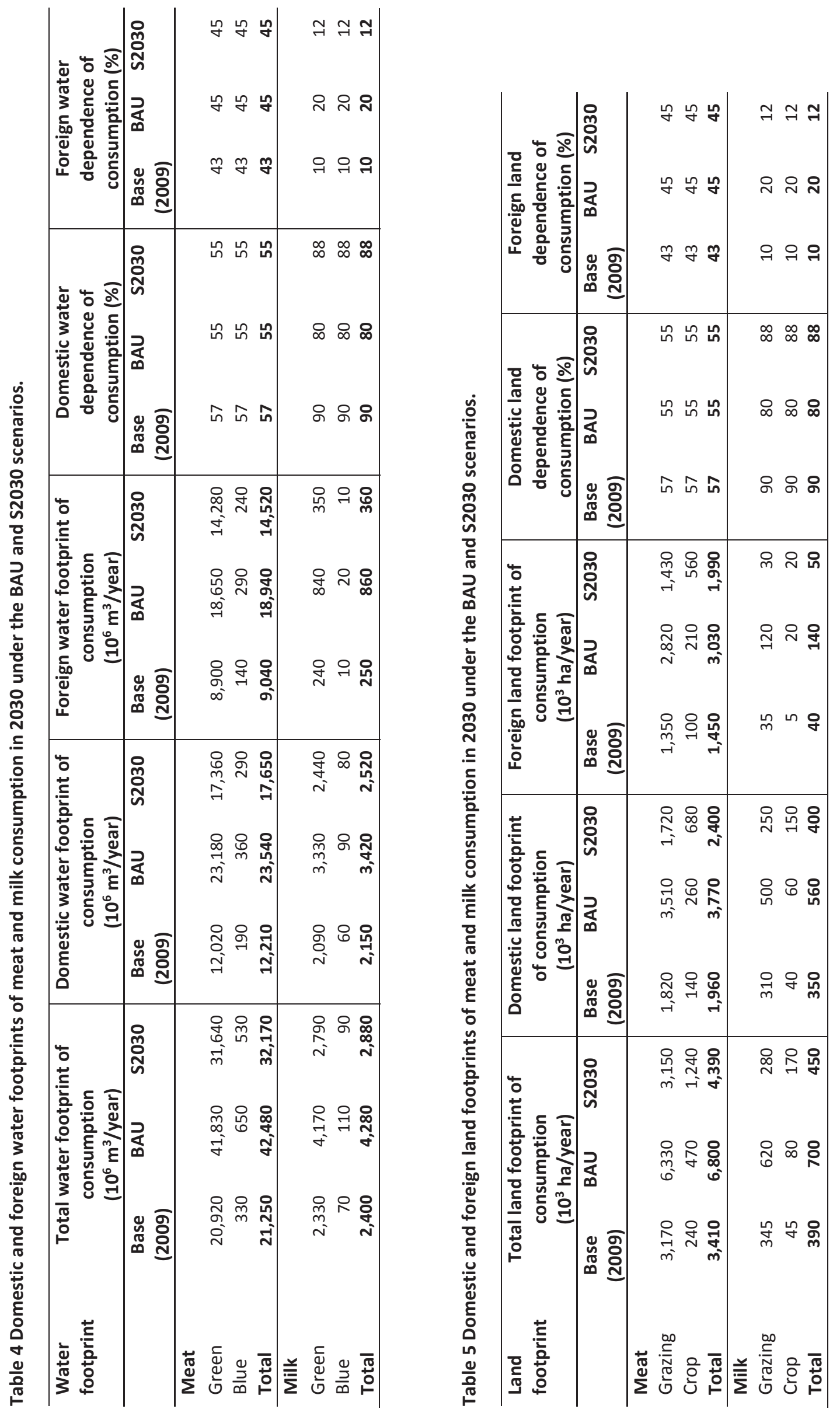




\subsection{Discussion}

\subsubsection{Population growth under the BAU and S2030 scenarios}

An important challenge is the combination of population growth and increasing affluence. The future size of Kenya's population will inevitably affect the ability of Kenya to feed itself (Schell et al. 2007). The available resources make it difficult to meet the self-sufficiency target. The main cause of population growth is that the average birth rate in Kenya remains high whilst the average mortality rate has dropped due to implementation of the Millennium Development Goals (GOK 2013). If Kenya is to achieve the Vision 2030 goal of an increase in income with associated increase in meat and milk consumption per capita, a more stringent demographic policy would be required than assumed in the S2030 scenario. This can be achieved if the birth rate is further lowered, commensurate with the reduced mortality rates.

\subsubsection{Consumption changes under the two scenarios}

Globally, consumption of meat and milk has grown since the 1970s, albeit at rates that vary across countries (Alexandratos and Bruinsma 2012a). Meat consumption in the developing regions has grown at a slightly faster rate (average rate of 5.1\% per annum over the period 1979-1997) than milk consumption (about 3.6 \% per annum over the same period). However, between 1997 and 2007, the growth rate in meat consumption in these countries decreased to $2.9 \%$ per annum (Alexandratos and Bruinsma 2012a). The demand for meat in Kenya, in particular, is assumed to be rising at an unprecedented rate (GOK 2010a), though various studies that focus on changes in meat consumption suggest that it may not be growing at the perceived high rate (Alexandratos and Bruinsma 2012a). One possible explanation for this discrepancy is that the growth in the middle class segment of Kenya's population may be pushing the perceived increase in demand. However, when averaged over all the income segments, the fast increase in demand is no longer apparent.

\subsubsection{Production changes under the two scenarios}

The increased consumption must be met by increased production or imports. An increase in production often forms a critical component of efforts to alleviate poverty. Indeed, agriculture-led growth in Africa is currently more than twice as effective in reducing poverty as growth led by industry (Conceição et al. 2016). The key to sustaining and enhancing growth in agricultural performance in 
Kenya will most likely lie in increasing smallholder productivity and investing in developing non-farm activities (IFAD, 2013).

Improvements in the livestock sector are contingent upon the production of sufficient quantities of compounded livestock feeds. Increasing livestock productivity should therefore also entail concurrently increasing productivity in the crop sector, increasing feed crop quality and decreasing water and land demand per unit of feed. In Kenya, maize is the major component of compounded livestock feeds, as well as the main staple food. Maize productivity is unfortunately declining in many parts of Kenya despite the rising demand, due to widespread land subdivision, land degradation through soil erosion and other factors (Jones and Thornton 2009, Maitima et al. 2009). To meet both the food and feed demands in Kenya, it will thus be necessary for farmers to be supported to increase productivity of cereals higher than the levels envisioned in Kenya's Vision 2030 strategy and Agricultural Sector Development Strategy. Realizing the potential for large-scale production of feed crops such as maize and wheat may lie in using the less exploited areas like Turkana and Tana River, where farmers may be able to use their excess produce to make animal feed and where land subdivision is still relatively less extreme.

\subsubsection{Options to attain food self sufficiency}

Meeting the food balance deficit can be achieved either through import or through increasing the productivity of both crops and livestock. A country may decide to import goods or services that are either essential to the country's economic well-being or products that are highly sought after by the citizens but are not sufficiently available in the domestic market. Additionally, a country may decide to import products that can be produced at a relatively low cost or more efficiently by another country, and therefore are sold at lower prices. In both cases, meeting the deficit through imports will require that the source areas are able to produce surpluses and that the country requiring the product is able to purchase the commodities (Bourguignon and Morrisson 1990). It is noteworthy, that some countries are able to produce surplus dairy and meat (such as Brazil, India and New Zealand) which are, in some instances, imported into Africa (Herrero et al. 2014). Currently, Kenya imports very low quantities of milk which is mainly in powder form (EADD 2008). However, meat imports in the form of live animals, are already equivalent to around $40 \%$ of the total demand. The trend of increasing import of meat is continued under the two scenarios, which also show an increase in milk imports. To ensure that Kenya 
is able to purchase the shortfall in internal supply, there will be a need for Kenya's income level to grow in tandem with the growth in deficit level.

Another option is to further increase domestic livestock production. In Africa, currently ranked as the continent with the lowest productivity per animal and therefore least productive in terms of livestock production in the world, there is still a large potential to improve productivity (Tittonell and Giller 2013). In Kenya, under both scenarios, there is a need to import meat and milk. Even with increased productivity under the $\mathbf{S} 2030$ scenario, there is still a need to import about $13 \%$ of milk and $45 \%$ of meat. Therefore, productivity will need to improve even faster than under the ambitious high productivity scenario S2030. However, several processes may diminish the likelihood of substantially enhancing livestock productivity. These include high population density associated with reduced fallow periods and land use intensification and the very limited level of successful non-farm diversification options to farmers that are forced off their farms (Headey and Jayne 2014).

\subsubsection{Water and land footprint associated with the two scenarios}

This study has shown that in Kenya, both meat and milk production are mainly dominated by grazing land and green water footprints, which have lower opportunity costs compared to cropland and blue water, especially in the arid and semi-arid regions. However, crop land footprints and blue water footprints are increasing under both scenarios, an increase related to the increasing use of feed crops. The increase in the proportion of compounded and supplemental feeds in livestock diet is associated with increases in meat and milk yields (Herrero et al. 2013). Supplying this increased proportion of compounded and supplemental feeds translates into an increased crop land footprint, with the potential to increase the competition for arable land for producing food crops. In the S2030 scenario, with a relatively high proportion of feed crops in the livestock diets, the risk of this type of conflict is higher than in the BAU scenario. In terms of the water footprint of meat and milk production, increasing the production of maize through irrigation in arid and semi-arid areas, which is also partly used as livestock feed, would increase the blue water footprint in both crop and livestock production. These production systems in Kenya are already blue water scarce (Hoekstra et al. 2012) and so increasing the use of irrigation would further elevate this scarcity and escalate the ongoing conflicts caused by water scarcity.

An alternative to way of achieving greater food security in Kenya that has not yet received adequate attention in governmental policies yet is to promote crop-based protein sources instead of animalbased protein sources. Since the former have a much smaller water and land footprint per unit of 
protein than the latter (Erb et al. 2012, Mekonnen and Hoekstra 2012), this offers a perspective on reducing the environmental footprint of a population through the diet (Steinfeld and Gerber 2010, Hoekstra 2014). Policies that aim to influence diets could thus supplement policies that aim to increase productivity.

\subsubsection{Economic water and land footprint associated with the two scenarios}

The total economic value of meat and milk production in Kenya in the base year is valued in this study at 342 billion Kenya shillings, an estimate which does not vary greatly from the estimate by Behnke and Muthami (2011). However, the main contribution to this economic value in this study is meat production as opposed to milk production as in Behnke and Muthami (2011). This apparent discrepancy in the economic estimates is caused by the difference in the data sources used to obtain the two estimates. Under the projections in the BAU and S2030 scenarios, the economic value of livestock products in Kenya is set to be, respectively, $78 \%$ and $136 \%$ larger than the 2009 levels, mainly due to increase in production as price has been assumed to remain constant for this analysis.

The economic water productivity of milk is much higher than that of meat, both in the base year and in both scenarios (Table 2). This implies that milk production in Kenya generates higher value per unit of water used compared to meat production. The same is observed for the economic land productivity of milk versus meat. This observation may suggest that it would be more economically sound to shift to or increase milk production and reduce meat production in Kenya and probably focus on importing the latter. However, in reality this is much more complex due to the varied agro-economic conditions in the production systems in Kenya. It would be possible to shift to specialization in milk production for farmers in the highland areas of the country because of favourable climatic and soil conditions. In the arid and semi-arid lands though, low and widely variable rainfall and land degradation make livestock rearing for meat environmentally more appropriate (mainly green water and grazing land used) in comparison to milk production.

\subsubsection{Limitations}

Underlying the $\mathbf{S} 2030$ scenario is the assumption that the necessary investments will be undertaken, and that policies will be successfully implemented. We however are cognizant of several issues that may introduce some bias into the outcomes of the projections used in this study. Firstly, completely missing is a consistent database on projections for consumption of livestock products in Kenya. Secondly, policy options for meat production and consumption are generally very limited. This hampers the use of such models as the T21 model and therefore limits our capacity to reliably project 
likely future consumption related to the two products. Additionally, reliable estimates on the total production estimates for meat production are scanty and inconsistent. There is more information pertaining to milk production and consumption in Kenya, mainly as an outcome of higher investment in the dairy sector in the more humid highland regions. Finally, we have not included the possible effects (negative and/or positive) of climate change in our long term meat and milk productions projections. The T21 model does not currently account for such factors, but we recognize that our results could change if we were to account for the potential impacts of climate change in our projections.

In this study, our milk and meat production estimates are aggregated over three production systems in Kenya. Each system has a varying range of conditions, bio-physical and socio-economic, that favour the production of either meat or milk and plausible changes may be expected to show different trends per production system. Future research could focus on trends that differentiate amongst the type of production systems of meat and milk production and additionally include effects of both climate change on projected longer term patterns.

\subsection{Conclusions}

If the budget for agriculture is increased to meet the recommendations of the Comprehensive Africa Agriculture Development Programme, meat and milk production in Kenya in 2030 can be expected to grow 1.5 to 2 times faster than if the budgets are maintained at their current levels. However, this magnitude of increase in production is not sufficient to meet the projected growth in demand for these two products, and diminishes the self-sufficiency aimed for in Kenya's policy strategy. It may be possible to achieve the self-sufficiency target in meat and milk production under a more modest increase in population numbers than that forecasted by the S2030 scenario. The projected growth in population and in meat and milk production under the two scenarios does not match the growth in consumption, leading to a widening of the gap between local supply and demand for these two products.

In order to meet meat demand, it may be worthwhile considering import of meat from the neighbouring countries or increasing production in the humid production system where the economic costs of production may be lower, but where the competition with food demand will be greater. Because meat has lower economic water and land productivities than milk, it may be worthwhile for Kenya to consider importing meat and enhancing milk production, especially in the humid systems, to meet the increased demand. 
Strategies that focus on increasing livestock and crop productivity lead to lowered water and land footprints per unit of production, which creates room for increased production. However, land and water resources in Kenya are already scarce and overexploited in some places. Besides, climate change may adversely impact on the availability of water resources in the future.

The results of this study show that the amount of water and land for producing meat and milk in Kenya will grow under both scenarios considered, but less in S2030 than in BAU, despite the stronger growth of meat and milk consumption per capita in S2030. This can be explained by the smaller population growth in S2030 and the greater improvements in water and land productivities in S2030. The Vision 2030 strategy for improving livestock production in Kenya is of great importance to reduce the speed with which the environmental footprint of the sector will increase, but it will be insufficient to stabilize or even reduce the sector's footprint. Besides, reducing the dependency on foreign land and water resources would require a yet more ambitious policy. 


\section{Discussion and conclusion}

\subsection{Overview of the main findings}

The discussion section is outlined based on overarching topics that are crosscutting through the various chapters. The main topics are production and consumption of livestock products and their associated environmental implications. The growing human population is exerting mounting pressure on various resources, including scarce resources in livestock production systems. To satisfy the growing demand for more livestock products, especially in developing countries, it is crucial and urgent to enhance the efficiency with which scarce natural resources are used in livestock production systems. This can be achieved through intensification of livestock production enterprises, as has been done in the industrialised systems in developed countries. Assessing the changes in efficiency of livestock production practices is thus an essential first step. Accordingly, this study assesses efficiency in livestock production in the three major production systems in Kenya, namely the arid, semi-arid and humid production systems, during the 1980s and 2000s. Past developments in livestock production in Kenya that have led to diverse production practices are analysed in chapter 2 . For these systems, the analysis documents severe declines in productivity in the arid and semi-arid lands but concurrent increase in productivity in the humid system where intensification has been achieved. Even so, a large portion of areas with high agricultural potential located mainly in the humid system are now considered as consisting of economically unviable farm sizes due to repeated land subdivision. In chapter 3, scenario analysis is used to quantitatively and comparatively evaluate pathways through which Kenya can enhance meat and milk production under the prevailing constraints. This analysis exposes huge gaps in productivity between developing countries, such as Kenya, and most of the developed countries (Godfray et al. 2010, Tittonell and Giller 2013). To bridge these gaps, we show that, in Kenya, where about $80 \%$ of the country is classified as arid and semi-arid lands, there is a good potential to more than double total meat production relative to the current levels by improving productivity per animal. Similarly, for the humid system in which most milk is produced, it is possible to increase production by about $50 \%$ through intensification. Chapter 5 highlights the need to raise productivities of the Kenyan production systems for meat and milk as described in chapter 3 to be able to meet the projected future demands for both commodities in Kenya in the near future. This is especially so if the country is to achieve the strategic goals outlined for increasing agricultural production in into the country by the year 2030 . 
The role of livestock in improving nutrition and alleviating poverty in developing countries like Kenya is well recognized and documented (Neumann et al. 2002, Randolph et al. 2007). However, consumption of meat and milk is not uniform across demographic segments. This is not surprising since the amount of animal source foods (ASFs) in diets increases with the level of income. Chapter 4 characterizes this difference in meat and milk consumption across income groups and its changes over a 30-year period. Urban growth also has an influential impact on the consumption of ASFs. Expansion in the number of people living in urban areas and the geographical extent of the urban areas, leads to decoupling urban consumers from the production areas. The importance of trade in meeting the growing urban consumptive demand increases (Seto et al. 2012). For instance, net imports of both meat and milk are projected to increase with growing per capita income in Kenya (chapter 5). The strategic goal to double milk consumption per person in the future contributes to an increased deficit in local production. The increase in import of meat to meet local demand can also be seen when we consider changes in consumption patterns of ASFs for Nairobi over a 30 year period (chapter 4). The increase in imports is linked to a decline in local production of meat in Kenya over this 30 year period. Considering the growth of the urban area in chapter 4, consumption of meat has not grown as much as is anticipated given the growth trajectories in other regions with similar urban growth (Delgado 2003). Alexandratos and Bruinsma (2012a) support the observation in chapter 4 and indicate that the growth in meat consumption expected from urban growth is usually not witnessed in most developing countries.

The livestock sector is considered to be one of the leading contributors to the increase in environmental degradation (Steinfeld et al. 2006b, Pelletier and Tyedmers 2010) and demand for freshwater resources (Mekonnen and Hoekstra 2012). In view of these contrasting traits associated with livestock, it can be expected that an increase in production to meet rising nutritional needs in developing countries will need to be met through sustainable intensification (Pretty et al. 2011, Tarawali et al. 2011). Chapter 3 presents and describes a few contrasting models for increasing livestock productivity and shows that it is possible to increase productivity in Kenya through sustainable intensification. The anticipated productivity increases are, however, likely not going to be uniform throughout the country and thus should be more appropriately considered at the production system level. At this scale, a better understanding of the appropriate intervention and level of investment can be determined. The amounts of freshwater and land resources used for production are determined mainly by production volumes, feed conversion efficiencies and related feed composition. Also, green water and grazing land footprints dominate production of meat and milk in Kenya. The increase in the water and land footprint associated with the decline in productivity over 
the 30-year period, demonstrated in chapter 2 is an indication of the inability of the current model of meat and milk production in Kenya to sustainably meet the increase in demand for livestock products. The avenues through which to increase meat and milk production at a lower environmental cost are described in chapters 3 . Though the efficiency improvement outlined in this chapter may increase competition between feed and food production for available cropland, there is a lowered demand for grazing land especially in the grasslands determined to be suitable for cultivation. This potentially avails some cropland for production of feed and food, thereby minimizing the possibility of conflicts between the production of these products. However, chapter 5 indicates that though the competition for resources to produce feed and food may be minimized, the productivity improvements proposed will still fall short of sustainably meeting the projected increased demand for ASFs.

Increase in imports through trade is often associated with a translocation of environmental pressure (Hoekstra and Chapagain 2008, Erb et al. 2009a). The translocation in resource demand is mainly linked to high-income countries (Weinzettel et al. 2013). As economic growth occurs in Kenya (Chapter 5), there is an associated increase in the foreign water and land dependency towards meeting the growth in demand for both meet and milk. Therefore, given the high scarcity levels of water and the conflict arising from the use of land for livestock production in the three production systems, the current policies aimed at increasing the proportion of meat and milk in the diet need to consider options such as import to ensure sustainability in meeting demand growth. These include increasing import from the more resource-endowed neighbours, and/or on improving efficiency within the meat and milk production chains to minimize damage to natural ecosystems due to increasing meat and milk production (Herrero et al. 2014). The latter can be achieved through improving feed conversion efficiencies by rehabilitating degraded rangelands, adopting improved breeds and using appropriate feed composition to ensure resource use efficiency under the water and land scarcity in Kenya.

\subsection{Limitations and future research}

There were several limitations encountered during this study. These have been used to make recommendations for improving future research on resource use in livestock production. Firstly, reliable time series data on resource use in livestock production systems are often either absent or incomplete, thus representing a serious limitation. For in-depth analysis of the changes associated with production and consumption of livestock products, there is a need for consistent and reliable data collection and reliable sources of information. In assessing changes associated with production, lack of information on yearly productivity changes in the different production systems restricted the scope of analysis. The disaggregation of income into classes was not similar for the 1980s and 2000s, limiting 
the household-scale analysis of the changes associated with segregation patterns between the two periods. As the current study has provided a baseline for analysis of production at disaggregated levels, it would be useful to have future analysis at this scale to enable comparisons. This will also facilitate the development of targeted interventions and policies. The land footprint as currently defined and used is purely an area-based metric. Further analysis that considers land use types with differing productivities will lead to improved method aimed at assessing land demand. This will greatly aid in relinking consumers and producers to their associated demand for natural resources (Kastner et al. 2015). Given the increasing importance of trade and the resultant telecoupling -interdependencies between apparently delinked consumption and production- future analyses of the land footprint of consumption should consider using the land productivity differences approach in order to gain a better understanding of the environmental implications of trade. This will likely also put land footprint analysis at par with water footprint analysis and enable more reliable analyses that use composite indicators of human appropriation of natural resources. Additionally, a land assessment that takes into account the competition between human food production and animal feed production will aid in better attribution of livestock's contribution to food supply (van Zanten et al. 2016). 


\section{References}

Aklilu, Y., P. Irungu, and A. Reda. 2002. An audit of the livestock marketing status in Kenya, Ethiopia and Sudan. Community-Based Animal Health and Participatory Epidemiology Unit, Pan African Programme for the Control of Epizootics (PACE), Organization of African Unity/Interafrican Bureau for Animal Resources (AU-IBAR), Nairobi.

Alexandratos, N. and J. Bruinsma. 2012a. World agriculture towards 2030/2050: the 2012 revision. ESA Working paper Rome, FAO.

Alexandratos, N. and J. Bruinsma. 2012b. World food and agriculture to 2030/50: The 2012 revision. ESA Working Paper No. 12-03. FAO, Rome, Italy.

Angelsen, A. 1995. SHIFTING CULTIVATION AND DEFORESTATION - A STUDY FROM INDONESIA. World Development 23:1713-1729.

Argwings-Kodhek, G., F. M'mboyi, M. Muyanga, and P. Gamba. 2005. Consumption patterns of dairy products in Kenya's urban centres: Report from an urban household survey. Njoro.

Ayele, Z. and C. Peacock. 2003. Improving Access to and Consumption of Animal Source Foods in Rural Households: The Experiences of a Women-Focused Goat Development Program in the Highlands of Ethiopia. The Journal of Nutrition 133:3981S-3986S.

Bac, D., A. Badulescu, and E. Lang. 2011. Excesses and challenges of the economic growth. A brief history: From malthus to al gore. Actual Problems of Economics 117:281-289.

Bai, Z. and D. Dent. 2006. Global assessment of land degradation and improvement: pilot study in Kenya. ISRIC Report.

Bebe, B. O., H. M. J. Udo, G. J. Rowlands, and W. Thorpe. 2003. Smallholder dairy systems in the Kenya highlands: cattle population dynamics under increasing intensification. Livestock Production Science 82:211-221.

Behnke, R. and D. Muthami. 2011. The contribution of livestock to the Kenyan economy. IGAD LPI Working Paper.

Benjelloun, S. 2002. Milk and dairy products in the Mediterranean diet. Prospects for a Sustainable Dairy Sector in the Mediterranean:14-22.

Bertzky, B., C. Corrigan, J. Kemsey, S. Kenney, C. Ravilious, C. Besançon, and N. Burgess. 2012. Protected Planet Report 2012: Tracking progress towards global targets for protected areas. IUCN, Gland, Switzerland and UNEP-WCMC, Cambridge, UK.

Bett, H. K., M. P. Musyoka, K. J. Peters, and W. Bokelmann. 2012. Demand for Meat in the Rural and Urban Areas of Kenya: A Focus on the Indigenous Chicken. Economics Research International 2012:10. 
Biggs, S. 2007. Building on the positive: an actor innovation approach to finding and promoting pro-poor institutional and technical innovations. International Journal Agricultural Resources, Governance and Ecology 6:144-164.

Bilsborrow, R. E. and H. Ogendo. 1992. Population-driven changes in land use in developing countries. Ambio 21:37-45.

Black, R. E., C. G. Victora, S. P. Walker, Z. A. Bhutta, P. Christian, M. De Onis, M. Ezzati, S. Grantham-McGregor, J. Katz, and R. Martorell. 2013. Maternal and child undernutrition and overweight in low-income and middle-income countries. The Lancet 382:427-451.

Blümmel, M., E. Zerbini, B. Reddy, C. Hash, F. Bidinger, and A. Khan. 2003. Improving the production and utilization of sorghum and pearl millet as livestock feed: progress towards dual-purpose genotypes. Field Crops Research 84:143-158.

Borucke, M., D. Moore, G. Cranston, K. Gracey, K. Iha, J. Larson, E. Lazarus, J. C. Morales, M. Wackernagel, and A. Galli. 2013. Accounting for demand and supply of the biosphere's regenerative capacity: The National Footprint Accounts' underlying methodology and framework. Ecological Indicators 24:518-533.

Boserup, E. 1993. The conditions of agricultural growth: the economics of agrarian change under population pressure. The conditions of agricultural growth: the economics of agrarian change under population pressure.

Bosire, C., M. Lannerstad, J. De Leeuw, M. Krol, J. Ogutu, P. Ochungo, and A. Y. Hoekstra. 2016a. Urban consumption of meat and milk and its green and blue water footprints patterns in the 1980s and 2000s for Nairobi, Kenya. Science of the total Envronment.

Bosire, C., N. Mtimet, M. Krol, J. De Leeuw, J. Ogutu, P. Guthiga, and A. Y. Hoekstra. Submitted. Implications of livestock policy on future water and land footprints in Kenya Food Policy.

Bosire, C. K., M. S. Krol, M. M. Mekonnen, J. O. Ogutu, J. de Leeuw, M. Lannerstad, and A. Y. Hoekstra. 2016b. Meat and milk production scenarios and the associated land footprint in Kenya. Agricultural Systems 145:64-75.

Bosire, C. K., J. O. Ogutu, M. Y. Said, M. S. Krol, J. d. Leeuw, and A. Y. Hoekstra. 2015. Trends and spatial variation in water and land footprints of meat and milk production systems in Kenya. Agriculture, Ecosystems \& Environment 205:36-47.

Bourguignon, F. and C. Morrisson. 1990. Income distribution, development and foreign trade: A cross-sectional analysis*. European Economic Review 34:1113-1132.

Bouwman, A. F., K. W. Van der Hoek, B. Eickhout, and I. Soenario. 2005. Exploring changes in world ruminant production systems. Agricultural Systems 84:121-153. 
Bruckner, M., G. Fischer, S. Tramberend, and S. Giljum. 2015. Measuring telecouplings in the global land system: A review and comparative evaluation of land footprint accounting methods. Ecological Economics 114:11-21.

Bruinsma, J. 2003. World agriculture: towards 2015/2030: an FAO perspective. Earthscan.

Campbell, D. J., D. P. Lusch, T. A. Smucker, and E. E. Wangui. 2005. Multiple methods in the study of driving forces of land use and land cover change: A case study of SE Kajiado District, Kenya. Human Ecology 33:763-794.

Cassidy, E. S., P. C. West, J. S. Gerber, and J. A. Foley. 2013. Redefining agricultural yields: from tonnes to people nourished per hectare. Environmental Research Letters 8:034015.

CBS. 2010. Population by Administrative Units. Central Bureau of Statistics, Nairobi, Kenya.

Chapagain, A. and A. Y. Hoekstra. 2003. Virtual water flows between nations in relation to trade in livestock and livestock products. Value of Water Research Report Series No. 13, Delft, Netherlands.

Chapagain, A. M. and A. Y. Hoekstra. 2011. The blue, green and grey water footprint of rice from production and consumption perspectives. Ecological Economics 70:749-758.

Chertow, M. R. 2000. The IPAT Equation and Its Variants. Journal of Industrial Ecology 4:1329.

Chouchane, H., A. Y. Hoekstra, M. S. Krol, and M. M. Mekonnen. 2015. The water footprint of Tunisia from an economic perspective. Ecological Indicators 52:311-319.

Claessens, L., J. Stoorvogel, and J. M. Antle. 2008. Exante assessment of dual-purpose sweet potato in the crop-livestock system of western Kenya: A minimum-data approach. Agricultural Systems 99:13-22.

Conceição, P., S. Levine, M. Lipton, and A. Warren-Rodríguez. 2016. Toward a food secure future: Ensuring food security for sustainable human development in Sub-Saharan Africa. Food Policy 60:1-9.

Costa, N. D. 2007. Reducing the meat and livestock industry's environmental footprint. Nutrition \& Dietetics 64:S185-S191.

Crosson, P. and J. R. Anderson. 1994. Demand and Supply - Trends in Global Agriculture. Food Policy 19:105-119.

Dawson, N., A. Martin, and T. Sikor. 2016. Green Revolution in Sub-Saharan Africa: Implications of Imposed Innovation for the Wellbeing of Rural Smallholders. World Development 78:204-218. 
De Fraiture, C., D. Molden, and D. Wichelns. 2010. Investing in water for food, ecosystems, and livelihoods: An overview of the comprehensive assessment of water management in agriculture. Agricultural Water Management 97:495-501.

De Leeuw, P. and B. Rey. 1995. Analysis of current trends in the distribution patterns of ruminant livestock in tropical Africa. People 11:24.

De Leeuw, P. N. and J. C. Tothill. 1990. The concept of rangeland carrying capacity in subSaharan Africa: Myth or reality. Overseas Development Institute, Pastoral Development Network London.

De Leeuw, P. N. and R. T. Wilson. 1987. Comparative productivity of indigenous cattle under traditional management in subSaharan Africa. Quarterly Journal of International Agriculture 26:377-390.

de Vries, M. and I. J. M. de Boer. 2010. Comparing environmental impacts for livestock products: A review of life cycle assessments. Livestock Science 128:1-11.

Delgado, C., M. Rosegrant, H. Steinfeld, S. Ehui, and C. Courbois. 1999. Livestock to 2020. The next revolution. Food, agriculture, and the environment discussion paper 28., IFPRI, FAO and ILRI, Washington, USA.

Delgado, C. L. 2003. Rising consumption of meat and milk in developing countries has created a new food revolution. The Journal of Nutrition 133:3907S-3910S.

Dietz, T., D. Foeken, S. Soeters, and W. Klaver. 2014. Agricultural dynamics and food security trends in Kenya. Overseas Development Institute, London, UK.

EADD. 2008. The dairy value chain in Kenya. Technoserve Kenya.

Erb, K.-H. 2004. Actual land demand of Austria 1926-2000: a variation on ecological footprint assessments. Land Use Policy 21:247-259.

Erb, K.-H., F. Krausmann, W. Lucht, and H. Haberl. 2009a. Embodied HANPP: Mapping the spatial disconnect between global biomass production and consumption. Ecological Economics 69:328-334.

Erb, K.-H., A. Mayer, T. Kastner, K.-E. Sallet, and H. Haberl. 2012. The impact of industrial grain fed livestock production on food security: an extended literature review. Alpen Adria University Klagenfurt-Vienna-Graz, Austria.(Retrieved 19 June 2013 from http://goo. gl/6smPcP).

Erb, K., H. Haberl, F. Krausmann, C. Lauk, C. Plutzar, J. Steinberger, C. Müller, C. Bondeau, K. Waha, and G. Pollack. 2009b. Eating the Planet: Feeding and Fuelling the World Sustainably, Fairly and Humanely-A Scoping Study. . Vienna Institute of Social Ecology and PIK Potsdam. 
Ercin, A. E. and A. Y. Hoekstra. 2014. Water footprint scenarios for 2050: A global analysis. Environment International 64:71-82.

Ewing, B. R., T. R. Hawkins, T. O. Wiedmann, A. Galli, A. E. Ercin, J. Weinzettel, and K. SteenOlsen. 2012. Integrating ecological and water footprint accounting in a multi-regional input-output framework. Ecological Indicators 23:1-8.

Falkenmark, M. and M. Lannerstad. 2010. Food security in water-short countries - Coping with carrying capacity overshoot. Pages 3-22 in L. Martinez-Cortina, A. Garrido, and E. Lopez-Gunn, editors. Re-thinking water and food security: fourth Marcelino Botin Foundation water workshop. Taylor \& Francis, London, UK.

Falkenmark, M., J. Rockström, and L. Karlberg. 2009. Present and future water requirements for feeding humanity. Food Security 1:59-69.

FAO. 2005. Kenya country report, in : Iriigation in Africa in Figures., Food and Agriculture Organisation of the United Nations, Rome, Italy.

FAO. 2010. LADA Land Use system maps. Food and Agriculture Organization.

FAO. 2013. Greening livestock sector growth: closing the efficiency gap in natural resource use. Food and Agiculture Organization., Rome. Italy.

FAO. 2016. FAOSTAT database Food and Agriculture Organization of the United Nations, Rome, Italy.

FAO, IFAD, and WFP. 2014. The state of food insecurity in the world 2014: Strengthening the enabling environment for food security and nutrition. Food and Agriculture Organization of the United Nations (FAO), Rome, Italy.

FAO, IFAD, and WFP. 2015. The State of Food Insecurity in the World 2015. Meeting the 2015 international hunger targets: taking stock of uneven progress., FAO, Rome, Italy.

Farmer, E. and J. Mbwika. 2012. End market analysis of Kenyan livestock and meat: a desk study. Rep. no. MicroREPORT 184.

Feder, G. and D. L. Umali. 1993. The adoption of agricultural innovations: A review. Technological Forecasting and Social Change 43:215-239.

Fiala, N. 2008. Measuring sustainability: Why the ecological footprint is bad economics and bad environmental science. Ecological Economics 67:519-525.

Fischer, G., W. Winiwarter, G. Y. Cao, T. Ermolieva, E. Hizsnyik, Z. Klimont, D. Wiberg, and X. Y. Zheng. 2011. Implications of population growth and urbanization on agricultural risks in China. Population and Environment:1-16. 
Foley, J. A., R. Defries, G. P. Asner, C. Barford, G. Bonan, S. R. Carpenter, F. S. Chapin, M. T. Coe, G. C. Daily, and H. K. Gibbs. 2005. Global consequences of land use. Science 309:570-574.

Foley, J. A., N. Ramankutty, K. A. Brauman, E. S. Cassidy, J. S. Gerber, M. Johnston, N. D. Mueller, C. O/'Connell, D. K. Ray, P. C. West, C. Balzer, E. M. Bennett, S. R. Carpenter, J. Hill, C. Monfreda, S. Polasky, J. Rockstrom, J. Sheehan, S. Siebert, D. Tilman, and D. P. M. Zaks. 2011. Solutions for a cultivated planet. Nature 478:337-342.

Folke, C., Å. Jansson, J. Larsson, and R. Costanza. 1997. Ecosystem appropriation by cities. Ambio 26:167-172.

Gamba, P. 2005. Urban domestic consumption patterns for meat: Trends and policy implications Egerton University/ Tegemeo Institute of Agriculture Policy and Development.

Georgiadis, N. J., J. G. N. Olwero, G. Ojwang', and S. S. Romañach. 2007. Savanna herbivore dynamics in a livestock-dominated landscape: I. Dependence on land use, rainfall, density, and time. Biological Conservation 137:461-472.

Gerbens-Leenes, P. W. and S. Nonhebel. 2002. Consumption patterns and their effects on land required for food. Ecological Economics 42:185-199.

Gerber, P., P. Chilonda, G. Franceschini, and H. Menzi. 2005. Geographical determinants and environmental implications of livestock production intensification in Asia. Bioresource Technology 96:263-276.

Gerber, P. J., H. Steinfeld, B. Henderson, A. Mottet, C. Opio, J. Dijkman, A. Falcucci, and G. Tempio. 2013. Tackling climate change through livestock: a global assessment of emissions and mitigation opportunities. Food and Agriculture Organization of the United Nations (FAO), Rome.

Gerten, D., J. Heinke, H. Hoff, H. Biemans, M. Fader, and K. Waha. 2011. Global water availability and requirements for future food production. Journal of Hydrometeorology 12:885-899.

Godfray, H. C. J., J. R. Beddington, I. R. Crute, L. Haddad, D. Lawrence, J. F. Muir, J. Pretty, S. Robinson, S. M. Thomas, and C. Toulmin. 2010. Food Security: The Challenge of Feeding 9 Billion People. Science 327:812-818.

GOK. 2010a. Agricultural sector development strategy 2010-2020. Government printers, Nairobi, Kenya.

GOK. 2010b. Kenya National Dairy Master Plan. Volume 1: A situtational analysis of the dairy sub-sector. Government Printers, Nairobi, Kenya.

GOK. 2010c. Population distribution by administrative unit. Central Bureau of Statistics, Nairobi, Kenya. 
GOK. 2012. Sessional paper No.3 of 2012 on population policy for national development. National Council for Population and Development, Nairobi, Kenya.

GOK. 2013. Millenium Development Goals: Status report for Kenya 2013. Ministry of Devolution and Planning, Nairobi, Kenya.

Gómez, M. I., C. B. Barrett, T. Raney, P. Pinstrup-Andersen, J. Meerman, A. Croppenstedt, B. Carisma, and B. Thompson. 2013. Post-green revolution food systems and the triple burden of malnutrition. Food Policy 42:129-138.

Grandin, B. E. 1988. Wealth and pastoral dairy production: A case study from Maasailand. Human Ecology 16:1-21.

Greer, J. and E. Thorbecke. 1986. A methodology for measuring food poverty applied to Kenya. Journal of Development Economics 24:59-74.

Hall, C. A. S. 2000. Quantifying sustainable development : the future of tropical economies. Academic Press, San Diego etc.

Headey, D. D. and T. S. Jayne. 2014. Adaptation to land constraints: Is Africa different? Food Policy 48:18-33.

Herrero, M., P. Havlik, J. McIntire, A. Palazzo, and H. Valin. 2014. African Livestock Futures: Realizing the potential of livestock for food security, poverty reduction and the environment in Sub-Saharan Africa. office of the Special Representative od the UN Secretary General for food security and Nutrition and United Nations System Influenza Coordination (UNSIC), Geneva, Switzerland.

Herrero, M., P. Havlík, H. Valin, A. Notenbaert, M. C. Rufino, P. K. Thornton, M. Blümmel, F. Weiss, D. Grace, and M. Obersteiner. 2013. Biomass use, production, feed efficiencies, and greenhouse gas emissions from global livestock systems. Proceedings of the National Academy of Sciences 110:20888-20893.

Herrero, M. and P. K. Thornton. 2013. Livestock and global change: Emerging issues for sustainable food systems. Proceedings of the National Academy of Sciences of the United States of America 110:20878-20881.

Herrero, M., P. K. Thornton, A. M. Notenbaert, S. Wood, S. Msangi, H. A. Freeman, D. Bossio, J. Dixon, M. Peters, J. van de Steeg, J. Lynam, P. P. Rao, S. Macmillan, B. Gerard, J. McDermott, C. Sere, and M. Rosegrant. 2010a. Smart Investments in Sustainable Food Production: Revisiting Mixed Crop-Livestock Systems. Science 327:822-825.

Herrero, M., P. K. Thornton, A. M. Notenbaert, S. Wood, S. Msangi, H. A. Freeman, D. Bossio, J. Dixon, M. Peters, J. van de Steeg, J. Lynam, P. P. Rao, S. Macmillan, B. Gerard, J. McDermott, C. Seré, and M. Rosegrant. 2010b. Smart Investments in Sustainable Food Production: Revisiting Mixed Crop-Livestock Systems. Science 327:822-825. 
Hoekstra, A., A. Chapagain, M. Aldaya, and M. Mekonnen. 2011. The water footprint assessment manual: Setting the global standard. Earthscan, London, UK.

Hoekstra, A. Y. 2009. Human appropriation of natural capital: A comparison of ecological footprint and water footprint analysis. Ecological Economics 68:1963-1974.

Hoekstra, A. Y. 2014. Water for animal products: a blind spot in water policy. Environmental Research Letters 9:074016.

Hoekstra, A. Y. and A. K. Chapagain. 2007. Water footprints of nations: Water use by people as a function of their consumption pattern. Water Resources Management 21:35-48.

Hoekstra, A. Y. and A. K. Chapagain. 2008. The global component of freshwater demand and supply: an assessment of virtual water flows between nations as a result of trade in agricultural and industrial products. Water International 33:19-32.

Hoekstra, A. Y. and P. Hung. 2002. Virtual water trade. A quantification of virtual water flows between nations in relation to international crop trade. Value of water research report series:166.

Hoekstra, A. Y. and M. M. Mekonnen. 2012. The water footprint of humanity. Proceedings of the National Academy of Sciences 109 (9):3232-3237.

Hoekstra, A. Y., M. M. Mekonnen, A. K. Chapagain, R. E. Mathews, and B. D. Richter. 2012. Global Monthly Water Scarcity: Blue Water Footprints versus Blue Water Availability. Plos One 7:e32688.

Hoekstra, A. Y. and T. O. Wiedmann. 2014. Humanity's unsustainable environmental footprint. Science 344:1114-1117.

Hubacek, K., D. Guan, J. Barrett, and T. Wiedmann. 2009. Environmental implications of urbanization and lifestyle change in China: Ecological and Water Footprints. Journal of Cleaner Production 17:1241-1248.

Huchzermeyer, M. 2007. Tenement City: The Emergence of Multi-storey Districts Through Large-scale Private Landlordism in Nairobi. International Journal of Urban and Regional Research 31:714-732.

ILRI. 2010. East African Dairy Development Project Baseline Survey: Feeds and Feeding Practices. International Livestock Research Insitute.

Jankhe, H. E. 1982. Livestock Production Systems and Livestock Development in Tropical Africa Kieler Wissenchaftsveerlag Vauk, Kiel, Germany.

Jolly, G. 1969. Sampling methods for aerial censuses of wildlife populations. East African Agricultural and Forestry Journal 34:46-49. 
Jones, P. G. and P. K. Thornton. 2009. Croppers to livestock keepers: livelihood transitions to 2050 in Africa due to climate change. Environmental Science \& Policy 12:427-437.

Juma, G. P., M. Ngigi, I. Baltenweck, and A. G. Drucker. 2010. Consumer demand for sheep and goat meat in Kenya. Small Ruminant Research 90:135-138.

K'Akumu, O. A. and W. H. A. Olima. 2007. The dynamics and implications of residential segregation in Nairobi. Habitat International 31:87-99.

Kahi, A. K., C. B. Wasike, and T. O. Rewe. 2006. Beef production in the arid and semi-arid lands of Kenya: Constraints and prospects for research and development. Outlook on Agriculture 35:217-225.

Karanja, A. M. 2003. The dairy industry in Kenya: The post-liberalization agenda. Tegemeo Institute of Agricultural Policy and Development, Egerton University, Kenya.

Kastner, T., K.-H. Erb, and H. Haberl. 2015. Global Human Appropriation of Net Primary Production for Biomass Consumption in the European Union, 1986-2007. Journal of Industrial Ecology:n/a-n/a.

Kastner, T., M. J. I. Rivas, W. Koch, and S. Nonhebel. 2012. Global changes in diets and the consequences for land requirements for food. Proceedings of the National Academy of Sciences 109:6868-6872.

Kearney, A. 2012. Global cities index and emerging cities outlook. AT Kearney Inc.

King, J. M. 1983. Livestock water needs in pastoral Africa in relation to climate and forage.

Klapwijk, C., C. Bucagu, M. van Wijk, H. Udo, B. Vanlauwe, E. Munyanziza, and K. Giller. 2014. The 'One cow per poor family'programme: Current and potential fodder availability within smallholder farming systems in southwest Rwanda. Agricultural Systems 131:11-22.

Koh, L. P. and T. M. Lee. 2012. Sensible consumerism for environmental sustainability. Biological Conservation 151:3-6.

Kosgey, I., S. Mbuku, A. Okeyo, J. Amimo, J. Philipsson, and J. Ojango. 2011. Institutional and organizational frameworks for dairy and beef cattle recording in Kenya: a review and opportunities for improvement. Animal Genetic Resources(C) Food and Agriculture Organization of the United Nations 48:1-11.

Ledant, M. 2011. Socio-economical and infrastructural mapping and analysis of Nairobi. French Insitute for Research in Africa (IFRA), Nairobi.

Liu, J., V. Hull, M. Batistella, R. DeFries, T. Dietz, F. Fu, T. W. Hertel, R. C. Izaurralde, E. F. Lambin, S. Li, L. A. Martinelli, W. J. McConnell, E. F. Moran, R. Naylor, Z. Ouyang, K. R. Polenske, A. Reenberg, G. de Miranda Rocha, C. S. Simmons, P. H. Verburg, P. M. Vitousek, F. 
Zhang, and C. Zhu. 2013. Framing Sustainability in a Telecoupled World. Ecology and Society 18.

Maitima, J. M., S. M. Mugatha, R. S. Reid, L. N. Gachimbi, A. Majule, H. Lyaruu, D. Pomery, S. Mathai, and S. Mugisha. 2009. The linkages between land use change, land degradation and biodiversity across East Africa. African Journal of Environmental Science and Technology 3.

Marra, M., D. J. Pannell, and A. Abadi Ghadim. 2003. The economics of risk, uncertainty and learning in the adoption of new agricultural technologies: where are we on the learning curve? Agricultural Systems 75:215-234.

Mboganie-Mwangi, A. and D. Foeken. 1996. Urban agriculture, food security and nutrition in low income areas of the city of nairobi, kenya. African urban quarterly 11:170-179.

McMichael, A. J. and C. D. Butler. 2011. Promoting Global Population Health While Constraining the Environmental Footprint. Annual Review of Public Health, Vol 32 32:179-197.

Mekonnen, M. and A. Y. Hoekstra. 2011a. National water footprint accounts: the green, blue and grey water footprint of production and consumption. Delft, The Netherlands.

Mekonnen, M. M. and A. Y. Hoekstra. 2010a. A global and high-resolution assessment of the green, blue and grey water footprint of wheat. Hydrology and Earth System Sciences 14:1259-1276.

Mekonnen, M. M. and A. Y. Hoekstra. 2010b. The green, blue and grey water footprints of farm animals and animal products. UNESCO-IHE Institute for Water Education, Delft.

Mekonnen, M. M. and A. Y. Hoekstra. 2011b. The green, blue and grey water footprint of crops and derived crop products. Hydrology and Earth System Sciences 15:1577-1600.

Mekonnen, M. M. and A. Y. Hoekstra. 2012. A global assessment of the water footprint of farm animal products. Ecosystems 15:401-415.

Mekonnen, M. M. and A. Y. Hoekstra. 2016. Four billion people facing severe water scarcity. Science Advances 2(2): e1500323.

Menkhaus, K. 2015. Conflict Assessment: Northern Kenya and Somaliland. Available at SSRN 2589109.

Meyer, B. M. and B. L. Turner, editors. 1994. Changes in land use and land cover: A Global Perspective. Press syndicate of the University of Cambridge, Great Britain.

Molden, D., editor. 2007. Water for food, water for life: a comprehensive assessment of water management in agriculture. Earthscan, London, UK. 
Molden, D., T. Oweis, P. Steduto, P. Bindraban, M. A. Hanjra, and J. Kijne. 2010. Improving agricultural water productivity: Between optimism and caution. Agricultural Water Management 97:528-535.

Monfreda, C., M. Wackernagel, and D. Deumling. 2004. Establishing national natural capital accounts based on detailed Ecological Footprint and biological capacity assessments. Land Use Policy 21:231-246.

Moran, D. D., M. Wackernagel, J. A. Kitzes, S. H. Goldfinger, and A. Boutaud. 2008. Measuring sustainable development - Nation by nation. Ecological Economics 64:470-474.

Mose, P., M. Kipsat, and E. Nguguna. 2012. Small Ruminants' Meat Consumption Patterns in Nairobi, Kenya.in The 8th Africa Farm Management Association (AFMA) Congress. Moi University Press.

Msangi, S. and M. W. Rosegrant. 2012. Feeding the Future's Changing Diets: Implications for Agriculture Markets, Nutrition, and Policy. Edited by Shenggen Fan and Rajul PandyaLorch:65.

Mundia, C. N. and M. Aniya. 2006. Dynamics of landuse/cover changes and degradation of Nairobi City, Kenya. Land Degradation \& Development 17:97-108.

Muthee, A. 2006. Kenya Livestock Sector Study: An Analysis of Pastoralist Livestock Products Market Value Chains and Potential External Markets for Live Animals and Meat. AUIBAR \&NEPDP, Consultancy report: Deloitte Consulting Ltd.

Muwonge, J. W. 1980. Urban Policy and Patterns of Low-Income Settlement in Nairobi, Kenya. Population and Development Review 6:595-613.

Narrod, C., M. Tiongco, and R. Scott. 2011. Current and predicted trends in the production, consumption and trade of live animals and their products. OIE Revue Scientifique et Technique 30:31-49.

Navarro, L. and H. Pereira. 2012. Rewilding Abandoned Landscapes in Europe. Ecosystems 15:900-912.

Ndambi, O. A., T. Hemme, and U. Latacz-Lohmann. 2007. Dairying in Africa - Status and recent developments. Livestock Research for Rural Development 19.

Ndung'u, N., K. Thugge, and O. Otieno. 2011. Unlocking the Future Potential for Kenya: The Vision 2030. Citeseer.

Neumann, C., D. M. Harris, and L. M. Rogers. 2002. Contribution of animal source foods in improving diet quality and function in children in the developing world. Nutrition Research 22:193-220.

Ngigi, M. 2005. The case of smallholder dairying in Eastern Africa. 
Ngigi, S. 2002. Review of irrigation development in Kenya. International Water Management Institute., Colombo, SriLanka.

Nicholson, C. F., P. K. Thornton, and R. W. Muinga. 2004. Household-level Impacts of Dairy Cow Ownership in Coastal Kenya. Journal of Agricultural Economics 55:175-195.

Njarui, D. M. G., M. Gatheru, J. M. Wambua, S. N. Nguluu, D. M. Mwangi, and G. A. Keya. 2011. Consumption patterns and preference of milk and milk products among rural and urban consumers in semi-arid Kenya. Ecology of Food and Nutrition 50:240-262.

Norton-Griffiths, M. 1975. Counting animals. African Wildlife Leadership Foundation.

Oago, D. O. and E. O. Odada. 2007. Sediment impacts in Africa's transboundary lake/river basins: Case study of the east African great lakes. Aquatic Ecosystem Health \& Management 10:23-32.

Obudho, R. A., editor. 1997. The urban challenge in Africa: Growth and management of its large cities. United Nations University Press, Tokyo.

Odhiambo, W. 2004. Pulling apart: Facts and figures on inequality in Kenya. Nairobi, Kenya: Society for International Development.

Ogutu, J. O., N. Owen-Smith, H.-P. Piepho, M. Y. Said, S. C. Kifugo, R. S. Reid, H. Gichohi, P. Kahumbu, and S. Andanje. 2013. Changing wildlife populations in Nairobi National Park and adjoining Athi-Kaputiei Plains: collapse of the migratory wildebeest. Open Conservation Biology Journal 7:11-26.

Ogutu, J. O., H.-P. Piepho, M. Y. Said, and S. C. Kifugo. 2014. Herbivore Dynamics and Range Contraction in Kajiado County Kenya: Climate and Land Use Changes, Population Pressures, Governance, Policy and Human-wildlife Conflicts. Open Ecology Journal 7:931.

Olembo, K., F. M'mboyi, S. Kiplagat, J. Sitieney, and F. Oyugi. 2010. Sorghum breeding in subSaharan Africa: the success stories.in The Africa Biotechnology Stakeholders Forum (ABSF) Publ. Nairobi, Kenya.

Olok-Asobasi, F. and M. Sserunjogi. 2001. Survey of Dairy Markets in Kenya and Rwanda and Opportunities for Ugandan Exports. Chemonics Internatinal Inc.

Omore, A., H. Muriuki, M. Kenyanjui, M. Owango, and S. Staal. 1999. The Kenyan Dairy SubSector: A Rapid Appraisal: Research Report of the MoA/KARI/ILRI Smallholder Dairy (R\&D) Project. International Livestock Research Institute. Nairobi (Kenya). 51pp.

Onono, J. O., B. Wieland, and J. Rushton. 2013. Productivity in different cattle production systems in Kenya. Tropical animal health and production 45:423-430.

Otte, J., A. Costales, J. Dijkman, U. Pica-Ciamarra, T. Robinson, V. Ahuja, C. Ly, and D. RolandHolst. 2012. Livestock sector development for poverty reduction: an economic and 
policy perspective. Livestock's many virtues. Food and Agriculture Organization of the United Nations (FAO).

Ottichilo, W. K., J. Grunblatt, M. Y. Said, and P. W. Wargute. 2000. Wildlife and livestock population trends in the Kenya rangeland. Pages 203-218 Wildlife Conservation by Sustainable Use. Springer.

Ouda, J. O. 2001. Feeding and care of livestock. Managing dryland resources. A manual for Eastern and Southern Africa. International Institute for Rural Reconstruction (IIRR).

Ouma, E., S. Staal, A. Omore, P. Wanjohi, L. Njoroge, and D. Njubi. 2000. Consumption patterns of dairy products in Kenya. KARI/MoARD/ILRI Report.

Owen, E., T. Smith, and H. Makkar. 2012. Successes and failures with animal nutrition practices and technologies in developing countries: A synthesis of an FAO e-conference. Animal Feed Science and Technology 174:211-226.

Owen, E., T. Smith, M. Steele, S. Anderson, A. Duncan, and M. Herrero. 2004. Responding to the livestock revolution: the role of globalisation and implications for poverty alleviation. Nottingham University Press.

Pahlow, M., J. Snowball, and G. Fraser. 2015. Water footprint assessment to inform water management and policy making in South Africa. Water Sa 41:300-313.

Pedercini, M., S. M. Blanco, and B. Kopainsky. 2011. Application of the malaria management model to the analysis of costs and benefits of DDT versus non-DDT malaria control. Plos One 6:e27771.

Pelletier, N. and P. Tyedmers. 2010. Forecasting potential global environmental costs of livestock production 2000 - 2050. Proceedings of the National Academy of Sciences 107:18371-18374.

Place, F., J. Njuki, F. Murithi, and F. Mugo. 2006. Agricultural enterprise and land management in the highlands of Kenya. Strategies for Sustainable Land Management in the East African Highlands:191-215.

Pratt, D. J. and M. D. Gwynne, editors. 1977. Rangeland management and ecology in East Africa. Hodder and Stoughton, London.

Pretty, J., C. Toulmin, and S. Williams. 2011. Sustainable intensification in African agriculture. International Journal of Agricultural Sustainability 9:5-24.

Randolph, T., E. Schelling, D. Grace, C. F. Nicholson, J. Leroy, D. Cole, M. Demment, A. Omore, J. Zinsstag, and M. Ruel. 2007. Invited review: Role of livestock in human nutrition and health for poverty reduction in developing countries. Journal of animal science 85:2788-2800. 
Rees, W. and M. Wackernagel. 1996. Urban ecological footprints: Why cities cannot be sustainable-And why they are a key to sustainability. Environmental Impact Assessment Review 16:223-248.

Rege, J. 2001. Zebu cattle of Kenya: Uses, performance, farmer preferences, measures of genetic diversity and options for improved use. ILRI (aka ILCA and ILRAD).

Renuka, N., C. Sathian, S. Sujatha, and S. Deepa. 2009. Impact of family income on consumption of Livestock products at Kalpetta, Kerala. Veterinary World 2:323-324.

Renwick, A. R., J. A. Vickery, S. G. Potts, S. Bolwig, D. Nalwanga, D. E. Pomeroy, D. Mushabe, and P. W. Atkinson. 2014. Achieving production and conservation simultaneously in tropical agricultural landscapes. Agriculture, Ecosystems \& Environment 192:130-134.

Ridoutt, B. G., P. Sanguansri, and G. S. Harper. 2011. Comparing Carbon and Water Footprints for Beef Cattle Production in Southern Australia. Sustainability 3:2443-2455.

Robinson, L. W., P. J. Ericksen, S. Chesterman, and J. S. Worden. 2015. Sustainable intensification in drylands: What resilience and vulnerability can tell us. Agricultural Systems 135:133-140.

Robinson, T., P. Thornton, G. Franceschini, R. Kruska, F. Chiozza, A. Notenbaert, G. Cecchi, M. Herrero, M. Epprecht, and S. Fritz. 2011. Global livestock production systems. Food and Agriculture Organization of the United Nations (FAO).

Robinson, T. P., G. R. W. Wint, G. Conchedda, T. P. Van Boeckel, V. Ercoli, E. Palamara, G. Cinardi, L. D'Aietti, S. I. Hay, and M. Gilbert. 2014. Mapping the Global Distribution of Livestock. Plos One 9:e96084.

Rockström, J., M. Falkenmark, L. Karlberg, H. Hoff, S. Rost, and D. Gerten. 2009. Future water availability for global food production: the potential of green water for increasing resilience to global change. Water Resources Research 45.

Rockström, J., L. Karlberg, S. P. Wani, J. Barron, N. Hatibu, T. Oweis, A. Bruggeman, J. Farahani, and Z. Qiang. 2010. Managing water in rainfed agriculture-The need for a paradigm shift. Agricultural Water Management 97:543-550.

Rockström, J., M. Lannerstad, and M. Falkenmark. 2007. Assessing the water challenge of a new green revolution in developing countries. Proceedings of the National Academy of Sciences of the United States of America 104:6253-6260.

Ruigu, G. M. 1988. Large-scale irrigation development in Kenya: past performance and future prospects.

Schell, C. O., M. Reilly, H. Rosling, S. Peterson, and A. M. Ekström. 2007. Socioeconomic determinants of infant mortality: a worldwide study of 152 low-, middle-, and highincome countries. Scandinavian journal of public health 35:288-297. 
Seto, K. C., A. Reenberg, C. G. Boone, M. Fragkias, D. Haase, T. Langanke, P. Marcotullio, D. K. Munroe, B. Olah, and D. Simon. 2012. Urban land teleconnections and sustainability. Proceedings of the National Academy of Sciences 109:7687-7692.

Shah, M. M. and H. Frohberg. 1980. Food Consumption Patterns-Rural and Urban Kenya. International Institute for Applied Systems Analysis, Laxenburg. Working Paper:80-13.

Shiferaw, B. 2002. Poverty and natural resource management in the semi-arid tropics: Revisiting challenges and conceptual issues. ICRISAT.

Spence, M., C. P. Annez, and R. M. Buckley, editors. 2009. Urbanization and growth. World Bank, Washington.

Staal, S., M. Owango, H. Muriuki, M. Kenyanjui, B. Lukuyu, L. Njoroge, D. Njubi, I. Baltenweck, F. Musembi, and O. Bwana. 2001. Dairy systems characterisation of the greater Nairobi milk shed. Smallholder Dairy Project (SDP (R \& D)), MALDM, KARI, ILRI.

Steffen, W., K. Richardson, J. Rockström, S. E. Cornell, I. Fetzer, E. M. Bennett, R. Biggs, S. R. Carpenter, W. de Vries, C. A. de Wit, C. Folke, D. Gerten, J. Heinke, G. M. Mace, L. M. Persson, V. Ramanathan, B. Reyers, and S. Sörlin. 2015. Planetary boundaries: Guiding human development on a changing planet. Science.

Steinfeld, H. and P. Gerber. 2010. Livestock production and the global environment: Consume less or produce better? Proceedings of the National Academy of Sciences 107:1823718238.

Steinfeld, H., P. Gerber, T. Wassenaar, V. Castel, M. Rosales, and C. de Haan. 2006a. Livestock's long shadow: environmental issues and options. FAO, Rome, Italy.

Steinfeld, H., P. Gerber, T. Wassenaar, V. Castel, M. Rosales, and C. Haan. 2006b. Livestock's long shadow: environmental issues and options. Food and Agriculture Organization, Rome.

Stroosnijder, L., D. Moore, A. Alharbi, E. Argaman, B. Biazin, and E. van den Elsen. 2012. Improving water use efficiency in drylands. Current Opinion in Environmental Sustainability 4:497-506.

Sutherland, A., J. Irungu, J. Kang'ara, J. Muthamia, and J. Ouma. 1999. Household food security in semi-arid Africa-the contribution of participatory adaptive research and development to rural livelihoods in Eastern Kenya. Food Policy 24:363-390.

Syagga, P., M. Mitullah, and S. Gitau. 2001. Nairobi Situational Analysis: A Consultative Report.

Syrstad, O. 1993. Evaluation of dual-purpose (milk and meat) animals. World Animal Review 77:56-59. 
Tarawali, S., M. Herrero, K. Descheemaeker, E. Grings, and M. Blümmel. 2011. Pathways for sustainable development of mixed crop livestock systems: Taking a livestock and propoor approach. Livestock Science 139:11-21.

Tempia, S., F. Braidotti, H. Aden, M. Abdulle, R. Costagli, and F. Otieno. 2010. Mapping cattle trade routes in southern Somalia: a method for mobile livestock keeping systems. Revue scientifique et technique 29:485.

Thornton, P., M. Herrero, H. Freeman, A. Mwai, E. Rege, P. Jones, and J. McDermott. 2007. Vulnerability, climate change and livestock-opportunities and challenges for the poor.

Thornton, P. K. 2010. Livestock production: recent trends, future prospects. Philosophical Transactions of the Royal Society B: Biological Sciences 365:2853-2867.

Thorpe, W., H. Muriuki, A. Omore, M. Owango, and S. Staal. 2000. Dairy development in Kenya: the past, the present and the future.

Tilman, D., C. Balzer, J. Hill, and B. L. Befort. 2011. Global food demand and the sustainable intensification of agriculture. Proceedings of the National Academy of Sciences 108:20260-20264.

Tilman, D., K. G. Cassman, P. A. Matson, R. Naylor, and S. Polasky. 2002. Agricultural sustainability and intensive production practices. Nature 418:671-677.

Tittonell, P. and K. E. Giller. 2013. When yield gaps are poverty traps: The paradigm of ecological intensification in African smallholder agriculture. Field Crops Research 143:76-90.

Tscharntke, T., Y. Clough, T. C. Wanger, L. Jackson, I. Motzke, I. Perfecto, J. Vandermeer, and A. Whitbread. 2012. Global food security, biodiversity conservation and the future of agricultural intensification. Biological Conservation 151:53-59.

Udo, H. M. J., H. A. Aklilu, L. T. Phong, R. H. Bosma, I. G. S. Budisatria, B. R. Patil, T. Samdup, and B. O. Bebe. 2011. Impact of intensification of different types of livestock production in smallholder crop-livestock systems. Livestock Science 139:22-29.

UN. 2013a. World Population Prospects, The 2012 Revision. United Nations, New York: Department for Economic and Social Affairs.

UN. 2013b. World Population Prospects: The 2012 Revision. Population Division of the Department of Economic and Social Affairs of the United Nations Secretariat.

UN. 2014. 2014 Revision of World Urbanization Prospects

UN. 2015. World Urbanization Prospects: The 2014 Revision. United Nations, Department of Economic and Social Affairs, Population Division, (ST/ESA/SER.A/366). New York, USA. 
Upton, M. 2004. The Role of Livestock in Economic Development and Poverty Reduction. Page $57 \mathrm{pp}$.

van 't Riet, H., A. P. den Hartog, D. A. P. Hooftman, D. W. J. Foeken, and W. A. van Staveren. 2003. Determinants of non-home-prepared food consumption in two low-income areas in Nairobi. Nutrition 19:1006-1012.

van der Zijpp, A. J. 1999. Animal food production: the perspective of human consumption, production, trade and disease control. Livestock Production Science 59:199-206.

van Oel, P. R., M. M. Mekonnen, and A. Y. Hoekstra. 2009. The external water footprint of the Netherlands: Geographically-explicit quantification and impact assessment. Ecological Economics 69:82-92.

van Velthuizen, H., B. Huddleston, G. Fischer, M. Salvatore, E. Ataman, F. O. Nachtergaele, M. Zanetti, M. Bloise, A. Antonicelli, and J. Bel. 2007. Mapping biophysical factors that influence agricultural production and rural vulnerability. 9251056897, Food and Agriculture Organization, Rome, Italy.

van Vuuren, D. P. and E. M. W. Smeets. 2000. Ecological footprints of Benin, Bhutan, Costa Rica and the Netherlands. Ecological Economics 34:115-130.

van Zanten, H. H., H. Mollenhorst, C. W. Klootwijk, C. E. van Middelaar, and I. J. de Boer. 2016. Global food supply: land use efficiency of livestock systems. The International Journal of Life Cycle Assessment 21:747-758.

Vanham, D. and G. Bidoglio. 2013. A review on the indicator water footprint for the EU28. Ecological Indicators 26:61-75.

Wackernagel, M. 2009. Methodological advancements in footprint analysis. Ecological Economics 68:1925-1927.

Wackernagel, M., C. Monfreda, K.-H. Erb, H. Haberl, and N. B. Schulz. 2004. Ecological footprint time series of Austria, the Philippines, and South Korea for 1961-1999: comparing the conventional approach to an 'actual land area' approach. Land Use Policy 21:261-269.

Wackernagel, M., L. Onisto, P. Bello, A. Callejas Linares, I. Susana López Falfán, J. Méndez García, A. Isabel Suárez Guerrero, and M. Guadalupe Suárez Guerrero. 1999. National natural capital accounting with the ecological footprint concept. Ecological Economics 29:375-390.

Waithaka, M., P. Thornton, M. Herrero, and K. Shepherd. 2006. Bio-economic evaluation of farmers' perceptions of viable farms in western Kenya. Agricultural Systems 90:243271.

WB. 2015. GDP growth 1980-2014. World Bank Publications, Washington DC, USA. 
Weinzettel, J., E. G. Hertwich, G. P. Peters, K. Steen-Olsen, and A. Galli. 2013. Affluence drives the global displacement of land use. Global Environmental Change 23:433-438.

Williams, A. P., C. Funk, J. Michaelsen, S. Rauscher, I. Robertson, T. G. Wils, M. Koprowski, Z. Eshetu, and N. Loader. 2012. Recent summer precipitation trends in the Greater Horn of Africa and the emerging role of Indian Ocean sea surface temperature. Climate Dynamics 39:2307-2328.

Wirsenius, S., C. Azar, and G. Berndes. 2010. How much land is needed for global food production under scenarios of dietary changes and livestock productivity increases in 2030? Agricultural Systems 103:621-638.

Zoumides, C., A. Bruggeman, M. Hadjikakou, and T. Zachariadis. 2014. Policy-relevant indicators for semi-arid nations: The water footprint of crop production and supply utilization of Cyprus. Ecological Indicators 43:205-214.

Züllich, G., K. Dianati, and M. Pedercini. 2015. Integrated simulation models for sustainable agriculture policy design. Global Sustainable Development Report.

Züllich, G., K. Dianati, M. Pedercini, S. Àrquitt, W. Qu, Z. Tan, and S. Assuad. 2014. T21 Kenya: Agriculture, Food and Nutrition Security and Rural Poverty Scenarios. Washington DC, USA. 


\section{List of publications}

Papers in peer-reviewed journals

Bosire, C.K., M. Lannerstad, J. De Leeuw, M. Krol, J. Ogutu, P. Ochungo, and A. Y. Hoekstra. (2016a). Urban consumption of meat and milk and its green and blue water footprints patterns in the 1980s and 2000s for Nairobi, Kenya. Science of the total Envronment.

Bosire, C.K., N. Mtimet, M. Krol, J. De Leeuw, J. Ogutu, P. Guthiga, and A. Y. Hoekstra. (Submitted). Implications of livestock policy on future water and land footprints in Kenya. Journal of the Science of Food and Agriculutre.

Bosire, C. K., M. S. Krol, M. M. Mekonnen, J. O. Ogutu, J. de Leeuw, M. Lannerstad, and A. Y. Hoekstra. (2016b). Meat and milk production scenarios and the associated land footprint in Kenya. Agricultural Systems 145:64-75.

Bosire, C. K., J. O. Ogutu, M. Y. Said, M. S. Krol, J. d. Leeuw, and A. Y. Hoekstra. (2015). Trends and spatial variation in water and land footprints of meat and milk production systems in Kenya. Agriculture, Ecosystems \& Environment 205:36-47.

\section{Research Reports}

Derek Baker, Caroline Bosire, Jo Cadilhon, Ayele Gelan, Nadhem Mtimet, Francis Wanyoike, Mohamadou Fadiga (2012). Identification and analysis of constraints faced by smallholder producers and traders in Tanzania and Uganda.

Conferences

Bosire, C. K. The water and land footprint of meat and milk production and consumption in Kenya: Sustainability and food security. Presented at the International workshop: Food security and sustainable agriculture: The future of smallholder farmers? Presented th the Right Livelihood College University of Bonn, Germany. 30 $0^{\text {th }}$ May- $4^{\text {th }}$ June 2015.

Bosire, C. K., J. O. Ogutu, M. Y. Said, M. S. Krol, J. d. Leeuw, and A. Y. Hoekstra. Spatiotemporal variability and trends in water and land footprints of meat and milk production systems in Kenya. Presented at the Global Water Sustainability Porgram (GWSP) conference Bonn, Germany. $19^{\text {th }}-21^{\text {st }}$ May 2014. 


\section{About the author}

Caroline Bosire was born on $5^{\text {th }}$ June, 1978 in Nairobi Kenya. She joined Alliance Girls High School in Kikuyu, Kenya and later the University of Nairobi. She obtained a Bachelor of Science Degree in Chemistry and Zoology in 2002. She started an MSc in Conservation Biology at University of Nairobi and graduated in 2007. She worked in the wildlife and environmental conservation field with African Wildlife Foundation, Earthwatch Institute and Grevy's Zebra Trust from 2004 until 2008. She then joined the International Livestock Research Institute (ILRI) in 2009 as a Research Associate working on Innovation Systems in livestock production under the Markets themes as well and other work in the People, Livestock and The Environment (PLE) theme.

In 2011, she was awarded a scholarship by the Netherlands Fellowship Programme to undertake PhD sandwich fellowship studies at the University of Twente, Twente Water Centre and the International Livestock Research Institute. During the PhD, she greatly advanced the understanding of the water and land use related to production and consumption of livestock products in Kenya. 


\section{UNIVERSITY OF TWENTE.}

ISBN 978-90-365-4246-3 